\title{
INNOVACIÓN EDUCATIVA
}

Nuevas metodologías y prácticas en el aula. Experiencias desde México y Colombia

COMPILADORAS:

DEISY DE LA ROSA DAZA ÁNGELA JULIETA MORA RAMÍREZ

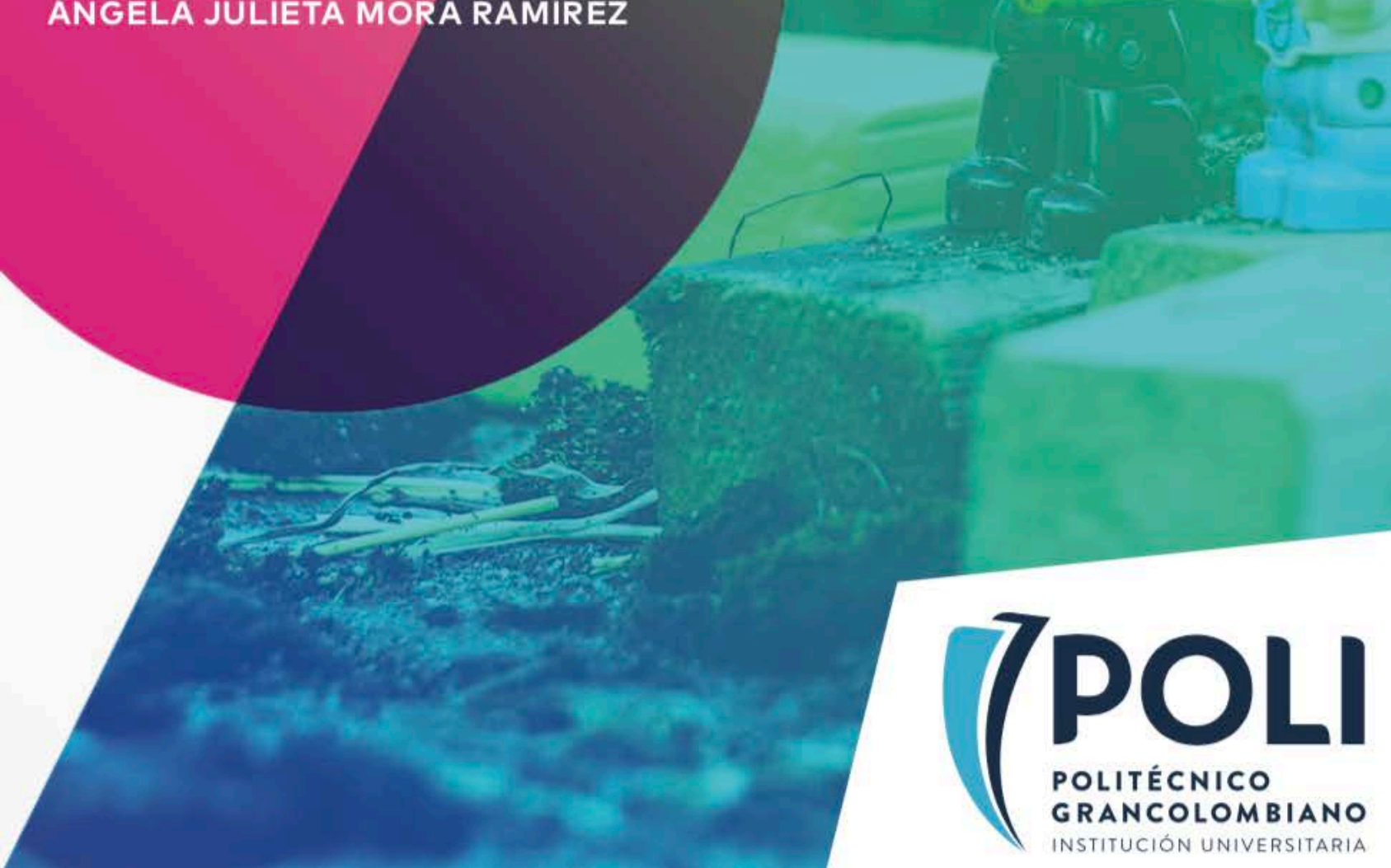




\section{INNOVACIÓN

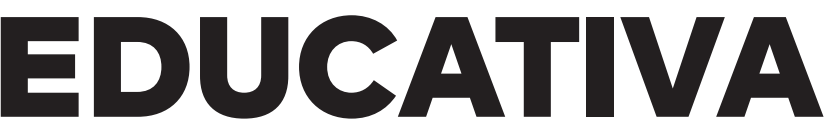

Nuevas metodologías y prácticas en el aula. Experiencias desde México y Colombia

COMPILADORAS:

DEISY DE LA ROSA DAZA

ÁNGELA JULIETA MORA RAMÍREZ

AUTORAS:

MAGDALENA BUENFIL MATA

MARITZA ALVARADO NANDO

MAYTE BARBA ABAD

TECNOLÓGICO DE MONTERREY

UNIVERSIDAD DE GUADALAJARA

POLITÉCNICO GRANCOLOMBIANO 


\section{POLI POLITÉCNICO GRANCOLOMBIANO \\ INSTITUCIÓN UNIVERSITARIA}

Institución Universitaria Politécnico Grancolombiano

Innovación educativa, nuevas metodologías y prácticas en

el aula. Experiencias desde México y Colombia

Primera edición: 2018

ISBN: 978-958-8721-94-1

e-ISBN: 978-958-8721-92-7

eBook-ISBN: 978-958-8721-93-4

\section{Editorial Politécnico Grancolombiano}

Calle 57 No. 3 - 00 este

Tel: 7455555 ext. 1516

E-mail: editorial@poligran.edu.co

Bogotá, Colombia.

\section{Compiladoras}

Deisy de la Rosa Daza

Ángela Julieta Mora Ramírez

\section{Autoras}

Ángela Julieta Mora Ramírez

Deisy de la Rosa Daza

Magdalena Buenfil Mata

Maritza Alvarado Nando

Mayte Barba Abad

Editor - Lider de publicaciones

Eduardo Norman Acevedo

Analista de producción editorial

Carlos Eduardo Daza Orozco

\section{Corrección de estilo}

Hernán Darío Cadena Cruz

Diseño y Diagramación

Santiago Arciniegas
Innovación educativa, nuevas metodologías y prácticas en el aula. Experiencias desde México y Colombia

Compiladoras Deisy de la Rosa Daza y Ángela Julieta Mora

Ramírez; - Bogotá D.C.: Editorial Politécnico Grancolombiano,

2018.

149 p. : il. ; $17 \times 24 \mathrm{~cm}$.

Incluye referencias bibliográficas.

ISBN: 978-958-8721-94-1

e-ISBN: 978-958-8721-92-7

eBook-ISBN: 978-958-8721-93-4

1. Educación superior -- México 2. Educación superior -- Colombia 3. Investigación Formativa 4. Modelos de enseñanza 5. Educación -- investigaciones I. Institución Universitaria Politécnico Grancolombiano II. Tecnológico de Monterrey III. Universidad de Guadalajara IV. Tít.

SCDD 378.007

Co-BolUP

Sistema Nacional de Bibliotecas - SISNAB

Institución Universitaria Politécnico Grancolombiano.

Impresión

Xpress Estudio Gráfico y Digital S.A.

Impreso en Colombia

Printed in Colombia

La Editorial del Politécnico Grancolombiano pertenece a la Asociación de Editoriales Universitarias de Colombia ASEUC.

El contenido de esta publicación se puede citar o reproducir con propósitos académicos siempre y cuando se de la fuente o procedencia. Las opiniones expresadas son responsabilidad exclusiva de los autores.

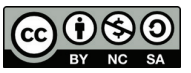

Atribución - No comercial - Compartir igual

¿Cómo citar este libro?

De la Rosa, D., \& Mora Ramírez, Á J. (2019). Innovación educativa, nuevas metodologías y prácticas en el aula. Experiencias desde México y Colombia. Bogotá: Editorial Politécnico Grancolombiano. 


\section{CONTENIDO}

\section{Jurgen Chiari Escobar}

Institución Universitaria Politécnico

Grancolombiano

\section{EDUCAR EN OTRA DIRECCIÓN: FORMAR PARA LA VIDA}

\section{Maritza Alvarado Nando}

Universidad de Guadalajara 9

MODELO DE ENSEÑANZAAPRENDIZAJE DE

EDUCACIÓN SUPERIOR POR

COMPETENCIAS

\section{Mayte Barba Abad y Magdalena Buenfil Mata}

Tecnológico de Monterrey sede Guadalajara.....

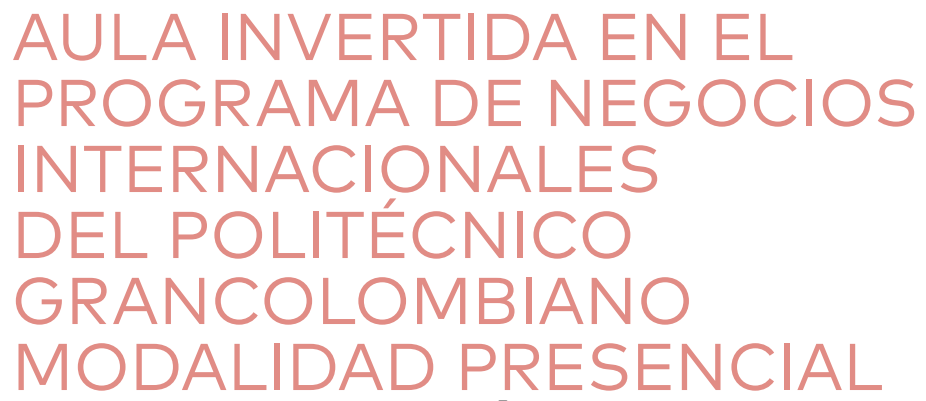

Deisy de la Rosa Daza y Ángela Julieta Mora Ramírez Institución Universitaria Politécnico Grancolombiano. 



\section{Presentación}

La educación a nivel mundial se transforma a un ritmo acelerado, la aplicación de nuevas metodologías de enseñanza, así como las tecnologías de información y herramientas para el aprendizaje evolucionan constantemente en los entornos educativos. Tanto los contenidos como las metodologías requieren de dinámicas que contemplen nuevos esquemas de apropiación adaptados a la realidad de nuestros estudiantes.

Hemos comprendido que los escenarios digitales requieren de elementos multimedia, por lo mismo, es necesario hablar múltiples 'lenguajes'. En este largo camino de educación, no solo los estudiantes han aprendido: "En el Politécnico Grancolombiano también hemos adquirido importantes experiencias que nos han ayudado a consolidar este sueño de brindar acceso a educación de calidad para los colombianos." (Norman-Acevedo, 2018, Pag.124).

Este camino no es solo de las instituciones, también es fruto del inquieto proceso de construcción de nuestros docentes dentro del aula, pues junto con los estudiantes son quienes producen los escenarios de aprendizaje que les permiten detectar y apropiar las herramientas necesarias para un proceso de formación integral. El proceso no consiste solamente en la aplicación de tecnologías, se trata de construir un marco pedagógico que respalde su ejecución. Pero este interés no es aislado, o de una sola institución, es así como universidades de la talla del Tecnológico de Monterrey y la Universidad de 
Guadalajara, comparten con nosotros estas inquietudes, lo que inevitablemente nos termina poniendo en el mismo trasegar.

El desafío innegable de la Academia en un mundo cambiante, exigente e inesperado radica en conciliar el rápido avance del conocimiento y la tecnología con los procesos de formación, que nos permiten entregar a la sociedad profesionales integrales; ciudadanos del mundo con competencias que los incluyan de manera activa en la solución de los problemas globales, pero que, a la vez, gestionen felizmente su vida y la de sus familias.

Nuestro interés en la innovación educativa se ve reflejado en proyectos como el aula invertida, como parte del desarrollo pedagógico constructivista basado en experiencias significativas. Este proyecto aplica constantemente estrategias flexibles y medibles orientadas a la formación por competencias y al fomento de la innovación en las estrategias de enseñanza.

En la literatura ya se ha medido la relación entre el impacto de la gamificación basada en el desafío en la enseñanza en línea y el nivel de innovación educativa en términos de resolución de problemas (Flores, Montoya, \& Mena, 2016). Esta relación también está presente en el escenario de la presencialidad, pues cada vez se disminuyen más las brechas entre las dos modalidades y comparten las mismas herramientas. Esta dinámica es motivo de constante evaluación en nuestra Institución.

Pero ¿estamos listos para recorrer ese camino? Seguramente la mayoría de las instituciones deben aprender en conjunto con los estudiantes la forma más adecuada de trazar esas rutas; por ello, todos los esfuerzos en la construcción colectiva de esos nuevos aprendizajes son absolutamente bienvenidos y deben ser tenidos en cuenta. Es así como validamos nuestro rutero con otras instituciones y nos sumamos a otros proyectos que ya analizan estos caminos, como el estudio titulado: "La enseñanza de las innovaciones en economia: Estrategias y Aplicaciones para la Instrucción Interactiva” (Salemi \&Walstad, 2010), que contribuye al desarrollo de estrategias docentes con resultados exitosos en la misma área de aplicación que la nuestra.

Desde el Politécnico Grancolombiano compartimos esta publicación que pretende aportar a la discusión acerca de las necesidades del entorno actual y futuro, a partir de una contextualización mundial de las respuestas 
que desde la educación se plantean y definen en políticas públicas en el marco de instituciones como UNESCO y Pacto Global.

El recorrido de esta publicación que asocia las prácticas de dos países como México y Colombia se concreta en el libro con un primer capítulo titulado "Modelo de Enseñanza-Aprendizaje de Educación Superior por Competencias" que nos aproxima al trabajo de las profesoras Mayte Barba Abad y Magdalena Buenfil Mata del Tecnológico de Monterrey y la Universidad de Guadalajara, quienes plantean interesantes modelos para desarrollar en los estudiantes las competencias genéricas requeridas en el mercado laboral. Esta propuesta deriva de la investigación de campo realizada en seis universidades del estado de Morelos, en México, tanto públicas como privadas, y seis empresas del mismo Estado, para determinar las competencias requeridas para el profesional del siglo XXI.

El segundo capítulo titulado "Educar en otra dirección: formar para la vida" de autoría de Maritza Alvarado Nando de la Universidad de Guadalajara plantea un modelo educativo basado en competencias. Alerta sobre las dificultades de implementar estos modelos y la inminente necesidad de hacer frente a una eventual transformación radical del modelo educativo. El capítulo llama la atención sobre los cambios en la manera de hacer docencia y la reflexión pedagógica, sobre todo, en los esquemas de formación. La propuesta analiza los elementos para tener en cuenta por parte de las instituciones y plantea una reflexión necesaria sobre la forma en la que se hace.

El último capítulo, titulado: "Aula invertida en el programa de Negocios Internacionales del Politécnico Grancolombiano, modalidad presencial”, comparte nuestra experiencia en este proyecto y es presentado por Deisy de la Rosa Daza, Decana de nuestra Facultad de Negocios, Gestión y Sostenibilidad, quien, en compañía de Ángela Julieta Mora Ramírez, docente del programa de Negocios Internacionales del Politécnico Grancolombiano, construyen mecanismos innovadores para gestionar conocimiento de manera colaborativa desde cualquier lugar del planeta. Este proceso basado en la co-creación entre el estudiante y el docente, consiste en analizar la forma en la que se hace y se recibe la clase para que los espacios de aprendizaje trasciendan las paredes del aula. 
Así pues, el libro "Innovación Educativa, Nuevas Metodologías y Prácticas en el Aula. Experiencias Desde México y Colombia" plantea el ejercicio de esta publicación como una urgente sistematización de nuevos retos y se constituye como un punto de partida para futuras reflexiones sobre las posibilidades de la Educación.

\section{JURGEN CHIARI ESCOBAR}

VICERRECTOR ACADÉMICO POLITECNICO GRANCOLOMBIANO

\section{Referencias}

1. Flores, E. G. R., Montoya, M. S. R., \& Mena, J. (2016). Challenge-based gamification as a teaching' Open Educational Innovation strategy in the energy sustainability area. In G.-P. F.J. (Ed.), 4th International Conference on Technological Ecosystem for Enhancing Multiculturality, TEEM 2016 (Vol. 02-04-November-2016, pp. 1127-1131). Escuela de Ingeniería Y Tecnología de la Información, Tecnológico de Monterrey, Avda. Garza Sada 2501 Sur; Col. Tecnológico, Monterrey, N. L., CP 64849, Mexico: Association for Computing Machinery. https://doi.org/10.1145/3012430.3012658

2. Norman-Acevedo. (2018). VIRTUAL EN EL POLITÉCNICO. (Institución universitaria Politécnico Grancolombiano, Ed.) (1st ed.). Bogotá: Politécnico Grancolombiano. Retrieved from https://comunicaciones.poligran.edu.co/ boletines/rompiendo/barreras.html

3. Salemi, M. K., \& Walstad, W. B. (2010). Teaching Innovations in Economics: Strategies and Applications for Interactive Instruction. Teaching Innovations in Economics: Strategies and Applications for Interactive Instruction. University of North Carolina, Chapel Hill, United States: Edward Elgar Publishing Ltd. Retrieved from https://www.scopus.com/inward/record.uri?eid=2-s2.0-84881937652 \& partnerID $=40 \& \mathrm{md} 5=1 \mathrm{efef363036e-}$ 1f27fa81340531e59d41 


\section{EDUCAR EN OTRA DIRECCIÓN: FORMAR PARA LA VIDA}

\section{LA EDUCACIÓN DEL SIGLOXXI}

En el contexto mundial, la calidad de la educación de los habitantes de la tierra cobra cada vez más un valor insoslayable. Vivimos un cambio vertiginoso en la gestión del conocimiento, que se encuentra vinculado al desarrollo tecnológico. El conocimiento se produce, difunde e intercambia al mismo tiempo que las tecnologías del conocimiento de una sociedad, porque estas lo conforman y determinan la naturaleza de los saberes socialmente válidos por las instituciones sociales que los gestionan (Castells, 2000).

En las sociedades del conocimiento se discuten los paradigmas, las teorías y modelos que sustenten diferentes conceptos para la formación relacionados con aprendizajes significativos; competencias genéricas y específicas; metodologías activas y tutorías; procesos como enseñar a pensar, aprender a aprender, entre otros.

En la educación superior, las instituciones libran una batalla sin fronteras para acoger las demandas y desafíos del mundo actual, que le permitirán incorporarse a un mundo globalizado y cambiante que

1 Doctora en Educación Superior, profesora investigadora titular "C" en la Universidad de Guadalajara, México. 
requiere desarrollar otras competencias y exige diversas maneras para la formación. Todo ello, para dar paso a un nuevo paradigma del proceso formativo de los estudiantes, un modelo centrado en el aprendizaje, en donde el papel protagónico es del alumno, priorizando sus necesidades para favorecer los conocimientos a lo largo de la vida.

Con base en lo anterior, los cambios en la educación se orientan hacia modelos educativos que toman en consideración tales propósitos. Uno de ellos es el modelo educativo basado en competencias. La implementación de estos modelos no es sencilla, ni son tareas a corto plazo en virtud de que demanda una transformación radical, implica cambios en la manera de hacer docencia, en la reflexión pedagógica y, sobre todo, en los esquemas de formación.

De esta manera, el mismo modelo conduce a una transformación o elaboración continua de las ideas y las creencias, lo que implica una innovación importante, que va a resultar en un cambio, en un rediseño del aprendizaje.

El desarrollo de las competencias, al requerir de aprendizajes significativos, exige a los docentes abordar los procesos cognitivos e intelectivos de manera individual dentro del proceso de formación del estudiante, para lograr los niveles de comprensión que este necesita.

Por lo anterior, el talento del docente y su participación activa son factores clave (UNESCO, 2014) en la adopción de un nuevo modelo educativo en el aula. Entender los retos que enfrenta el docente al cambiar o no sus prácticas educativas frente a la innovación de un nuevo proceso y modelo de enseñanza, resulta difícil.

Tal es el caso de la imperiosa necesidad que se plantea para la comprensión del proceso de transferencia de conocimiento en al aula. Por ejemplo, en un modelo educativo basado en competencias se tiene que considerar que la transferencia es un proceso de interacción, que no puede ser analizada fuera del contexto en el que tiene lugar y que es posible gracias a la existencia de una serie de estructuras y mecanismos creados ad hoc, que contienen, crean y trasfieren el conocimiento para estimular la creatividad e innovación (New Zealand Teachers' Council, 2009). 
En un modelo basado en formación por competencias, el docente se enfrenta a un proceso de cambio de concepciones y prácticas que va mucho más allá de un simple aprendizaje por acumulación de información o bien centrado en la adquisición y traslado al aula de nuevas técnicas didácticas; representa un cambio de paradigma en el que el docente abandona la enseñanza transmisora-receptiva y migra hacia un enfoque centrado en el alumno, la construcción del conocimiento y la colaboración, donde los conocimientos se perciben como herramientas útiles para la resolución de problemas y de nuevo conocimiento.

Este modelo por competencias se concibe como un sistema complejo de estructuras, conocimientos, creencias, atributos y tareas que permiten que ocurran varias acciones intencionales simultáneamente (Tobón, 2013). Tiene como base el contexto (cultura y lugar) en el cual se lleva a cabo la acción, pero incluye la posibilidad de transferir y aplicar habilidades y conocimientos a nuevas situaciones y ambientes con ética (UNESCO, 2015).

Los conocimientos, unidos a las habilidades y actitudes, hacen posible que se construyan las competencias. Para ello es necesario que los conocimientos se apliquen de manera práctica.

Por lo anterior, las competencias implican poner en acción en forma armónica diversos conocimientos (saber qué y para qué), habilidades (saber bacer) y actitudes (detrás de las cuales siempre hay valores), que guían la toma de decisiones (saber ser), y que se enfocan en la reconstrucción de saberes, creencias y formas de actuación en el aula (saber convivir), que repercutirán en lograr la innovación.

Desde esta perspectiva apremia a repensar la docencia y el aprendizaje, además de considerar que es la propia persona que deberá reflexionar para reaprender en contextos complejos. Un pensamiento complejo, crítico y divergente, tanto en profesores como en el alumnado, solo se podrá lograr a partir de desarrollar el talento humano.

Hay que estar inmersos y profundizar en la comprensión de cómo aprenden los profesores, qué les motiva, qué procesos ocurren cuando se enfrentan a la tarea de innovar o qué condiciones se requieren para que un 
cambio real ocurra y se consolide. Por lo anterior es importante identificar sus significados y prácticas en el aula.

Aplicar las bases y postulados teóricos que subyacen al desarrollo del talento humano orienta a los actores, sujetos clave de la educación a reiniciar procesos olvidados sobre la gestión del talento humano para alcanzar las metas tan marcadas en los objetivos de la Organización de las Naciones Unidas para la Educación, la Ciencia y la Cultura (UNESCO) sobre la educación de calidad para todos.

En el Informe de 2015 se presenta una evaluación de los progresos realizados desde 2000 hasta la fecha fijada para el logro de los objetivos establecidos en el marco de Dakar. Particularmente se evaluó si el mundo logró los objetivos y si las instancias interesadas cumplieron sus objetivos. Cuando se explican los factores que posiblemente influyeron en el ritmo del progreso, se encuentra que son los aspectos de política educativa y las estrategias instrumentadas para desarrollarlas las que aún presentan deficiencias. Sin embargo, lo más rescatable de dicho informe es la configuración de la Agenda Mundial de la educación posterior al año 2015. Ahí se plantea que urge localizar pautas de reflexión y acción para poner la comunicación y la información al servicio de la transmisión del conocimiento. Esta transmisión debe arraigarse en el tiempo, extenderse en el espacio y funcionar entre las generaciones y las culturas.

\section{FORMAR PARA LA VIDA}

La fluidez de la modernidad a lo largo del siglo XX diversificó sustancialmente la naturaleza del conocimiento y su papel en sociedad, lo que trajo por consecuencia la necesidad de modificar nuestra relación con el mismo, es decir, pasar de una relación de dominio a otra de gestión y uso competente de tal conocimiento en el siglo XXI. Este hecho ha provocado un cambio muy profundo en la concepción sobre educación, formación, instrucción, docencia y también en los planteamientos evaluadores de los aprendizajes. 
Desde hace más de 25 años ya se planteaba entre los postulados de la Declaración Mundial sobre la Educación Superior en el Siglo XXI: Visión y Acción de la Organización de la Naciones Unidas para la Ciencia y la Cultura, que la educación superior tenía que adaptar sus estructuras y métodos de enseñanza a las nuevas necesidades. Se establecía como una prioridad pasar de un paradigma centrado en la enseñanza y la transmisión de conocimientos a otro, centrado en el aprendizaje y el desarrollo de competencias transferibles a contextos diferentes en el tiempo y en el espacio. Señalaba entre sus artículos que «en un mundo en rápido cambio se percibe la necesidad de una nueva visón y un nuevo modelo de enseñanza superior» (UNESCO, 1998, p. 126).

Con respecto a la educación, la Organización de las Naciones Unidas para la Educación, la Ciencia y la Cultura (UNESCO, 2004) ha manifestado, desde el año 2004, que uno de los grandes retos que siguen planteados desde los inicios del siglo XXI y que forman parte de la Agenda 2030 son los siguientes: a). La construcción de un mundo más solidario; b). La supresión de la pobreza; c). La mundialización con carácter humano; d). Las medidas tendientes a un desarrollo sostenible; e). La construcción de la paz; f). La lucha contra la pandemia de VIH-SIDA y su prevención entre los jóvenes.

Evidentemente, se sabe que la educación no podrá por sí misma resolver todos estos problemas, pero jugará un papel primordial, en particular a la hora de apelar por la eliminación de las disparidades entre los géneros, la cohesión social y para «vivir mejor juntos», en la adquisición de aptitudes para la vida o en la función que cumplen los docentes en la mejora de la calidad de la educación.

Igualmente, se sabe que los esfuerzos no tendrán frutos sin una participación decidida de todos los actores de los sistemas educativos, sin que se establezca un diálogo político y social y que se creen vínculos de colaboración, en particular con la sociedad civil.

Desde la UNESCO se impulsa una participación de tipo reflexiva y una acción con miras a apoyar políticas más eficaces en todos los ámbitos del sistema educativo. Los problemas aún prevalecen, pero también se han en- 
contrado soluciones y se han determinado ciertas tendencias significativas. Se aboga por un diálogo político abierto, profundo y renovado, ya que se considera de primordial importancia.

Lo anterior constituyó el objetivo fundamental de la 47a Conferencia Internacional de Educación de la UNESCO, reunión celebrada en Ginebra en septiembre de 2004, con el tema «Una educación de calidad para todos los jóvenes: desafíos, tendencias y prioridades». Lo anterior es congruente con los objetivos estratégicos fijados por la UNESCO en aras de la educación.

Una gran mayoría de cuestiones que atañen a la calidad de la educación no son nuevas, particularmente porque la UNESCO se ha ocupado de ellas desde hace varias décadas, pero la mayoría de los problemas aún no han sido resueltos.

De lo anterior se desprenden algunas reflexiones y testimonios rescatados de la propia conferencia (UNESCO, 2004), y de los documentos de la organización que dan sustento a los temas que se plantean en este artículo. Se describen a continuación:

A. Se menciona en este punto que el número de adolescentes y de jóvenes que terminan la educación primaria crece rápidamente. Los efectivos escolarizados en la enseñanza secundaria en todo el mundo se han multiplicado por más de diez años en el transcurso de los últimos cincuenta. Entre 1990 y 2000, el índice bruto de escolarización en la enseñanza secundaria pasó, como media mundial, de un $56 \%$ a un $77,5 \%$ (UNESCO, 2004). Hay un incremento en la demanda de educación básica; este fenómeno, por un lado, es paralelo al importante crecimiento demográfico en determinadas regiones del mundo, sobre todo en las regiones más pobres, y por otro, a la convicción de millones de personas de que una educación secundaria parece ser el camino más fácil para encontrar un trabajo, asegurarse un salario decente y mejorar sus condiciones de vida.

De este modo, de acuerdo con los datos del informe del programa de las Naciones Unidas para el Desarrollo (PNUD), en los 20 países de «desarrollo humano bajo» (para los que se dispone de cifras), el índice medio de escolarización en la enseñanza secundaria durante el curso 2000-2001 ascendía como media a un 19\% (con variaciones de entre un 5 y un 40\%); 
en 59 países de «desarrollo humano medio» dicho índice es del 55\% (con variaciones de entre un 21 y un 88\%), mientras que para 45 países de «desarrollo humano alto», el índice medio es del $83 \%$.

Las poblaciones mantienen la gran esperanza de ver a cada uno de sus adolescentes conseguir una formación dentro de la educación secundaria formal - inferior y superior - para así desarrollar todos sus talentos, vivir mejor, salir de la pobreza, insertarse en la vida activa y contribuir al desarrollo.

B. Un malestar general se hace notar tanto en los países ricos como en los países pobres dentro de las estructuras que apuntan a la formación de élites o dentro de las estructuras dirigidas a nuevas capas sociales que acceden a la educación secundaria e incluso a adolescentes y jóvenes que no están integrados en el sistema de educación. Dicho malestar presenta importantes matices según las regiones y los distintos grupos humanos, y parece asociado a una gran dificultad por definir y hacer frente a las necesidades educativas tan diversificadas en un mundo que se caracteriza por las interdependencias y las desigualdades cada vez más latentes. En el mundo hay un consenso relativamente generalizado sobre el hecho de que las necesidades educativas para una mundialización están estrechamente relacionadas con la adquisición de competencias para aprender todo a lo largo de la vida, que será cada vez más larga, alternando periodos de formación y trabajo. Incluirá del mismo modo riesgos cada vez mayores de marginalización o de exclusión de cualquier beneficio del crecimiento económico. Parece también que regiones enteras van a sufrir aún más por culpa de pandemias mundiales, por el aumento de una movilidad geográfica (migración de cerebros), y de un crecimiento de los movimientos migratorios «voluntarios» o «forzados», así como otros fenómenos aún difíciles de identificar. El VIH-SIDA, por ejemplo, crea necesidades específicas en términos de competencias, ya que lo que realmente se necesita son cambios de comportamiento y no solo la adquisición de conocimientos. Ocurre lo mismo con el desarrollo sostenible y llegar a vivir juntos en paz.

C. El sentido mismo de la educación formal se ha puesto, en determinadas ocasiones, en tela de juicio, así como su valor como un medio para acceder al mundo laboral y contribuir al desarrollo sostenible, la cohesión social y el asentamiento de las bases para la paz. Algunos investigadores se preguntan si el esfuerzo financiero, organizacional y familiar realizado para alcanzar la escolarización universal en su forma actual, especialmente después de la enseñanza primaria, vale realmente la pena. Aprender a querer vivir juntos 
sigue siendo muy difícil. La violencia física escolar toma un lugar cada vez más importante, tanto entre las mujeres jóvenes como en otras situaciones de diversa índole. En las regiones más pobres, dicha violencia aparece a menudo muy alejada de las posibilidades de llegar a ser un incentivo para el desarrollo local y para la integración mundial.

D. Los sistemas educativos fueron creados y desarrollados en un entorno caracterizado por economías y estados nacionales, una población rural bastante importante y peticiones de democratización relativamente limitadas y homogéneas. Las exigencias actuales son a la vez más globales y diversificadas, con estructuras familiares y de comunicación e información completamente diferentes. El marco de acción adoptado en Dakar pide, en su objetivo número 3 «velar porque las necesidades de aprendizaje de todos los jóvenes y adultos se satisfagan mediante un acceso equitativo a un aprendizaje adecuado y a programas de preparación para la vida activa» (UNESCO, 1998). Sin embargo, no responde a cuestiones cruciales como: ser escolarizados: ¿para aprender qué? ¿Dónde? ¿Durante cuánto tiempo? ¿Cómo? ¿Con qué profesorado? Preguntas que no tienen respuesta a más de 10 años de su planteamiento.

E. La educación de nivel básico «tradicional y técnica» es puesta en entredicho por distintos países desarrollados. En los países de América Latina se multiplican los establecimientos tales como: «escuelas» secundarias y de «institutos», de «escuelas superiores» o de «escuelas comunitarias» para hacer frente a un número creciente de jóvenes que ya han terminado sus estudios primarios. Los gobiernos nacionales y los poderes públicos, en general, hacen lo que pueden para llevar la escolarización a un número cada vez mayor de adolescentes y jóvenes que desean formarse o que no tienen otra opción de integración social más que el recurso a las distintas instituciones de enseñanza.

Aun cuando existen más instituciones en muchos países con «buenas políticas» $\mathrm{y}$ «mejores prácticas», estas son poco conocidas y no se cuenta con un estudio detallado sobre el valor que pudieran representar para ser aplicadas a fines diferentes de los que las originaron. ¿Se pueden inventar modelos nuevos de educación para adolescentes y jóvenes en los países pobres que sufren un importante aumento demográfico, o se deben franquear todas las etapas que ya han recorrido los países ricos? ¿Podrían importarse los nuevos conceptos que se desarrollan en determinados países ricos como, por ejem- 
plo, el de las distintas formas de "centros de aprendizaje», haciendo abstracción de la historia y del entorno socioeconómico de los que surgieron?

F. La cuestión de las características de la oferta de la educación que sucede a la educación primaria es especialmente importante cuando se trata de encontrar una educación de gran calidad para ambos sexos y para los «recién llegados». Los jóvenes nacionales de países o de familias que no cuentan con una historia de escolarización larga y bien establecida se enfrentan a numerosos problemas de integración y de aprendizaje cuando llegan a los establecimientos tradicionales de enseñanza secundaria general o técnica. Las preocupaciones a nivel mundial afectan particularmente al acceso, la equidad y la calidad de la educación de mujeres jóvenes, pero se constata que en determinadas regiones, el colectivo de hombres jóvenes supone también un problema importante. Las verdaderas dificultades parecen estar siempre vinculadas a un sentimiento de inadecuación o incluso de distanciamiento entre las necesidades en educación de los jóvenes y las respuestas que los sistemas ofrecen a dichas necesidades. Muchos jóvenes que acceden al nivel de enseñanza secundaria no se adaptan a la «norma escolar» de alumnos medios, haciendo patente que los sistemas educativos y su funcionamiento pueden ser fuente de marginalización y de exclusión. En un sentido más amplio, ¿qué puede hacer la educación para luchar contra la pobreza y favorecer la cohesión social? Sin duda alguna, en estos ámbitos existen también distintas formas de «buenas políticas» y «mejores prácticas», pero ¿̇cuáles son? ¿Cuál es su nivel de transferencia y su posibilidad de generalización?

G. Los gobiernos nacionales y los poderes públicos deben ser muy activos en la regulación, la definición de normas y sistemas de seguimiento de la educación de los adolescentes y los jóvenes, lo cual forma parte de un consenso internacional. Nadie pone en tela de juicio el papel de los gobiernos a la hora de definir las finalidades y los objetivos de una educación de calidad para todos los jóvenes. Sin embargo, se suceden los debates y las distintas opiniones sobre la forma en que los gobiernos los deben definir para dicha educación. ¿Deben seguir haciéndolo cada uno por su parte, como en el periodo de los estados nacionales con fronteras «compactas», o deben hacerlo de forma cada vez más cooperativa? ¿Es posible definir «normas» mundiales de adquisición de experiencias o competencias deseadas? ¿Es conveniente, política y socialmente, para lograr una mundialización de índole humana, definir distintas competencias para los distintos grupos o categorías de países (desarrollados/en desarrollo, ricos/pobres)? ¿Se pueden evaluar las experiencias adquiridas con respecto a un concepto y unas refe- 
rencias universales que caracterizan la calidad de la enseñanza para todos los adolescentes y los jóvenes? ¿Es eso deseable?

Frente a los desafíos internacionales que plantean la pobreza, el entorno, la cohesión social o la construcción de la paz, ¿es razonable pensar que se puede salir sin ayuda de esas situaciones?

H. Asegurar de la misma forma que antes el funcionamiento de los sistemas educativos en general -y de las formas educativas en particular- para adolescentes y jóvenes, ya no es posible solo desde los gobiernos nacionales. La cuestión de una «buena gobernabilidad» de la educación basada en el diálogo político y social, se ha convertido en el eje central, y la constitución o ampliación de nuevas relaciones de colaboración aparecen como la estrategia mejor adaptada para alcanzar dicho objetivo. La buena gobernabilidad hace referencia, entre otras, a la organización del «gobierno» de la educación y de su gestión con respecto al territorio (centralización o descentralización), al poder en sí mismo (con más o menos participación de los distintos actores) y a la financiación.

I. Para garantizar una enseñanza de calidad para todos los jóvenes son imprescindibles las relaciones de colaboración internacionales y entre diferentes actores a escala nacional. Adoptando el Marco de Acción de Dakar, la comunidad internacional afirmó que «ningún país que se comprometa seriamente con la Educación para Todos se verá frustrado por falta de recursos en su empeño por lograr esa meta» (UNESCO, 2004). Pero la financiación de una enseñanza de calidad para todos los jóvenes carece todavía de medios. La mayor parte de los proveedores de fondos bilaterales tienen como objetivo contribuir con el $0,7 \%$ de su producto nacional bruto (PNB) a la ayuda al desarrollo, pero la mayor parte de ellos, a excepción de los países nórdicos, no han alcanzado dicho objetivo y los recursos disponibles son principalmente asignados a la educación primaria o la educación no formal. Algunos países siguen invirtiendo, proporcionalmente, más en la enseñanza superior que en la secundaria. La cuestión que se plantea en la actualidad no es realmente la de su reconocimiento o su legitimidad, sino la de su articulación productiva y creativa en un sistema de buena gobernabilidad. ¿Cómo crear las condiciones y las metodologías de diálogo y de acción necesarias para crear un círculo virtuoso entre todos los agentes que intervienen en la educación de adolescentes y jóvenes? ¿Cómo poner en marcha y gestionar dichas asociaciones en el día a día? 
J. Las nuevas tecnologías y otras alternativas educativas fracasarán frente al desafío de garantizar el derecho a una educación de calidad para todos los jóvenes, si no se produce una mediación adecuada por parte de los docentes. Tras periodos de cierta fascinación frente a las nuevas tecnologías emergentes, nadie duda hoy en día de su importancia, y al mismo tiempo, de la necesidad de poder contar con un profesorado bien formado, suficientemente remunerado y capaz de seguir los procesos de evolución de los conocimientos y de su propia estructura, y que disponga, al mismo tiempo, de las competencias necesarias para hacer frente a las interdependencias cada vez mayores que afectan al mundo en general y a la escuela en particular. Del mismo modo, aparecen nuevas disciplinas como la promoción de la salud, la prevención del VIH-SIDA, la educación sexual, la adquisición de competencias para la vida y que hoy en día implican métodos diferentes de enseñanza basados en las fuertes relaciones humanas e interpersonales, al mismo tiempo que requieren el uso de las nuevas tecnologías. ¿Cómo definir los perfiles del profesorado para una educación de calidad para todos los jóvenes? ¿Cómo garantizar la actualización de la formación? ¿Cómo acompañar y apoyar el trabajo de los profesores frente a las «nuevas generaciones»? ¿Cómo ayudar a los docentes y jefes de los establecimientos a mejorar la calidad de vida escolar para prevenir y luchar contra la violencia en la sociedad y en la escuela?

Las reflexiones y cuestionamientos precedentes muestran la sagacidad de los problemas y la urgencia de tomar medidas eficaces e innovadoras para mejorar realmente la calidad de la educación de todos los jóvenes. Existe, además, en todos los sistemas educativos, una fuerte tensión entre el malestar y la esperanza, entre la inquietud frente a los desafíos del futuro y el deber de afrontar resueltamente los problemas.

La calidad y riqueza de los debates efectuados durante la 47a Conferencia han permitido reflexionar acerca de que esta ha alcanzado sus objetivos, y que sus conclusiones podrán orientar nuevas políticas que respondan de manera más adecuada a las necesidades de los jóvenes en un mundo que se caracteriza por la complejidad de una mundialización que se acelera y por necesidades locales a las cuales se encuentran confrontados a diario.

En el año 2015 se presentó un informe sobre la educación para todos. De dicho informe se rescata el objetivo 6 , sobre calidad de la educación, dise- 
ñado en Dakar en 2000 para lograrse en 2015. El objetivo se centra en lo siguiente:

Calidad de la educación. Tanto en Jomtien, en 1990, como en Dakar, en 2000, se hizo hincapié en la necesidad de garantizar que los niños aprendan realmente como resultado de su experiencia educativa. Sin embargo, se concluye que el aumento del acceso a la educación ha planteado problemas nuevos a la hora de velar porque ese mayor número de personas escolarizadas recibiera una educación de buena calidad.

También se encontró que el aumento de las evaluaciones del aprendizaje llevadas a cabo a gran escala desde el año 2000 refleja una mayor atención a la medición de los resultados de los sistemas educativos. La mayor disponibilidad de datos ha permitido comprender mejor la gravedad de la crisis del aprendizaje y las evidentes disparidades en la adquisición de los niveles de aprendizaje más básicos, tanto entre los distintos países como dentro de cada uno de ellos. Sobre la base de las evaluaciones nacionales, regionales e internacionales del aprendizaje, en el Informe se describe la relación entre los resultados de los alumnos en la escuela y las desventajas que tienen su origen en el medio familiar y la comunidad a la que pertenecen.

Con frecuencia se afirma que la ampliación de la educación en los países más pobres desde el año 2000 ha redundado en un empeoramiento de la calidad. No obstante, aunque es muy elevado el número de niños que no están adquiriendo los conocimientos básicos, algunos países han logrado que estén escolarizados más niños y que estos aprendan una vez que asisten a la escuela. En los nuevos análisis para el Informe se emplearon datos de evaluaciones, llevadas a cabo a lo largo del tiempo, a fin de entender qué reformas y programas se utilizaron para combinar un mayor acceso a la educación con una mejora de los resultados del aprendizaje y una disminución de la desigualdad.

En el mismo informe de la UNESCO, se considera que los docentes son fundamentales para resolver la crisis del aprendizaje. Se enfatiza la necesidad de que los gobiernos de distintas partes del mundo se aseguren de que hay un número suficiente de docentes que cuentan con la formación y la motivación adecuadas, y que están presentes en las zonas desfavorecidas 
para evitar que continúen aumentando las desigualdades en los resultados del aprendizaje. Lo primordial es avanzar en los marcos normativos de estas esferas para velar porque los mejores docentes presten apoyo a quienes más lo necesiten.

Desde el año 2000 se han efectuado llamamientos enérgicos a reformar la gobernanza de la educación, sustituyendo el control centralizado por una autoridad descentralizada y una toma de decisiones participativa. Su propósito ha sido lograr que las escuelas rindan cuentas de sus resultados.

El impulso en favor de la descentralización debe ir acompañado de orientaciones y un apoyo suficiente a las escuelas sobre la forma de aplicar los nuevos enfoques para mejorar el aprendizaje. A causa de lo limitado de sus recursos humanos y financieros, pocos países en desarrollo disponen de servicios de supervisión que sean adecuados para la tarea que se pretende realizar. Se apremia a que haya una instalación de sistemas para promover enfoques cooperativos que permitan lograr una mejora de los resultados del aprendizaje y una disminución de la desigualdad. Efectuar un seguimiento de los procesos de enseñanza y aprendizaje escolares, utilizando, entre otros instrumentos, las evaluaciones del aprendizaje en las aulas, reviste una importancia fundamental para elaborar políticas de mejora de la calidad.

Es importante visualizar posibles escenarios de la manera en que los responsables de formular las políticas puedan utilizar esa información para mejorar los entornos de aprendizaje en favor de los más desfavorecidos. También es necesario que se realicen cambios y rediseño de planes y programas de estudios para que sean innovadores e integradores desde el punto de vista de la mejora de los resultados del aprendizaje.

\section{LA EDUCACIÓN SUPERIOR PARA EL SIGLOXXI}

Los procesos actuales de modernización están en gran medida determinados por la emergencia de la sociedad del conocimiento (también entendida como de la información o postindustrial); más que una transformación social acabada, se trata de una tendencia, y para los países en vías de desarrollo, 
de un horizonte al que aspiran (Castells, 2000). Un aspecto fundamental de esta transformación es la centralidad que adquiere el conocimiento en todas las relaciones sociales. La estructura ocupacional cada vez demanda más calificaciones; las nuevas tecnologías de la información y comunicación redefinen nuestras vidas (incluso las relaciones más personales), exigiendo progresivamente un mayor uso de conocimientos aplicados, habilidades de comunicación compleja, capacidades matemáticas básicas, pensamiento experto y sistémico, entre otras (Levy y Murnane, 2004).

Para atender al objetivo 3, "Velar por que las necesidades de aprendizaje de todos los jóvenes y adultos se satisfagan mediante un acceso equitativo a un aprendizaje adecuado y a programas de preparación para la vida activa" que se encuentra en el documento de la UNESCO se han llevado a cabo diversas acciones con las directrices que mejoren la educación de este nivel.

Ante estos cambios, en el mundo se han redefinido los espacios institucionales de la sociedad moderna para la producción y reproducción de su conocimiento más elaborado: las universidades. Tradicionalmente, estas eran las responsables de las funciones de formación de los recursos humanos calificados, la producción del conocimiento avanzado, la ciencia, las humanidades, incluso las artes, y la reproducción social tanto de las élites como de los cuadros profesionales (asociados a las capas medias). Las nuevas condiciones alteraron estas funciones clásicas. La sociedad le exigió a las universidades una mayor apertura social para dar respuesta a la creciente demanda por movilidad social a través de los estudios. A su vez, la universidad vio terminada su exclusividad en la producción científica con la aparición de otros actores sociales en tal actividad principal. Los actuales sistemas de educación superior se hacen cargo de una formación masiva de profesionales altamente diferenciada y heterogénea; junto a la universidad aparecen nuevas instituciones de formación profesional que contribuyen, en conjunto con el sector privado y otros actores, a la producción científica y de la alta cultura; se financian de diferentes formas con distintas fuentes; y se organizan con base en los indicadores estandarizados de calidad que tienden a medir objetivamente la calidad institucional por medio de los servicios que se prestan. 


\section{EDUCACIÓN SUPERIOR Y RESPONSABILIDAD SOCIAL}

En este apartado se describe de manera sucinta los principales ejes desarrollados en la Conferencia Mundial sobre la Educación Superior (2009), con el propósito de tender puentes entre la exigencia de implementar nuevos modelos de formación y las posibilidades de cambio e innovación que se espera lograr en este nivel.

Actualmente la inversión en los estudios superiores, por su condición de fuerza primordial para la construcción de sociedades del conocimiento integradoras y diversas, y para fomentar la investigación, la innovación y la creatividad, ha cobrado gran importancia. La educación superior contribuye a erradicar la pobreza, a fomentar el desarrollo sostenible y a adelantar en la consecución de los objetivos de desarrollo acordados en el plano internacional, entre otros, los Objetivos de Desarrollo del Milenio (ODM) y de la Educación para Todos (EPT); se espera que los programas mundiales de educación reflejen estas realidades.

Desde la UNESCO se plantea que la educación es un bien público y es un imperativo estratégico para todos los niveles de enseñanza. También se enfatiza que la educación superior debe ser responsabilidad de todos los gobiernos y recibir su apoyo económico. A continuación, se describen las orientaciones y ejes de desarrollo emanados de la conferencia para el logro de las metas y los objetivos estratégicos (UNESCO, 2015).

1. La educación superior, en tanto que bien público, es responsabilidad de todas las partes interesadas, en particular de los gobiernos.

2. Ante la complejidad de los desafíos mundiales, presentes y futuros, la educación superior tiene la responsabilidad social de hacer avanzar nuestra comprensión de problemas polifacéticos con dimensiones sociales, económicas, científicas y culturales, así como nuestra capacidad de hacerles frente. En este nivel educativo se debería asumir el liderazgo social en materia de creación de conocimientos de alcance global para abordar retos mundiales, entre los que figuran la seguridad alimentaria, el cambio climático, la gestión del agua, el diálogo intercultural, las energías renovables y la salud pública. 


\section{[ 24 ] Innovación educativa: nuevas metodologías y experiencias en el aula}

3. Los centros de educación superior, en el desempeño de sus funciones primordiales (investigación, enseñanza y servicio a la comunidad) en un contexto de autonomía institucional y libertad académica, deberían centrarse aún más en los aspectos interdisciplinarios y promover el pensamiento crítico y la ciudadanía activa, contribuyendo así al desarrollo sostenible, la paz y el bienestar, así como a hacer realidad los derechos humanos, entre ellos la igualdad entre los sexos.

4. La educación superior debe no solo proporcionar competencias sólidas para el mundo de hoy y de mañana, sino contribuir además a la formación de ciudadanos dotados de principios éticos, comprometidos con la construcción de la paz, la defensa de los derechos humanos y los valores de la democracia.

5. Existe la necesidad de lograr más información, apertura y transparencia en lo tocante a las diversas misiones y actuaciones de cada establecimiento de enseñanza.

6. La autonomía es un requisito indispensable para que los establecimientos de enseñanza las puedan cumplir con su cometido gracias a la calidad, la pertinencia, la eficacia, la transparencia y la responsabilidad social.

7. En los últimos diez años se han realizado ingentes esfuerzos a fin de mejorar el acceso y garantizar la calidad. Este empeño debe continuar. Pero el acceso, por sí solo, no es suficiente. Será preciso hacer mucho más. Hay que llevar a cabo esfuerzos para lograr que los alumnos obtengan buenos resultados.

8. La ampliación del acceso a la educación se ha convertido en una prioridad en la mayoría de los Estados Miembros y el aumento de los índices de participación en la enseñanza superior es una de las grandes tendencias mundiales. Sin embargo, aún subsisten fuertes disparidades, que constituyen una importante fuente de desigualdad. Los gobiernos y las instituciones deben fomentar el acceso, la participación y el éxito de las mujeres en todos los niveles de la enseñanza.

9. Al ampliar el acceso, la educación superior debe tratar de alcanzar simultáneamente los objetivos de equidad, pertinencia y calidad. La equidad no es únicamente una cuestión de acceso; el objetivo debe ser la participación 
y conclusión con éxito de los estudios, así como la garantía del bienestar del alumno. Este empeño debe abarcar el adecuado apoyo económico y educativo para los estudiantes que proceden de comunidades pobres y marginadas.

10. La sociedad del conocimiento necesita diversos sistemas de educación superior, con una gama de instituciones que tengan cometidos variados y lleguen a diversos tipos de estudiantes. Además de los centros de enseñanza públicos, las entidades privadas de enseñanza superior con objetivos de interés público han de desempeñar una función importante.

11. Nuestra capacidad para alcanzar los objetivos de la EPT dependerá de nuestra capacidad para enfrentarnos con la escasez mundial de docentes. La educación superior debe ampliar la formación de docentes, tanto inicial como en el empleo, con planes y programas de estudios que den a los docentes la capacidad de dotar a sus alumnos de los conocimientos y las competencias que necesitan en el siglo XXI. Este objetivo exigirá nuevos enfoques, como por ejemplo la implementación de sistemas de aprendizaje abierto y a distancia y del uso de las tecnologías de la información y la comunicación (TIC).

12. La formación de expertos en planificación educativa y la realización de investigaciones pedagógicas con el fin de mejorar las estrategias didácticas contribuyen también a la consecución de los objetivos de la EPT.

13. El aprendizaje abierto y a distancia y el uso de las TIC ofrecen oportunidades de ampliar el acceso a la educación de calidad, en particular cuando los recursos educativos abiertos son compartidos fácilmente entre varios países y establecimientos de enseñanza superior.

14. La aplicación de las TIC a la enseñanza y el aprendizaje encierra un gran potencial de aumento del acceso, la calidad y los buenos resultados. Para lograr que la aplicación de las TIC aporte un valor añadido, los establecimientos y los gobiernos deberían colaborar a fin de combinar sus experiencias, elaborar políticas y fortalecer infraestructuras, en particular en materia de ancho de banda. 


\section{[ 26 ] Innovación educativa: nuevas metodologías y experiencias en el aula}

15. Los establecimientos de educación superior deben invertir en la capacitación del personal docente y administrativo para desempeñar nuevas funciones en sistemas de enseñanza y aprendizaje que se transforman.

16. Es esencial para todas las sociedades que se haga más hincapié en los ámbitos de las ciencias, la tecnología, la ingeniería y las matemáticas, así como en las ciencias sociales y humanas.

17. Los resultados de la investigación científica deberán difundirse más ampliamente mediante las TIC y el acceso gratuito a la documentación científica.

18. La formación que ofrecen los establecimientos de enseñanza superior debería atender las necesidades sociales y anticiparse al mismo tiempo a ellas. Esto comprende la promoción de la investigación con miras a elaborar y aplicar nuevas tecnologías, y a garantizar la prestación de capacitación técnica y profesional, la educación para la gestión del conocimiento y los programas de aprendizaje a lo largo de toda la vida.

19. La ampliación del acceso plantea un desafío a la calidad de la educación superior. La garantía de calidad es una función esencial en la enseñanza superior contemporánea y debe contar con la participación de todos los interesados. Es una tarea que exige tanto la implantación de sistemas para garantizar la calidad como de pautas de evaluación, así como el fomento de una cultura de la calidad en los establecimientos.

20. Deberían ponerse en práctica, en todo el sector de la educación superior, mecanismos de regulación y garantía de la calidad que promuevan el acceso y creen condiciones para que los alumnos concluyan los estudios.

21. Los criterios de calidad deben reflejar los objetivos globales de la educación superior, en particular la meta de cultivar en los alumnos el pensamiento crítico e independiente y la capacidad de aprender a lo largo de toda la vida. Dichos criterios deberían estimular la innovación y la diversidad. Para garantizar la calidad en la enseñanza superior es preciso reconocer la importancia de atraer y retener a un personal docente y de investigación calificado, talentoso y comprometido con su labor. 
22. Las políticas y las inversiones deben prestar apoyo a una amplia gama de actividades de educación e investigación de tercer ciclo o postsecundarias - comprendidas las de las universidades- y deben atender las necesidades que están en rápida mutación, una nueva y diversa población estudiantil.

23. La sociedad del conocimiento exige una diferenciación cada vez mayor de funciones dentro de los sistemas y establecimientos de educación superior, con redes, excelencia investigadora, innovaciones en materia de enseñanza y aprendizaje, así como nuevas estrategias al servicio de la comunidad.

Los siguientes puntos que se presentan hacen referencia al aprendizaje y la investigación e innovación, tal como se describen en el documento original de la conferencia, razón por la cual mantiene su numeración.

35. Los establecimientos deberán buscar nuevas formas de aumentar la investigación y la innovación mediante iniciativas conjuntas de múltiples copartícipes entre el sector público y el privado, que abarquen a las pequeñas y medianas empresas.

36. Los sistemas de investigación deberían organizarse de manera más flexible con miras a promover la ciencia y la interdisciplinariedad al servicio de la sociedad, ya que resulta cada vez más difícil mantener un buen equilibrio entre la investigación básica y la aplicada, debido a los altos niveles de inversión que necesita la investigación básica y al reto que representa el vincular el conocimiento de ámbito mundial con los problemas locales.

37. La libertad de enseñanza es un valor fundamental que es preciso proteger en el contexto internacional actual de inestabilidad y evolución constante. En aras de la calidad y la integridad de la educación superior, es importante que el personal docente disponga de oportunidades para realizar investigaciones y obtener becas.

38. Los establecimientos de enseñanza superior deberían buscar esferas de investigación y docencia capaces de abordar los asuntos que atañen al bienestar de la población y crear bases sólidas para la ciencia y la tecnología pertinentes en el plano local.

39. Los sistemas de conocimiento indígenas pueden ampliar nuestra comprensión de los nuevos problemas; la educación superior debería establecer aso- 
ciaciones de mutuo beneficio con las comunidades y las sociedades civiles, con miras a facilitar el intercambio y la transmisión de los conocimientos adecuados.

40. Estudiar e intensificar el uso de los recursos e instrumentos de las bibliotecas electrónicas, con la intención de apoyar la enseñanza, el aprendizaje y la investigación ante la creciente escasez de recursos, insta a las partes interesadas.

Finalmente, se puede decir que en cada uno de los puntos mencionados se articulan una serie de elementos, que van desde el planteamiento de una problemática hasta las indicaciones que se diseñaron para la solución de los mismos. Cabe señalar que no se incluyeron en este apartado otros asuntos referidos a temas que no se corresponden directamente con el artículo, como es el caso de la educación superior en África.

\section{EN LA NUEVA SOCIEDAD DEL CONOCIMIENTO EL PROFESORADO HARÁ LA DIFERENCIA}

El mundo caracterizado por cambios constantes, en el que el proceso de aprendizaje se ha visto limitado y reducido, el profesorado ha optado por rechazar su participación para liderar los procesos de cambio. Con base en lo expuesto hasta aquí y partiendo de los postulados que argumentan las diferentes organizaciones (UNESCO) es importante analizar muestro sistema de educación superior para identificar sus problemáticas y proponer nuevas orientaciones pedagógicas en la búsqueda de la formación de calidad para la vida.

Como ya se dijo antes, en los resultados de la Conferencia Mundial de la Educación Superior, los modelos de reforma educativa verticales y directivos que se han extendido en la gran mayoría de los países niegan la diversidad y han agotado los recursos tanto humanos como materiales en una búsqueda en vano por encontrar soluciones rápidas para resolver los problemas complejos de la educación, y todo ello dentro de un clima que 
no guarda relación alguna con la historia o la tradición de las instituciones educativas en las que el pasado se consideraba como una herramienta irrelevante y sin valor alguno para contribuir a la modernización del futuro.

Existe un modelo alternativo emergente que sustenta una red de conexiones capaz de contribuir a la mejora del aprendizaje vía la creación de una red de interconexiones entre los diferentes centros para funcionar como comunidades profesionales consolidadas, en las que la participación comprometida de todos los involucrados favorezca lazos de intercomunicación y se fomente el aprendizaje sostenible dirigido al alumnado.

Cambiar un sistema educativo y construir nuevos modelos de formación implica bastantes retos. Iniciemos por señalar que el cambio y la mejora sostenibles en la escuela comienzan con el propósito de alcanzar la integridad de sus resultados. En este tipo de procesos se sitúa, en primer lugar, al aprendizaje, por delante del rendimiento escolar o de los exámenes, puesto que el aprendizaje se considera requisito esencial para conseguir todo lo demás.

El hecho de tener presente el aprendizaje hace que este sea profundo y amplio, y se consigue que vaya más allá de lo básico o fundamental. No importan las recomendaciones que se le dan a los centros, sistemas y naciones con diferencias históricas y culturales significativas que vienen impuestas desde las tendencias planteadas en el exterior. Se trata de ir más allá de lo realmente trascendental en lugar de esperar por siempre una respuesta a la formación cuando ya sea tarde; se trata, pues, de darle a todo el alumnado la ventaja de ser parte en la «economía del conocimiento creativo» y no solo en los trabajos artesanales o de mano de obra barata, puesto que el conocimiento básico apenas los capacitará para poder desempeñarlos de manera eficaz. Tener presente el aprendizaje es un proceso lento, pero que perdura. No se materializa en la obtención de una serie de rendimientos bruscos y poco consolidados con los que se pretende satisfacer los objetivos a corto plazo impuestos desde fuera.

Desde esta perspectiva, las teorías actuales se basan en tres tipos de postulados invalidados por los conocimientos que tenemos de las sociedades, o por lo menos sobre organizaciones y sistemas de acción, que al decir 
de Crozier y Friedberg (1990) son: un postulado de coherencia, uno de jerarquía de los elementos de la realidad social y, otro, la homogeneidad del campo social.

En una propuesta o reforma para el cambio se debe considerar que un sistema puede sustraer no solo las incoherencias, sino que también la simbiosis de mecanismos en apariencia contradictorios.

Lo que es urgente saber se refiere no solo a la naturaleza de la ruptura que hace ineluctable la evolución de las fuerzas actuales, sino a plantear mejor el problema en términos de: ¿en qué condiciones las tensiones que hasta ahora habían tenido como consecuencia reforzar el sistema de acción existente, pueden en lo sucesivo provocar una explosión? El problema no es evitar crisis y rupturas o reemplazarlas con una evolución gradual, sino comprender cómo y en qué condiciones una crisis puede ser el principio de mecanismos de innovación y no mecanismos regresivos (Crozier y Friedberg, 1990).

Las políticas de cambio sostenible en la escuela no se oponen al establecimiento de objetivos a corto plazo, sino que constituyen una parte muy útil que se circunscribe al proceso de cambio. Por otra parte, las políticas educativas firmes y acertadas tienen continuidad en el tiempo y alcanzan una difusión notoria, al fomentar la consecución de una serie de objetivos que se desarrollan de forma conjunta como una responsabilidad duradera y compartida entre profesor y estudiante y entre profesores y directivos. La forma o formas de difusión de estos procesos dependen ampliamente del contexto de liderazgo que haya en cada institución educativa.

En el contexto internacional puede observarse que un creciente consenso en el liderazgo escolar eficaz es esencial para conseguir la mejora educativa (Hargreaves y Goodson, 2006).

Cuando se comparte la responsabilidad en el aprendizaje, así como en la conformación de escenarios futuros con sus objetivos y metas a lograr en la comunidad educativa, tiene prioridad un tipo de liderazgo distribuido mediante y entre todos los participantes de una organización, junto con la creación de lo que se denomina «comunidades profesionales de aprendizaje 
consolidadas», es decir, las celdas resistentes de un sistema sostenible (Bolívar y Moreno, 2002).

Actualmente se realizan diversas acciones de tipo colaborativo-participativas en la formación de actores educativos y se apuesta a la formación a partir de invertir para acrecentar la confianza y promover el trabajo en equipo, con la intención de lograr procesos autogestivos de las propias comunidades, ya sin la presencia de los formadores de recursos humanos y expertos en el tema.

Por tal razón, los proyectos de cambio y planes de mejora se toman con seriedad y, al ser autogestivos, marcan nuevas rutas del camino a seguir por los líderes o se designan papeles innovadores a los integrantes de la comunidad de aprendizaje, a fin de orientar cambios inéditos. Las estrategias de cambio y mejora sostenibles dan lugar a un tipo de liderazgo al que aspira la mayoría, una vez consciente de que se constituirá en los próximos líderes para la estructura del cambio de la institución cuando se aprende en colaboración, así como que la tarea de la gestión del aprendizaje y directiva se hace más ágil.

Generalmente, en estos procesos participativos se lucha porque el profesorado permanezca en las escuelas que se encuentran en su fase de mejora, para que las prácticas se arraiguen al contexto cultural y social. Al final, lo más importante es preparar a la comunidad profesional de aprendizaje en la toma de decisiones más pertinentes y en el desarrollo del desempeño que le toca a cada uno de ellos, con la intención de continuar las acciones participativas y autogestivas hacia otras instituciones educativas.

Las políticas relacionadas con el ámbito de «sostenibilidad» prestan una atención especial en la satisfacción de necesidades de la escuela, sin desperdiciar los recursos del alumnado, de los miembros del personal y de todos los involucrados.

El enfoque del cambio y de mejora sostenible incide sobre aquellos principios firmes y sólidos que perduran en el tiempo, no en programas fijos que finalmente acaban por desaparecer. Este enfoque pondera que la diversidad lingüística y cultural requiere de una diversidad pedagógica; por otro lado, parte de la base de que los profesores aprenden de forma diferente, de igual 
modo que sucede con el alumnado. En las políticas del cambio sostenible escolar se reconoce y fomentan múltiples formas para lograr la excelencia pedagógica y ampliar el repertorio de los profesores, creando una red de conexiones entre diferentes aulas, cursos y departamentos, así como añadiendo elementos extra sobre lo que se conoce acerca de la investigación respecto a métodos de enseñanza mediante la formación y desarrollo en aquellos lugares en los que la escuela carece todavía de ellos.

Las estrategias de cambio y mejora sostenibles renuevan las energías de las personas. Los agentes encargados de ello se muestran asertivos y se niegan a poner en marcha agendas externas insostenibles que perjudicarían el proceso de aprendizaje en el alumnado. Por otra parte, esos agentes del cambio y mejora sostenibles no tratan de hacer todas las modificaciones ellos mismos, sino que delegan y dan oportunidad a otros involucrados para equilibrar esfuerzos, sin tener que trabajar largas jornadas después de horarios laborales.

Por último, valga mencionar que en las estrategias para conseguir el cambio y la mejora sostenibles en la escuela se consideran todos los procesos que se han desarrollado con anterioridad, a fin de reconstruir las nuevas fases de la transformación e innovación. De igual manera, localizan los puntos de quiebre institucional, así como las oportunidades de cambio, y las socializan con el resto de los participantes para vencer cualquier tipo de resistencias.

En este tenor, lo dicho antes trae consigo una clara disposición y un serio compromiso por parte de los actores clave implicados en tales procesos de mejora por trabajar de manera colaborativa y participativa, a fin de lograr los mejores resultados posibles.

El problema básico con que se encuentran hoy los sistemas educativos es el de la finalidad de la educación y de sus instituciones en la sociedad de la información. Este problema debe hacer repensar la pedagogía y, dentro de esta, la teoría de la educación. En el proceso de construcción de una pedagogía cognitiva no se pueden ignorar algunos de los principales problemas sobre el conocimiento. Entre estos, se identifican los siguientes: la contraposición entre conocimiento y conocer, la persistencia o disgregación del sujeto 
que conoce (y, en el caso de su existencia, quién es efectivamente ese sujeto que conoce), la consistencia y persistencia de lo conocido, el de su valor y, por último, las vías para llegar al propio conocimiento.

Un examen de tal situación desde la perspectiva de la ciencia cognitiva como de la teoría del conocimiento, obliga a dar una respuesta única. Desde la cognitiva, se reconoce a profesionales de una pluralidad de disciplinas preocupados por ese objeto de estudio, de modo que se tiende a hablar no de ciencia cognitiva, sino de las ciencias (disciplinas y tecnologías) cognitivas. En términos filosóficos, la dificultad se formula en términos de una teoría del conocimiento; y algo semejante sucede desde la perspectiva epistemológica si se admite que el conocimiento no es completo, ni definitivo, tampoco el conocimiento sobre el mismo conocimiento.

Cuando se afronta el punto de la elaboración o construcción del conocimiento en la sociedad actual, se tiende a dar por supuesto que lo que existe es la posibilidad de la experiencia del conocer, más que de la realidad del conocimiento. La filosofía clásica considera el conocimiento como el efecto de adecuar el entendimiento del sujeto cognoscente y la realidad conocida.

Scardamalia y Bereiter (2003) hacen énfasis en que no hay métodos bien probados para formar a la gente para ser buenos productores de conocimiento, de tal manera que cabría hacer uso de algunas soluciones provisionales:

a) Educar con base en el conocimiento básico disponible;

b) Buscar la formación en destrezas más o menos específicas;

c) Adoptar la perspectiva de la construcción social del conocimiento dentro de enfoques tales como las «comunidades de aprendizaje», el «aprendizaje basado en proyectos» o el «descubrimiento guiado».

Los dos primeros enfoques entrañan, según estos autores, el riesgo de desplazar el conocimiento avanzado al ámbito de una educación terminal a la que llegan muy pocos, sea en el nivel de posgrado o en el mundo del trabajo cualificado. En el enfoque de la construcción social se considera al conocimiento como una producción y mejora continuas del capital de ideas en una comunidad, generadas dentro de un proceso continuo a lo largo de toda la vida, dentro y fuera de la educación formal. 
Los enfoques señalados antes no tienen un carácter necesariamente antagónico, sino que pueden actuar de forma sinérgica y convergente. Situados en la perspectiva de la construcción social del conocimiento, como modelo integral y amplio, adquiere sentido que en los primeros estadios se emplee más el conocimiento básico, y que el aprendizaje basado en problemas y en proyectos adquiera su mayor eficacia en fases más avanzadas, como se está haciendo desde hace mucho tiempo en la educación media superior y superior, así como en el ejercicio profesional.

De modo que en la actualidad es preciso no solo pensar la educación, sino repensar la pedagogía que, lejos de ser un lujo, resulta una necesidad en la sociedad cognitiva (Rodríguez, 2013).

La preocupación por pensar la pedagogía se ha formulado en términos de preguntarse cuál es el tipo de pedagogía requerida en los tiempos actuales. Esta pregunta tiene diversos significados. Primero, que cada sociedad implica un tipo de educación e instituye un tipo de escuela y alienta una forma de pensar la educación. Segundo, que el progreso de la ciencia produce cambios en la estructura del pensamiento. Tercero, que la nueva sociedad, y la evolución de la ciencia y la tecnología como construcciones sociales, demanda una nueva pedagogía. Aceptadas estas premisas, nada hay de extraño en admitir la crisis actual del sistema educativo y de la institución escolar.

De tal manera se han complicado las relaciones dentro del sistema educativo, en donde se entiende que es necesario reconsiderar conceptos tales como inteligencia, información, aprendizaje, enseñanza, formación, tiempo y espacio educativos. Para intentar comprender estos sendos cambios, la teoría de la educación ha asumido el enfoque propio de las ciencias cognitivas en torno a las teorías de la complejidad, al tiempo que se adopta el estudio y símil del cerebro humano como modelo explicativo, tanto de la construcción del conocimiento «objetivo» como del constructo de ideales, sea acerca de acciones y procesos, como de ideales sobre educación.

Del mismo modo que en tales estudios se distingue entre procesos de recogida y elaboración de información, el conocimiento sobre educación y sobre el propio conocimiento educativo se ve obligado a estimar las dos 
lógicas del cerebro y la mente humana, así como al conocimiento explícito -más cercano a la construcción social del conocimiento-, tácito e implícito en el sujeto que aprende, del profesorado y de los expertos educativos. Esto rige al conocimiento ordinario como al conocimiento científico, por ejemplo en el caso de la pedagogía de la ciencia y en el conocimiento sobre la educación (Vázquez, 1991).

Hacia fines de siglo pasado, la cibernética aplicada en educación daba lugar al reconocimiento de la pedagogía cibernética en un sentido tal que, sin renunciar a los conceptos clave de información y control, permitía interpretar la educación en un sentido humanístico, es decir, se reconocía la posibilidad de explicarla en el sentido proyectivo, superador, abierto a la autoconciencia y a la autodeterminación (Sanvisens, 1991).

De acuerdo con Hendricks (2001, citado en Zaballos, 2013), la cognición situada asume diferentes formas y nombres, directamente vinculados con conceptos como aprendizaje situado, participación periférica legítima, aprendizaje cognitivo (cognitive apprenticeship) o aprendizaje artesanal.

El paradigma de la cognición situada representa una de las tendencias actuales más representativas y promisorias en la teoría y la actividad sociocultural (Daniels, 2003). Los teóricos de la cognición situada parten de la premisa de que el conocimiento es situado, es parte y producto de la actividad, el contexto y la cultura en que se desarrolla y utiliza. Así, la enseñanza situada ha desembocado en un enfoque instruccional, en el cual se destaca la importancia de la actividad y el contexto para el aprendizaje y se reconoce que el aprendizaje escolar es, ante todo, un proceso de enculturación en el cual los estudiantes se integran gradualmente a una comunidad o cultura de prácticas sociales. En esta misma dirección, se comparte la idea de que aprender y hacer son acciones inseparables (Díaz Barriga, 2003).

Dentro de la cognición situada hay estudiosos que critican a la institución escolar por las formas en que se intenta promover el aprendizaje y la manera como se enseñan los aprendizajes que en algunos casos son de tipo declarativos, abstractos y descontextualizados, conocimientos inertes, poco útiles y escasamente motivantes, de relevancia social limitada. Desde una visión situada, se aboga por una enseñanza centrada en prácticas educativas 
auténticas, las cuales requieren ser coherentes, significativas y propositivas; la autenticidad de una práctica educativa puede determinarse por el grado de relevancia cultural de las actividades en que participa el estudiante, así como mediante el tipo y nivel de actividad social que estas promueven.

Hendricks (2001) propone que, desde una visión situada, el alumnado debe involucrarse en el mismo tipo de actividades que enfrentan los expertos en diferentes campos del conocimiento. En la universidad, por lo general, y en todo tipo de institución educativa, la enseñanza no transcurre en contextos significativos, no se enfrentan problemas ni situaciones reales, no hay tutelaje, ni se promueve la reflexión en la acción, ni se enseñan estrategias adaptativas y extrapolables.

El aprendizaje implica el entendimiento e internalización de símbolos y signos de la cultura y grupo social al que se pertenece (posición vigotskiana), los actores que aprenden se apropian de las prácticas y herramientas culturales por medio de la interacción con miembros más experimentados. En un modelo de enseñanza situada, resalta la importancia de la influencia de los agentes educativos, que se traducen en prácticas pedagógicas deliberadas, en mecanismos de mediación y ayuda ajustada a las necesidades del alumno y del contexto, así como de las estrategias que promuevan un aprendizaje colaborativo o recíproco.

La unidad básica de análisis no es el individuo en singular ni los procesos cognitivos, sino la acción recíproca, es decir, la actividad de las personas que actúan en contextos determinados. De esta manera, una situación educativa, para efectos de su análisis e intervención instruccional, requiere concebirse como un sistema de actividad cuyos componentes a ponderar incluyen:

a). El sujeto que aprende;

b). Los instrumentos utilizados en la actividad, privilegiadamente los de tipo semiótico;

c). El objeto a apropiarse u objetivo que regula la actividad (saberes y contenidos); 
d). Una comunidad de referencia, en que la actividad y el sujeto se insertan;

e). Normas o reglas de comportamiento que regulan las relaciones sociales de esa comunidad;

f). Reglas que establecen la división de tareas en la misma actividad.

Finalmente, queda establecido que lograr los cambios en las formas de comprensión y participación de los sujetos en una actividad conjunta y debe comprenderse como un proceso multidimensional de apropiación cultural, ya que se trata de una experiencia que involucra el pensamiento, la afectividad y la acción (Díaz Barriga, 2003).

Un empleo importante de la cognición se relaciona con los procesos de reflexión, particularmente del profesorado en situación de comunidad de aprendizaje. El proceso reflexivo puede coadyuvar al análisis crítico y más objetivo de la propia práctica docente. Para ello, se utiliza la «ruta» cognitiva, que no es otra cosa más que una estructura conceptual centrada en el contenido procesado durante la clase: conceptos, representaciones empleadas, herramientas aplicadas, consignas hechas al alumnado.

Las rutas cognitivas se centran en la actividad que el profesor propone a los alumnos. Son un medio que esboza la estructura de contenidos que se van a aprender y además son los procesos que podrán realizar los alumnos para responder a la actividad del tema propuesto; asimismo, dan paso a que el docente proponga nuevas actividades para abordar el objeto de conocimiento de la clase.

Mediante las rutas cognitivas se organizan las competencias y situaciones o secuencias didácticas que se espera lograr. Para la gestión de estas se identifican previamente los posibles procesos de aprendizaje de los alumnos, a fin de diseñar nuevas acciones que orienten al alumnado al logro de la competencia. Se construyen en las comunidades de aprendizaje, en las que mediante la reflexión del profesorado se planea la sesión de clase. Posteriormente, en otro espacio de proceso reflexivo, sobre la práctica se elabora una nueva ruta cognitiva que recupera los procesos sobre la acción docente instrumentada o argumentada. 
Algunos teóricos de la reflexión sobre la práctica docente mencionan que es posible recuperar procesos de reflexividad de la práctica a partir de que el profesorado se desprende de sus temores y se identifica con la persona que ven (puede ser en un video o en la narración argumentada de lo que hicieron en clase).

La siguiente cita de Schön (1992, p. 73) sustenta las ideas previas, ya que describe la idea de encadenamiento - valga mencionar que dicho encadenamiento es la generación de una intervención que da pie a otra y así sucesivamente-:

\section{Todo está encadenado. [...] La cadena de acciones y reflexiones recíprocas} que constituye el diálogo entre docente y alumnado puede analizarse al seleccionar eventos que evidencian al profesor su práctica real, porque favorece un diálogo a través de preguntas en donde las respuestas se conectan a otra pregunta hasta llegar a construir una idea reflexiva completa.

Las situaciones de reflexión en la acción son aquellas en que se usan respuestas espontáneas y rutinarias. Cuando hay una sorpresa y el evento no corresponde a lo que se cree saber, llama la atención del profesor y lo enfrenta a la situación sorpresa que lo orienta a la reflexión.

La reflexión cuestiona la estructura de suposición del conocimiento en la acción y la reflexión da lugar a la experimentación. El hecho de volver a pensar sobre alguna parte del conocimiento sobre lo que se hace, lleva al profesor a la experimentación y a pensar más allá, lo cual afecta lo que hace, tanto en la situación inmediata como en otras similares.

El conocimiento y la reflexión en la acción forman parte de la experiencia del pensar y el hacer, como ya se dijo antes. El conocimiento en la acción de un profesional está incrustado en el contexto estructurado en los ámbitos social e institucional que comparte una comunidad de práctica. El conocimiento en la práctica se ejercita en el contexto de cada profesión y se organiza en función de las características de las situaciones de la práctica, el cual se facilita por el conocimiento profesional y el sistema de valores. 
La reflexión en la acción del profesorado universitario se ha puesto en práctica en la universidad y se ha observado cómo dicha reflexión se evidencia en la clase, en su interacción con los alumnos. Las reflexiones del profesorado universitario se han evidenciado en la forma en cómo actúan o reaccionan ante diferentes situaciones inesperadas en que tienen que poner a prueba sus conocimientos o falta de ellos, y en las que organiza todos los recursos que selecciona para la instrumentación didáctica.

Ante el dinamismo, retos y problemas del mundo actual, es necesario un aprendizaje y una enseñanza que logren sentido y conecten con el entorno, tanto para el que aprende como para el que enseña, lo cual constituye un reflejo de la calidad del modelo educativo instrumentado.

La educación, en general, y el aprendizaje, en particular, implican mucho más que recolectar conocimientos, o construirlos; deben abocarse a proponer respuestas a los problemas y necesidades que enfrentamos en las nuevas condiciones en que vivimos, por lo que se requiere movilizar toda la experiencia acumulada, los saberes de los distintos dominios de conocimiento, de las capacidades de acción, de interacción, para generar un modelo que integre saberes, acciones, de interacción social y de autoconocimiento, desde una perspectiva integral.

Para Vázquez y Bárcena (1999), el conocimiento debe ser el producto de contenidos multidisciplinarios y multidimensionales, que demanden una acción personal de compromiso, en el marco de las interacciones sociales, en que tienen y tendrán su expresión concreta.

Por lo anterior, un modelo educativo centrado en el aprendizaje se deberá fundamentar en el constructivismo, que en términos de aprendizaje resulta ser el más propicio para desarrollar competencias, en este paradigma, con este enfoque el profesor se constituye en guía o facilitador para cada estudiante.

Entonces, la universidad ha de ser un espacio de construcción del saber que forma personas desde una perspectiva compleja, que tal como lo plantean Sotomayor y Gysling (2011) viene a ser el reflector principal de generación de conocimiento. 
Hoy es común, en el ámbito universitario, hablar del aprendizaje en términos de «competencias». Muchos programas educativos y planes de estudio «se diseñan por competencias». Las empresas y diversos centros de trabajo seleccionan y evalúan a los empleados de acuerdo con «las competencias» que demuestran en el campo laboral. Esto ha motivado a las instituciones de educación superior a evolucionar de un sistema tradicional de planeación educativa centrada en contenidos a un sistema dinámico de planeación educativa con base en la formación por competencias profesionales que se espera desarrollar en los alumnos universitarios.

Desde esta óptica, una competencia profesional es la integración de aprendizajes relacionados con el saber, el hacer y el ser del estudiante, en función del desarrollo del perfil que se espera en él para el ejercicio de una profesión determinada.

Las competencias integran varios tipos de aprendizaje, fundamentalmente conocimientos, habilidades y actitudes (que expresan valores), a los cuales también pueden agregarse hábitos y destrezas. Desarrollar competencias en los alumnos, por tanto, supone un dominio de los distintos tipos de aprendizajes que se están buscando en ellos y de la integración que estos deben conseguir entre sí. Evaluar competencias implica diseñar instrumentos específicos para valorar cuantitativa y cualitativamente el desempeño eficaz de los estudiantes.

Tanto desarrollar como evaluar competencias en alumnos universitarios exige de la planta docente una capacitación y formación pedagógica específica para el desarrollo de un estilo de docencia ad hoc, distinto a la cátedra tradicional.

Además, aprender a ser competente denota que el alumno practica y desarrolla diferentes capacidades y aptitudes, con el objetivo de dar respuesta a una situación problema determinada.

Una competencia se evidencia en la exploración, el conocimiento, la comprensión, la aplicación, el análisis, la síntesis y la evaluación de la gestión de la actividad académica que el estudiante trabaja, individual o colectivamente, en cada asignatura. En consecuencia, «trabajar por competencias» significa que el alumno debe entender el aprendizaje como un circuito 
multidireccional en que debe tomar la iniciativa y estimular la capacidad crítica, ética, creativa y sensible en la gestión de su aprendizaje a todos los niveles para favorecer su formación integral. En este caso, el profesor es un guía, un facilitador, un «despertador de curiosidades» que acompaña al alumno en dicho trayecto (Monereo, 2006).

Por lo tanto, el reto es crear un clima en que el alumno sea responsable de su proceso continuo de aprendizaje, y en el cual los profesores adopten el papel de guías. Asumir la responsabilidad significa que, poco a poco, se crean esquemas y metodologías de trabajo con un sentido, con una razón de ser. Así, el estudiante acumulador de contenidos sin un objetivo claro deja paso al estudiante que investiga los procesos para llegar a esos contenidos.

El cambio acelerado del contexto social ha influido fuertemente sobre el papel a desempeñar por el profesor en el proceso de enseñanza-aprendizaje, sin que muchos docentes hayan sabido adaptarse a estos cambios, ni las administraciones educativas hayan diseñado ninguna estrategia de adaptación, sobre todo en los programas de formación del profesorado, que no se han aplicado sistemáticamente para responder a las exigencias planteadas por dichos cambios. «El resultado más patente es el desconcierto de los profesores sobre el sentido y el alcance del trabajo que realizan» (Monereo, 2006, p. 24).

Por otro lado, la resistencia al cambio y el rechazo a la innovación tecnológica en el campo educativo se puede situar en tres niveles: social, institucional y profesional, a saber:

a). La sociedad necesita de instituciones que transmitan una forma y un estilo de vida que garantice cierto tipo de cohesión social. La educación es un medio adecuado para garantizar el inmovilismo o cierta continuidad social;

b). El rechazo a los nuevos medios se debe a la concepción elitista que prevalece en el sistema acerca de la cultura y al temor a una cierta pérdida del control individual-social. Otra de las causas por las que no se utilizan los medios audiovisuales son la desfasada formación del profesorado, así como la desarticulada política de medios audiovisuales; 
c). Desde el punto de vista profesional, la resistencia a utilizar los medios se debe a diversas causas, entre otras, que los profesores han sido formados de una determinada forma y suelen reproducir ese mismo esquema.

Fullan y Miles (citados en Escudero, 1992) hacen énfasis en que:

... mientras que los alumnos de hoy pertenecen a una era caracterizada por la tecnología y la electrónica, las instituciones educativas, a nivel global, continúan aferradas al pasado. Han sido precisamente los docentes quienes más se han podido escapar de su influencia. Resulta enormemente curioso que los medios que ofrecen más posibilidades de democratización sean rechazados por los docentes, los intelectuales y los actores aparentemente progresistas, en definitiva, la supuesta inteligencia de una sociedad (p. 58).

Cabe resaltar que «el grado de resistencia al cambio depende del tipo de cambio y de lo bien que se conozca. La gente no presenta resistencia al cambio, sino ante la pérdida o posibilidad de pérdida» (Escudero, 1987, p. 466).

Para Havelock y Huberman (1980), los reformadores creen que sus innovaciones cambiarán las escuelas, pero es importante reconocer que las escuelas cambian las reformas. Continuamente, los profesores han implantado y alterado reformas:

En lugar de mirar esta mutación como un problema a evitar, deberíamos entender que ello supone una virtud potencial, las reformas pueden diseñarse para ser concretadas en función de las necesidades y conocimientos locales. Los seres humanos crean organizaciones y las cambian. La escuela como construcción cultural ha cambiado a lo largo del tiempo y puede de nuevo cambiar (p. 478).

Hopkins, Ainscow y West (1994) hablan de cuatro tipos de cambios en función de dos criterios: nivel de calidad de los cambios introducidos y su nivel de implantación. 
A partir de esta clasificación tendríamos cuatro tipos de cambios:

a). De buena calidad, pero escasamente implantados.

b). Buena calidad y bien implantados.

c). De baja calidad de cambio y escasa implantación.

d). Baja calidad y con alta implantación, que sería el tipo de cambio a evitar.

A partir de los planteamientos de los teóricos consultados, se puede decir que el contexto organizativo es un elemento clave, no único, del proceso de innovación, en la medida en que el trabajo en grupo, en comunidad, facilita la tarea de innovar, además de propiciar la autorreflexión, la autoevaluación dentro de una dinámica participativa, ya que de cara a la institucionalización los grupos, los órganos y no los individuos aislados, son quienes mejor respuesta pueden dar para atender a las necesidades reales de la institución. Los cambios actuales en los sistemas educativos se orientan hacia la formación de personas, organizaciones y comunidades competentes, entendida la competencia como capacidad para identificar y resolver problemas valiosos desde la perspectiva integrada de la lógica racional y emocional. La pedagogía cognitiva, con otras ciencias cognitivas, aplica en el estudio de la cognición, emoción, memoria y mente este enfoque al análisis y desarrollo de acciones sobre problemas complejos como la educación en la sociedad en red, la educación intercultural, la creatividad o la dirección de organizaciones de aprendizaje (Sotomayor y Gysling, 2011).

Es válido pensar que el profesorado potencia el cambio en la medida en que se encuentra mejor informado y formado en el desarrollo de todas sus competencias posibles. Se confirma lo anterior al mencionar hallazgos sobre las características de los sistemas educativos en diferentes países, y en donde la formación y el aprendizaje permanente de profesores es uno de sus principales indicadores de calidad educativa. Sotomayor y Gysling (2011) señalan tres aspectos comunes entre naciones con mejores resultados en la prueba internacional PISA:

a). Seleccionan a los mejores docentes; 


\section{[ 44 ] Innovación educativa: nuevas metodologías y experiencias en el aula}

b). Apoyan su desarrollo y formación;

c). Garantizan la mejor educación posible a todos los niños.

Tal como se observa, al profesorado - pieza clave del cambio- se le debe apoyar para el incremento de competencias digitales durante su formación tecnológica, el desarrollo de la innovación educativa y mejorar las condiciones de infraestructura tecnológica, con el propósito de que se modifiquen no solo tiempos y espacios en el aula, sino que también las condiciones de agrupamiento y aprendizaje comunitario favorecen los intercambios y la reflexión permanente en la puesta en práctica de los saberes pedagógicos al utilizar la tecnología como apoyo para la enseñanza y participar de la innovación con niños, jóvenes y adultos (UNESCO/ Orealc, 2013).

El desarrollo de competencias digitales docentes plantea un verdadero reto a la docencia de todos los niveles educativos, pero particularmente al profesorado cuyo desafío es incursionar de lleno en su profesionalización y superación académica. No sobra mencionar que la responsabilidad no es solo del profesorado, sino de toda la estructura educativa que permea un nuevo modelo educativo orientado al proceso de cambio.

El desarrollo de la innovación exige considerar la dimensión personal o biográfica, por cuanto la puesta en práctica depende de este agente de cambio. Reparar en el papel del profesor ante la innovación es una necesidad ineludible, no solo para descubrir los procesos personales implicados en el cambio, sino además para poder diseñar las estrategias más idóneas a fin de que este sea viable (Rodríguez, 2013, p. 34).

Para comprender el cambio en educación se puede combinar la idea de cambio con la de perfeccionamiento profesional. La investigación al respecto habría de estar inmersa en un proceso educativo reflexivo que concibe el cambio como algo basado en el examen crítico de la práctica.

La reflexión en los profesores es un prerrequisito para su desarrollo profesional; examina, además, las relaciones profesor-agente externo. La colaboración con la escuela se establece en términos de igualdad, y profesor e investigador son vistos como expertos en su campo. Los docentes desem- 
peñan un papel dual, por una parte, con la deliberación y reinterpretación del concepto «igualdad de oportunidades en educación» y, seguidamente, la experimentación o prueba de hipótesis generadas, como profesores investigadores, que depende de su habilidad para tratar con la nueva situación de enseñanza (Perrenoud, 2005).

Son tres las etapas en el proceso de aprendizaje de su nuevo papel: en la primera, produce un efecto de desconcierto a causa de que los profesores encuentran inapropiado su conocimiento-en-la-acción en la nueva situación; en la segunda, la reflexión-sobre-la-acción en el grupo, y en la tercera, la construcción gradual de nuevo conocimiento-en-la-acción practicado en diferentes formas de enseñanza y reflexión-en-la-acción, alternativamente. «Las creencias ideológicas de los profesores acerca de la educación juegan un rol central en la determinación de si son adoptadas las innovaciones instructivas y si es apoyada la implementación de nuevos métodos» (Shön, 1992, p. 89).

El profesor de hoy, por las exigencias de su práctica,

es un profesional que toma decisiones, flexible, libre de prejuicios — actitud de anteponerse y rectificar a tiempo-, comprometido con la práctica - reflexiona sobre la misma y aporta elementos de mejora-, que se convierte en un recurso más para el grupo (Shön, 1992, p. 91).

Los saberes relacionados con la educación han cumplido un papel específico en la constitución del orden social. Han sido configurados histórica y socialmente y han transmitido un modo de entender la educación que ha formado parte de una dinámica más amplia de reestructuración del campo del saber, asociada a procesos de regulación social de los estados. Los saberes pedagógicos tradicionalmente se han encargado de racionalizar y legitimar una organización escolar y unas formas pedagógicas dadas, sin examinar su carácter arbitrario; esta forma de actuar se extiende también al cambio educativo.

Sobre este último punto, la atención a la regulación social permite descubrir cómo los discursos sobre el cambio educativo configuran formas 
específicas y contextuales de poder, que modelan y producen relaciones y prácticas sociales ligadas a la mejora de las instituciones educativas. También permite explorar las posibilidades que el cambio educativo ofrece a los individuos para la creación social de sus capacidades, es decir, de sus deseos personales, necesidades corporales e intereses cognitivos.

La transformación de las instituciones educativas trasciende los límites de una disciplina específica; porque, en primer lugar, las escuelas son espacios sociales que reflejan cambios y mutaciones procedentes de la esfera social más amplia y porque, en segundo lugar, los profesionales de la educación no han esperado la aparición de la ciencia del cambio educativo para formarse ideas sobre este asunto y articular prácticas de mejora, y ni la ciencia del cambio educativo resulta imprescindible para que se produzcan cambios en las aulas y las escuelas. Es precisamente el intento por regular el espacio difuso del cambio de las instituciones educativas, que subyace en la creación y configuración de la disciplina del cambio educativo, lo que justifica su examen.

En la actualidad se está produciendo un cuestionamiento generalizado de los conocimientos y prácticas educativas que también afecta al cambio educativo. El conocimiento sobre el cambio educativo se ha configurado mediante una relación más dinámica entre producción del conocimiento y prácticas de innovación. Esta visión interactiva entre conocimiento científico y prácticas sociales propugna la constitución de los campos del saber por la reincorporación de las categorías producidas por la reflexión teórica en la práctica, y viceversa. El conocimiento aplicado reflexivamente a las condiciones de reproducción del sistema altera intrínsecamente las circunstancias a que inicialmente se referiría, es decir, que el uso de producciones intelectuales sobre el cambio educativo en las prácticas de innovación inevitablemente las modifica. Por lo tanto, hay que tener en cuenta la posibilidad de revisión de cualquier elemento dado del conocimiento, el carácter inestable de todo conocimiento empírico y la subversión que conlleva el reingreso del discurso científico social en los contextos que se analizan.

Difícilmente puede hablarse de lo que ha pasado con el cambio educativo sin referirse al escenario social más amplio. Este contexto social se caracteriza por estar plagado de transformaciones que no son fácilmente 
comprensibles, porque están alterando radicalmente nuestra cotidianidad y nuestra manera de ver el mundo.

\section{COMPETENCIAS DOCENTES DEL PROFESORADO, UN RETO INELUDIBLE}

Hoy, la necesidad de educar para la vida demanda múltiples competencias a los maestros, de modo que estos sean agentes de cambio que contribuyan a elevar los aprendizajes en los alumnos, en dotarles de herramientas para el pensamiento complejo y para un desarrollo humano pleno e integral, así como competencias cívicas y sociales que contribuyan a que todas las personas gocen de iguales derechos, libertades y oportunidades, así como elevar el bienestar general. En el enfoque de competencias para la vida, se busca un desarrollo pleno e integral de los niños y jóvenes hacia la generación de competencias y capacidad para la vida personal, pública y laboral, tales como los aprendizajes que les brinden capacidades necesarias para tener acceso a las oportunidades, el bienestar, la libertad, la felicidad, y el ejercicio de los derechos (UNESCO, 2014). En este sentido, es necesario que los profesores y profesoras de educación básica eduquen con equidad, que trabajen en cerrar brechas en las desigualdades sociales, para evitar la exclusión de las personas y favorecer sus derechos y oportunidades. Así también, es necesaria su intervención para consolidar una cultura cívico-democrática, en desarrollar formas de vida más coincidentes con el respeto y el cuidado de los derechos propios y de los demás, así como de promoción y cuidado de la salud y una mejor relación entre el ser humano, el medio ambiente y la vida.

Como señala Perrenoud, «... desarrollar seriamente competencias representa mucho tiempo, pasa por otro compromiso didáctico y otra evaluación y exige situaciones de formación creativas, complejas y diferentes a las sucesiones de cursos y ejercicios» (2005, p. 174). Para ello, el maestro movilizará sus competencias de manera interactiva, utilizando una variedad de recursos didácticos para la enseñanza. Hoy en día las tecnologías de la comunicación y la información (TIC) proporcionan innumerables recursos para la enseñanza. 
Práctica reflexiva, profesionalización, trabajo en equipo y por proyectos, autonomía y responsabilidad, ampliadas, tratamiento de la diversidad, énfasis en los dispositivos y las situaciones de aprendizaje, sensibilidad con el conocimiento y la ley, conforman un «escenario para un nuevo oficio» (Perrenoud, 2005).

En este espacio se mencionan algunas competencias que se deben desarrollar para que el profesorado de cualquier nivel educativo participe en procesos de capacitación y actualización docente y sea capaz de desarrollar competencias con sus alumnos para la vida profesional, formación permanente y a lo largo de la vida.

Se enumeran las siguientes porque se considera que pueden ser factibles para gestionar procesos innovadores en el aula y la escuela. El profesorado de educación superior debe conocer, por medio de una disciplina determinada, los contenidos a enseñar y su traducción en niveles de desempeño y competencias a lograr. En este caso, la competencia docente se refiere a la organización y animación de la situación de aprendizaje (Sarramona, 2004) y (Sladogna, 2005).

1. Trabajar a partir de las representaciones de los alumnos y a partir de los errores y los obstáculos en el aprendizaje. Construir y planificar dispositivos y secuencias didácticas. Implicar a los alumnos en actividades de investigación, en proyectos de conocimiento

2. Gestionar la progresión de los aprendizajes. Concebir y hacer a frente a situaciones problema ajustadas al nivel y a las posibilidades de los alumnos. Adquirir una visión longitudinal de los objetivos de la enseñanza y establecer vínculos con las teorías que sostienen las actividades de aprendizaje. Observar y evaluar a los alumnos en situaciones de aprendizaje, según un enfoque formativo. Establecer controles periódicos de competencias y tomar decisiones de progresión.

3. Elaborar y hacer evolucionar dispositivos de diferenciación. Hacer frente a la heterogeneidad en el mismo grupo. Compartimentar, extender la gestión de clase a un espacio más amplio. Practicar un apoyo integrado, trabajar con los alumnos con grandes dificultades. Desarrollar la cooperación entre alumnos o formas simples de enseñanza mutua. 
4. Fomentar el deseo de aprender, explicitar la relación con el alumno en su aprendizaje y en su trabajo, conocer el sentido del trabajo escolar y desarrollar la capacidad de autoevaluación. Instituir y hacer funcionar un consejo de alumnos (consejo de clase o de escuela) y negociar con ellos varios tipos de reglas y de acuerdos. Ofrecer actividades de formación opcionales, menús y favorecer la definición de un proyecto personal del alumno.

5. Trabajar en equipo y elaborar un proyecto de representaciones comunes. Impulsar un grupo de trabajo, dirigir reuniones. Formar y renovar un equipo pedagógico. Afrontar y analizar conjuntamente situaciones complejas, prácticas y problemas profesionales. Hacer frente a crisis y conflictos entre personas.

6. Participar en la gestión de la escuela. Elaborar y negociar un proyecto institucional. Administrar los recursos de la escuela. Coordinar, fomentar una escuela con todos los componentes (extraescolares, del barrio, asociaciones de padres, profesores de lengua y cultura de origen). Organizar y hacer evolucionar, en la misma escuela, la participación de los alumnos.

7. Informar e implicar a los padres. Favorecer reuniones informativas y de debate. Dirigir las reuniones. Involucrar a los padres en la valorización de la construcción de los conocimientos.

8. Utilizar las nuevas tecnologías. Utilizar los programas de edición de documentos. Explotar los potenciales didácticos de programas en relación con los objetivos de los dominios de enseñanza. Comunicar a distancia por medio de la telemática. Utilizar los instrumentos multimedia en su enseñanza.

9. Afrontar los deberes y los dilemas éticos de la profesión. Prevenir la violencia en la escuela o la ciudad. Luchar contra los prejuicios y las discriminaciones sexuales, éticas y sociales. Participar en la creación de reglas de vida común referentes a la disciplina en la escuela, las sanciones, la apreciación de la conducta. Analizar la relación pedagógica, la autoridad, la comunicación en clase. Desarrollar el sentido de la responsabilidad, la solidaridad, el sentimiento de justicia.

10. Organizar la propia formación continua. Saber explicitar sus prácticas. Establecer un control de competencias y un programa personal de formación continua propios. Negociar un proyecto de formación común con los com- 
pañeros (equipo, escuela, red). Implicarse en las tareas a nivel general de la enseñanza o del sistema educativo. Aceptar y participar en la formación de los compañeros.

En el contexto escolar, los retos actuales de la docencia se vuelven más complejos debido a la multiplicidad de competencias para la formación humana y pedagógica de los jóvenes que debe desarrollar el maestro en su desempeño docente. Entre las principales competencias está que el maestro domine los contenidos de enseñanza del currículo y que sepa desarrollar capacidades intelectuales y de pensamiento abstracto y complejo en los jóvenes Así también, se espera que los docentes despierten la curiosidad intelectual del alumnado, fomentando en ellos el gusto, el hábito por el conocimiento, el aprendizaje permanente y autónomo (aprender a aprender), poniendo en práctica recursos y técnicas didácticas innovadoras, cercanas a los enfoques pedagógicos contemporáneos y motivadoras del aprendizaje (ambientes de aprendizaje), utilizando las TIC.

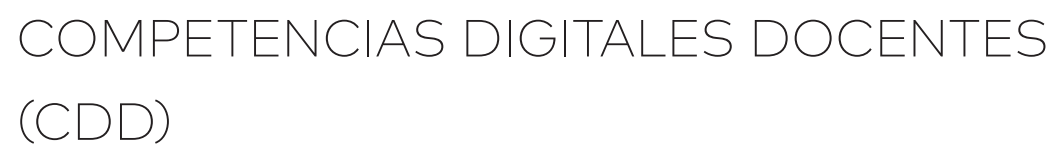

Es sorprendente cómo la tecnología ha cambiado el mundo y ha dado lugar a nuevas formas de educación nunca pensadas. Los jóvenes han desarrollado competencias digitales que anteriormente no se hubiera imaginado, y pasan más tiempo interactuando con sus dispositivos móviles de lo que interactúan con sus propios familiares. Es cierto que este auge digital tiene repercusiones tanto positivas como negativas en el alumnado. En realidad, hay varias ventajas para el uso de la tecnología en la educación. En términos generales, nadie discute sobre el hecho de que las ventajas de la tecnología en la educación y en nuestra vida en general, superan sus desventajas.

La formación en competencias es un imperativo curricular que, en el caso de la competencia digital, ha tenido hasta ahora una especificación poco desarrollada y diversa en sus descriptores al no existir un marco de referencia común (Leithwood, 2009). 
Desarrollar la competencia digital en el sistema educativo requiere que los docentes tengan la formación necesaria en esa competencia. El marco común de competencia digital docente es una propuesta estandarizada que especifica la competencia digital mediante descriptores de 21 sub-competencias organizados en tres niveles y cinco áreas competenciales (información, comunicación, creación de contenidos, seguridad y resolución de problemas). El profesorado también necesita desarrollar competencias que los dotarán de un mejor dominio de esas tecnologías, aunque, en ciertos momentos, sean un desafío.

Entre todos los retos a los que se enfrenta el profesorado, se encuentra con un cambio de enfoque pedagógico y metodológico dirigido a aumentar la participación del alumnado en el proceso de aprendizaje. Por esa razón, se destacan en este apartado las capacidades del profesorado que se espera logren durante el siglo XXI y son las que se citan a continuación:

- Crear y editar audio digital.

- Utilizar marcadores sociales para compartir los recursos con/entre los estudiantes.

- Usar blogs y wikis para generar plataformas de aprendizaje en línea dirigidas a sus estudiantes.

- Aprovechar las imágenes digitales para su uso en el aula.

- Usar contenidos audiovisuales y vídeos para involucrar a los estudiantes.

- Utilizar infografías para estimular visualmente a los estudiantes.

- Utilizar las redes sociales para conectarse con colegas y crecer profesionalmente.

- Crear y entregar presentaciones y sesiones de capacitación.

- Compilar un e-portafolio para su autodesarrollo. 


\section{[ 52] Innovación educativa: nuevas metodologías y experiencias en el aula}

- Tener un conocimiento sobre seguridad online.

- Ser capaz de detectar el plagio en los trabajos de sus estudiantes.

- Crear vídeos con capturas de pantalla y video-tutoriales.

- Recopilar contenido web apto para el aprendizaje en el aula.

- Usar y proporcionar a los estudiantes las herramientas de gestión de tareas necesarias para organizar su trabajo y planificar su aprendizaje de forma óptima.

- Conocer el software de votación: se puede utilizar, por ejemplo, para crear una encuesta en tiempo real en la clase.

- Entender las cuestiones relacionadas con derechos de autor y uso honesto de los materiales.

- Aprovechar los juegos de ordenador y videoconsola con fines pedagógicos.

- Utilizar herramientas digitales para crear cuestionarios de evaluación.

- Uso de herramientas de colaboración para la construcción y edición de textos.

- Encontrar y evaluar el contenido web.

- Usar dispositivos móviles como tabletas o smartphones.

- Identificar recursos didácticos online seguros para los estudiantes.

- Utilizar las herramientas digitales para gestionar el tiempo adecuadamente.

- Conocer el uso de Youtube y sus potencialidades dentro del aula. 
- Usar herramientas de anotación y compartir ese contenido con sus estudiantes.

- Compartir las páginas web y las fuentes de los recursos que ha expuesto en clase.

- Usar organizadores gráficos, online e imprimibles.

- Usar notas adhesivas (post-it) en línea para captar ideas interesantes.

- Usar herramientas para crear y compartir tutoriales con la grabación fílmica de capturas de pantalla.

- Aprovechar las herramientas de trabajo online en grupo/en equipo que utilizan mensajería.

- Buscar eficazmente en internet, empleando el mínimo tiempo posible.

- Llevar a cabo un trabajo de investigación utilizando herramientas digitales.

- Usar herramientas para compartir archivos y documentos con los estudiantes.

Los profesores necesitan una alfabetización digital que les permita utilizar de manera eficaz y eficiente los nuevos instrumentos tecnológicos que constituyen las TIC en sus actividades profesionales (docentes, de investigación, de gestión) y personales.

Con respecto a las experiencias novedosas, se puede decir que existen una gran cantidad de recursos que pueden hacer el cambio en la docencia de muchos profesores. Algunas de ellas se presentan en los siguientes párrafos, porque describen los procesos que se desarrollan en otras latitudes y dejan ver el alcance de las transformaciones e innovaciones a nivel mundial.

Las prácticas de tipo colaborativas son observables durante la planeación o el trabajo grupal de los profesores, igualmente durante los registros de clases, las cuales se apoyan por otros observadores y con apoyo de la tecno- 
logía. Para llegar a identificar las prácticas que se desarrollan en otros contextos se han realizado una gran cantidad de estudios entre los que destacan Aguado y Arranz (2005), quienes se han enfocado en registrar los procesos de formación docente.

Las prácticas colaborativas incluyen la observación también de los talleres colaborativos que involucran la reacción de colegas o de un observador externo (mentor). En los talleres de reflexión, por ejemplo, se encuentran desencadenados procesos formativos que se basan en la narración de experiencias, el intercambio de opiniones o ideas, y las observaciones de clases.

Los esfuerzos realizados para documentar todas las experiencias formativas que dan origen a nuevas estrategias para la capacitación y actualización docente se han obtenido de diversos estudios. ¿Qué hacen los profesores para aprender más y mejor en sus centros escolares y transformar sus prácticas educativas conforme las demandas y tendencias internacionales? Algunas respuestas al cuestionamiento anterior se pueden encontrar en el Informe Mckinsey y Company (2007).

En los siguientes párrafos se describen las prácticas colaborativas que se desarrollan en diferentes países con el propósito de que el lector de esta obra tenga un acercamiento al panorama de las innovaciones que pueden ser sustraídas para diseñar nuevas estrategias de cambio en las instituciones educativas del país. Tampoco se trata de hacer lo mismo, sino de reflexionar ante las posibilidades que brinda una reforma y los cambios que trae consigo. Cabe mencionar que en México se han desarrollado e implementado experiencias para recuperar las prácticas docentes y su vinculación con el contexto social desde la vida cotidiana.

El proyecto Aspire en los Estados Unidos, que es un ejemplo de las prácticas colaborativas, centra su estrategia en la planificación conjunta de las clases, actividad que se realiza en media jornada de los viernes. Esta planeación incluye la revisión de los resultados de los estudiantes. Los docentes se agrupan por niveles o por áreas y siempre que sea posible con acompañantes. Cada plan de clase es revisado, evaluado y se establecen las rúbricas correspondientes con apoyo de los docentes con más experiencia, en el caso de planeaciones realizadas por docentes nuevos (apoyo de pares). 
Para el seguimiento en el aula de clase se utilizan micrófonos como los de los presentadores de televisión, con el fin de garantizar la información de retorno. También se filma en vídeo para su posterior análisis. Se incentivan foros de apoyo entre pares y la participación de los directores, que conforman un grupo de líderes (seleccionados de entre los directores altamente eficaces), que está en condiciones de asumir mentorías de otros directores de la agrupación (Informe Mckinsey \& Co., 2007).

Como se observa, la planificación de clases conjunta se ha convertido en una piedra angular de la práctica colaborativa de este proyecto Aspire. Al visitar una serie de instituciones educativas y sus aulas, se describe en el informe que la similitud entre ellas, así como de las prácticas docentes, es evidente. Se han identificado altos logros ente los docentes y las instituciones educativas que participan en esta experiencia (Informe Mckinsey \& Co., 2007).

Aspire aplica el mismo criterio en relación con sus entrenadores de instrucción (coach), ya que al principio había una gran variedad de métodos de entrenamiento, sin tener mucha claridad sobre lo que funcionó mejor. Por ello, se recogió la opinión de sus instituciones educativas sobre lo que estaba ayudando a los estudiantes, y a partir de ello, se formularon directrices estandarizadas para el entrenamiento, denominadas los cuatro actos del entrenador.

Otro ejemplo de prácticas colaborativas lo conforman las redes de apoyo escolar. En el caso de Hong Kong, las instituciones educativas están conectadas y trabajan conjuntamente en los procesos de reforma curricular y los docentes generalizan las buenas prácticas.

Boston creó nueve grupos geográficos escolares que participan en foros de apoyo. Con la conexión formal a nivel de los directores de las instituciones educativas, los grupos escolares conformaron también una red entre instituciones educativas e impulsaron la interacción entre profesores y alumnos (Informe Mckinsey \& Co., 2007).

El desarrollo profesional tiende cada vez más a incluir una variedad de experiencias formales e informales, algunas de las cuales incluyen aprendizaje profesional colaborativo como es el caso del Ontario Learning Con- 
sortium. Esta experiencia que involucró cuatro instituciones educativas vecinas en Toronto, con la Universidad de Toronto y el Instituto Ontario para la Educación, incluyó aprendizaje cooperativo y coaching entre pares, mentorías, redes y análisis de prácticas.

Experiencias diversas descritas en el informe que se analiza mencionan como han obtenido buenas prácticas de trabajo colaborativo para la formación docente. Tal es el caso de la North Carolina Teachers' Academy, que ofreció 40 talleres semanales basados en experiencias, visiones y necesidades de los maestros participantes. El Middle School Mathematics Project en Boston combinó talleres con redes y discusiones grupales sobre dificultades de los docentes. El Chautauqua Project combinó talleres, cursos, becas y laboratorios. Otro caso es el de Nueva Zelanda, en donde la reforma curricular involucró talleres con información y apoyo adicional, que incluyó visitas a las instituciones.

El aprendizaje profesional colaborativo por medio de proyectos en Estados Unidos reportó que son dos proyectos emblemáticos por su permanencia en el tiempo y por los efectos que han logrado en los alumnos a cargo de los docentes que han participado en ellos. Al analizar estas experiencias, se identifican las siguientes características asociadas al aprendizaje colaborativo: los docentes aprenden enseñando a otros; aprenden haciendo pública su práctica y sometiéndola a discusión entre pares; aprenden a escribir y aprenden a enseñar a escribir como un propósito compartido; se someten a una evaluación continua y rigurosa; además, conforman redes de apoyo.

En el mismo sentido, se tiene también el National Writing Project, que afianza habilidades de redacción y, en general, fortalece el manejo de un área curricular como es el lenguaje. La estrategia consiste en escribir en grupos pequeños para enseñarse unos a otros, retroalimentarse, hasta que cada uno pueda sentirse listo y realizar presentaciones individuales públicas. El proyecto también ha propiciado la conformación de redes con las comunidades escolares y con los sistemas educacionales a los que cada participante pertenece. Entre sus logros, se cuenta la mejora en las concepciones acerca de la enseñanza de la redacción, que aumentan el tiempo que los docentes dedican a la enseñanza de esta y que demuestran formas de enseñanza que pueden considerarse como ejemplares. Los estudiantes a cargo 
de estos docentes redactan en forma más organizada y coherente, con lo que demuestran un buen uso de las normas del lenguaje escrito.

$\mathrm{El}$ otro proyecto es el «Classroom assessment in Mathematics network project», que se basa en el trabajo en pequeños grupos de discusión sobre los resultados de los estudiantes. Incluye, además, coaching, redes entre maestros, supervisores y miembros de la oficina de evaluación del Educational Development Center en los Estados Unidos. Los docentes cuentan con tiempo para aplicar las innovaciones y estas acciones se complementan con talleres y reflexión acción.

Los dos proyectos se asocian con centros universitarios, talleres de verano, aprendizaje práctico, redes y comunicación constante e influyen en la calidad de la enseñanza y en los logros de los estudiantes, en dos de las principales asignaturas del currículo escolar.

La documentación analizada permitió identificar una tendencia que recoge los planteamientos de las escuelas efectivas de cualquier nivel educativo y de las organizaciones que aprenden. Las experiencias de aprendizaje colaborativo que las caracterizan colocan en la institución educativa las posibilidades de desarrollo profesional docente. En este sentido, las comunidades de aprendizaje encontrarían su razón de ser en la posibilidad de compartir y analizar lo que acontece en el quehacer institucional cotidiano, en el liderazgo para asumir la responsabilidad por la calidad de los aprendizajes y en la posibilidad de desarrollo profesional, sin el abandono de la docencia.

Las prácticas colaborativas en la institución educativa tienen que ver con lo que hacen los docentes y directivos cuando trabajan juntos para desarrollar prácticas efectivas de aprendizaje, analizan lo que acontece realmente en las aulas y velan porque no solo su actuación individual, sino la de todo el colectivo, se realice bien (Barber y Mourshed, 2007).

Como se decía en el apartado uno de este texto, los docentes aprenden desde lo que hacen. Aprenden en la práctica a partir de clases observadas y analizadas; del análisis de datos; de los resultados de los alumnos; del análisis de las tareas. Estos análisis no necesariamente se realizan en tiempo real. Pueden efectuarse desde casos reconstruidos a partir de los datos recogidos con anterioridad. También pueden involucrar la resolución de problemas en 
forma colaborativa y el análisis de las necesidades individuales y colectivas; esto es, la resolución de problemas comunes. Según Hargreaves (2000), el nuevo profesionalismo está marcado por el trabajo y el aprendizaje en equipo. Las culturas colaborativas tienen estrechas relaciones y están orientadas a hacer mejor las cosas y con menos errores.

La cultura colaborativa se refiere a la formulación de normas en equipo; se clarifica y determina lo esencial en el aprendizaje; desarrollan guías rápidamente; hacen acuerdos expeditos frente a las decisiones que se deben tomar; determinan estándares y cómo debe trabajar el estudiante para lograrlos; elaboran rúbricas comunes para evaluar; establecen acuerdos colectivos; analizan conjuntamente el trabajo y los resultados del aprendizaje del estudiante; definen las intervenciones específicas para atender individualmente del alumnado; monitorean el resultado de las estrategias planteadas; reflexionan colectivamente sobre la efectividad de las estrategias de aprendizaje y también sobre la del equipo (Fullan, 2005).

En las comunidades de aprendizaje la colaboración representa un proceso sistemático en el cual los docentes trabajan juntos de una manera interdependiente, con el objetivo de impactar las prácticas de aula para lograr aprendizajes más efectivos, está asociado con metas más amplias, tanto de la institución educativa como del sistema educativo y retroalimenta las prácticas escolares y la evaluación. Cuando el profesorado trabaja junto, cara a cara, mano a mano, logra mejores resultados en el aprendizaje de sus alumnos. Los docentes pueden llegar a avanzar a planos de metareflexión cuando comparten sus saberes con otros y ponen en discusión sus creencias. No se trata de saber más a nivel de tener mayor información almacenada, se trata de que cada profesor utilice de la mejor manera sus saberes pedagógicos y los transfiera al campo de la enseñanza para el logro de competencias y el desarrollo del talento humano de todos los sujetos que participan en el proceso educativo.

Las prácticas colaborativas como estrategias de desarrollo profesional influyen positivamente y determinan la dinámica de la institución educativa, porque movilizan a la escuela de una práctica tradicional a otra en la que las prácticas de enseñanza son públicas y en las que ellos son enteramente responsables del aprendizaje de los estudiantes. Del mismo modo, 
dichas prácticas favorecen la organización de la institución y desarrollan una nueva gestión directiva. También promueven un cambio cultural desde la enseñanza hacia el aprendizaje. De allí el énfasis en cómo lograr mejores aprendizajes por medio del trabajo colaborativo para desarrollar mecanismos permanentes.

Las prácticas colaborativas comportan rutinas excelentes de aprendizaje y liderazgo en comunidades de aprendizaje docente, volviendo pública la enseñanza y convirtiendo a los docentes en acompañantes de sus pares. Estas prácticas contribuyen al análisis y la formación de otros, en habilidades pedagógicas, por medio del sistema. No se requiere de algo externo, ni de alguien de afuera. Al ser visto el proceso como un sistema, el líder del grupo colaborativo se convierte en una persona que ayuda, orienta y facilita la toma de conciencia de lo que es mejor para todos y para cada uno. Por otra parte, hacen que los docentes y las autoridades educativas trabajen juntos, con el fin de lograr prácticas efectivas de enseñanza a partir de lo que acontece realmente en las aulas, prestando atención a los elementos que constituyen las buenas prácticas y teniendo como meta el aprendizaje de los alumnos. En este tipo de trabajo colaborativo el estilo de liderazgo interaccional se transforma en un estilo transformacional, en el que los involucrados aprenden mejor cuando interactúan con los colegas y relacionan las nuevas ideas con el conocimiento compartido común existente.

El trabajo en las instituciones ya no se concibe de manera vertical ni con una gestión tradicional, mucho menos con procesos de transferencia lineal de conocimientos, prescribiendo unos determinados conocimientos pedagógicos para conformar las prácticas de los docentes. En el caso de México se está conformando una nueva cultura de trabajo colaborativo en la que el profesorado y los asesores del desarrollo profesional se relacionan mediante aspectos básicos de igualdad y comunicación horizontal, cara a cara, desde abajo y desde dentro de los grupos colaborativos para llegar a la reflexión conjunta de la situación, deliberando de manera compartida sobre ella y sobre las decisiones a tomar (Alvarado, 2016).

En las instituciones de educación superior (IES), al igual, existen los Cuerpos Académicos (CA) para la realización de la investigación y generación del conocimiento; también deberán existir grupos colaborativos para la pro- 
fesionalización docente (GCPD), que permitan al profesorado universitario desarrollar competencias docentes para mejorar el aprendizaje del alumnado. En estos espacios se favorece el aprendizaje colaborativo e intercambian las experiencias formativas. El acompañamiento para realizar el análisis y recuperación de la práctica educativa será clave, ya que se generan espacios de reflexión y metareflexión que llevarán al docente a la creación de nuevas rutas cognitivas para que sus alumnos aprendan mejor. Los líderes de estos grupos colaborativos orientan y apoyan al profesorado en las actividades pedagógicas y disciplinares y orientan su desarrollo profesional hacia la gestión del conocimiento (Alvarado, 2016).

De la misma manera, para el caso de la implementación de las prácticas colaborativas y la creación de los GCPD, las universidades deberán concentrarse en otro modelo de gestión centrado en la práctica de los actores, caracterizado por una línea metodológica que tenga como punto de partida el debate de las ideas y de los proyectos, la generación de los consensos, el respeto a las diferencias y la actitud para buscar diferentes lecturas de una realidad institucional que debe cambiar hacia una nueva cultura para repensar las prácticas de gobierno y de gestión directiva (Rosario, 2015).

Se le apuesta a una gestión directiva de intervención permanente, que no es otra cosa que la implementación de nuevas prácticas académicas, mediante una actitud investigativa de los responsables de las instituciones educativas, sobre su propia práctica directiva en la que hace una recuperación de su cotidianeidad con el apoyo de mediaciones que rescaten la memoria histórica del centro escolar.

Se trata, pues, de formar nuevos líderes académicos que privilegien la toma de decisiones en la misma línea de actuación en la que se colegia y se promueve la participación de todos los actores involucrados.

Por supuesto que para lograr el involucramiento de todos los actores sociales se deben construir procesos descentralizados, participativos, interactivos, corresponsables con un liderazgo compartido y una comunicación horizontal y transparente con los miembros de la comunidad (Rosario, 2015). 


\section{REFERENCIAS}

1. Aguado, D. y Arranz, V. (2005). «Desarrollo por competencias mediante blended learning: un análisis descriptivo». Revista de Medios y Educación, (26), 79-88. Recuperado de: http://www.rieoei.org/deloslectores/1118/ Arranz.pdf.

2. Alvarado, M. (2016). Gestión del talento humano e innovación en la enseñanza y el aprendizaje. Estados Unidos: Palibrio.

3. Ausubel, D., Novak, J. y Hanesian, H. (1987). Psicología educativa. Un punto de vista cognoscitivo. México: Trillas.

4. Ausubel, D. (1991). Psicología educativa, México: Trillas.

5. Barber, M. y Mourshed, M. (2007). How the World's Best-Performing School Systems Come Out On Top. McKinsey \& Company, Social Sector Office. Recuperado de: http://www.mckinsey.com/clientservice/social_sector/ our_practices/education/knowledge_highlights/best_performing_school. aspx

6. Benítez, K. (2005). Consideraciones sobre la gestión del talento humano. Revista Visión Gerencial, 4(2), 97.

7. Bertalanffy, L. (1976). Teoría general de los sistemas. México: Fondo de Cultura Económica.

8. Bolivar, A. y Moreno, J. (2002). Between transaction and transformation: The role of school principals as education leaders in Spain. Journal of Educational Change, 7(1) 19-31. Recuperado de: researchgate.net/journal/1389_journal_of_educational_charge

9. Brown, M. (2008). El proceso de la presencia. España: Ediciones Obelisco. 


\section{[ 62 ] Innovación educativa: nuevas metodologías y experiencias en el aula}

10. Broderick, P. (2009). Learning to BREATHE: A Pilot Trial of a Mindfulness Curriculum for Adolescents. Recuperado de: http:// learning2breathe.org/ content/wpcontent/uploads/2009/03/ broderick-metz-2009.pdf.

11. Bruner, J., Ausubel, J. y Henessien, J. (1989). Psicología educativa. Un punto de vista cognoscitivo. México: Trillas

12. Cañal de León, P., et al. (2002). La innovación educativa. Madrid: Universidad de Andalucía.

13. Castells, M. (2000). La era de la información. Madrid: Alianza

14. Castells, M. (2001). Materiales para una teoría preliminar sobre la sociedad de redes. Revista de Educación, 45-46.

15. Colom, R. (2009). Educación y capital humano. Psicothema, 21(3), 446452.

16. Crozier, M. y Friedberg, E. (1990). El actor y el sistema. Las restricciones de la acción correctiva. México: Ed. Alianza.

17. Chiavenato, I. (2002). Gestión del talento humano. Colombia: Mc Graw-Hi11 .

18. Daniels, H. (2003) Vigotsky y la pedagogía. Barcelona: Planeta.

19. Damanpour, F. (1991). Organizational Innovation: A meta-analysis of effects of determinants and moderators. Academy of Management Journal, $34,555-590$. 
20. Damanpour, F. y Evan, M. (1984). Organizational innovation and performance: The problem of "organizational lag". Administrative Science Quarterly, 29, 392-409.

21. Davenport, T. (1994). Saving its soul: human-centered information management. Harvard business review, 119-131.

22. Diamond, J. (2005). Colapso: por qué unas sociedades perduran y otras desaparecen. Madrid: GRAO.

23. Díaz Barriga, F. (2003). Cognición situada y estrategias para el aprendizaje significativo. Revista Electrónica de Investigación Educativa, 5(2). Recuperado de: http://redie.ens.uabc.mx/vol5no2/contenido-arceo.html.

24. Escudero, J. (1992). Los desafíos de las reformas escolares. Cambio educativo y formación para el cambio. Sevilla, España: Arquetipo.

25. Estebaranz, A. (1994). Didáctica e innovación curricular. España: Universidad de Sevilla-Servicio de publicaciones.

26. Ettlie, J.; Bridges. W. y O'Keefe. R. (1984). Organization strategy and structural differences for radical versus incremental innovation. Management Science, (30), 682-695.

27. Falgueras, I. (2008). La teoría del capital humano: orígenes y evolución. Temas actuales de economía, 2, 17-48.

28. Flook, L. (2010). Effects of Mindful Awareness Practices on Executive Functions in Elementary School Children. Recuperado de: http://mindfulyouth. org/ assets/flook-et-al---effects-of-mindful-awareness-practices.pdf. 


\section{[ 64 ] Innovación educativa: nuevas metodologías y experiencias en el aula}

29. Fullan, M. (2005). Leadership and Sustainability. System thinkers in action. San Francisco: Jossey-Bass.

30. Gardner, H. (2005). Arte, mente y cerebro. Una aproximación a la creatividad. España: Paidós.

31. Goleman, D. (1999). Inteligencia emocional. España: Editorial Kairós.

32. González, M. y Escudero, J. (1987). Innovación educativa: teorías y procesos de desarrollo. España: Humánitas.

33. Hage, J. (1999). Organizational innovation and organizational change. Annual Review of Sociology, (25), 597-622.

34. Hargreaves, A. (2000). Professional and parents: A social movement for educational change, en N. Bascia, A. Hargreaves (eds.): The sharp edge of educational change. London: Routledge/Falmer Press.-— y Fink, D. (2003): «Sustaining leadership», en Phi Delta Kappan, 84(9), 693-700.

35. Goodson, I. (2006). Educational change over time? The sustainability and non-sustainability of three decades of secondary school change and continuity. Educational Administration Quarterly. London: Maidenhead Open University Press.

36. Hopkins, D. (1991). The empowered school: The management and practice of school development. London: Caseel.

37. Huberman, A. (1980). Innovación y problemas en la educación. París: UNESCO.

38. Hopkins, D. Ainscow, M., y West, M. (1994). School improvement in an era of change. New York: Teacher College Press. 
39. Huang, J. y Tansley, C. (2012). Sneaking throung the minefield of talent management: the notion of rhetorical obfuscation. The International Journal of Human Resource Management. doi: 1080/09585192.2011.639029.

40. Imbernón, F. (1996). En busca del discurso perdido. Buenos Aires: Ed. Magisterio del Río de la Plata.

41. Iribarne, A. (1989). La compétitivité: Un défi social, un enjeu éducatif. Paris: C.N.R.S.

42. Kuyken, W. (2013) Effectiveness of the Mindfulness in Schools Programme: non-randomised controlled feasibility study. Recuperado de: http:// mindfulyouth.org/assets/flook-et-al---effects-of-mindful-awareness- practices.pdf

43. Koulopoulos, T. y Frappaolo, C. (2001). Gerencia del conocimiento. España: McGraw Hill.

44. Lengnick-Hall, C. (1992). Innovation and competitive advantage: What we know and what we need to learn. Journal of Management, 18(2), 399429 .

45. Leithwood (2009). ¿Cómo liderar nuestras escuelas? Aportes desde la investigación. Santiago de Chile: Fundación Chile.

46. Levy, F. y R. Murnane (2004). The new division of labor: how computers are creating the next job market. New Jersey: Princeton University Press.

47. Liquidano, M. (2006). El Administrador de recursos humanos como gestor de talento humano. Sus competencias y la relación de las prácticas de Administración de recursos humanos. Administración de procesos de negocios, 123-155. 
48. Mckinsey \& Co. (2007). Cómo hicieron los sistemas educativos con mejor desempeño del mundo para alcanzar sus objetivos. Recuperado de: http:// www.mckinsey.com/clientservice/social_sector/our_practices/ education/ knowledge_highlights/ /media/Images/Page_Images/Offices/SocialSector/PDF/Como_hicieron_los_sistemas_educativos. ashx

49. Mckinsey \& Co. (2010). ¿̨ómo se convierte un sistema educativo de bajo desempeño en uno bueno? Sumario ejecutivo en español del informe "How the world's most improved school systems keep getting better”. Recuperado de: http://www.mckinsey.com/clientservice/Social_Sector/our_practices/ Education/Knowledge_Highlights/ /media/Reports/SSO/Education Intro_Standalone_Nov\%2029_Spanish.ashx

50. Del Águila, J. Mañas, I., Franco, C., Gil, M. y Gil, C. (2011). Entrenamiento mental: la meditación en psicología clínica. Gaceta de Psicología, (50), 29.

51. Martins, E. y Terblanche, F. (2003). Building organizational culture that stimulates creativity and Innovation. European Journal of Innovation Management, 6(1), 64-74. doi: 10.1108/14601060310456337

52. Milgran, S. (2007). Obediencia a la autoridad: un punto de vista experimental. Vol. 9, Biblioteca de Psicología. Estados Unidos: Desclée de Brouwer Series.

53. Miron, E., Erez, M. y Naveh, E. (2004). Do personal characteristics and cultural values that promote innovation, quality, and efficiency compete or complement each other? Journal of Organizational Behavior, (25), 175- 199.

54. Molina, J. y Marsal, M. (2002). Gestión del conocimiento. Recuperado de: http://www.librosenred.com/libros/lagestiondelconocimientoenlasorganizaciones.aspx. 
55. Monereo, C. [coord]. (2006). Estrategias de enseñanza y aprendizaje. Formación del profesorado y aplicación en la escuela. Barcelona: Colofón/ GRAO.

56. Montano, B. (2005). Innovations of Knowledge Management. Estados Unidos: IRM Press.

57. Morrish, I. (1976). Cambio e innovación en la enseñanza. Salamanca: Anaya.

58. New Zealand Teachers' Council. (2009). Registered Teacher Criteria.

59. OCDE. (2012). Profesores para el Siglo XXI. Usando la Evaluación para mejorar la enseñanza. París: Publicaciones OCDE.

60. O'Sullivan, K. (2008). Strategic Knowledge Management in Multinational Organizations. New York: Institute of Tecnology.

61. Perrenoud, P. (1990). La construcción del éxito y del fracaso escolar. Madrid: Morata.

62. - - (2005). Desarrollar la práctica reflexiva en el oficio de enseñar. Profesionalización y razón pedagógica. Barcelona: Colofón/ GRAÖ.

63. PNUD (2003). Informe sobre desarrollo bumano 2003, Los objetivos de desarrollo del Milenio: un pacto entre las naciones para eliminar la pobreza. Dinamarca: Ediciones Mundi-Prensa.

64. Rivas, M. (2003). La innovación educativa. Madrid: Síntesis.

65. Rodríguez, E. (2013). Evaluación de centros y profesores. Madrid: UNED-Colección Unidades Didácticas. 
66. Rodríguez Neira, T. (1999). La cultura contra la escuela. Barcelona: Ariel.

67. Rosario, V. (2013). La gestión directiva en la Universidad de Guadalajara. México, Editorial Universitaria.

68. - - (2015). La gestión directiva de intervención permanente. Una alternativa para la transformación de las prácticas académicas en las instituciones de educación superior. México: Amaya Ediciones $\mathrm{S}$ de RL de C.V.

69. Sáez, F. (1987). Computadores personales. Hacia un mundo de máquinas informáticas. Madrid: Fundesco.

70. Sanvisens, A. (1991). Concepción sistémico-cibernética de la educación, en Castillejo, J. et al., Teoría de la educación. Conceptos y propuestas. Murcia: Límites.

71. Sarramona, J. (2004). Competencias básicas en la escolaridad obligatoria. Barcelona: Ceac.

72. Scardamalia, M., y Bereiter, C. (2003). Knowledge Building. Encyclopedia of Education. New York: Macmillan Reference.

73. Sladogna, M. (2005). Una mirada a la construcción de las competencias desde el sistema educativo. México: LIMUSA.

74. Siegel, D. (2007). Mindfulness training and neural integration: differentiation of distinct streams of awareness and the cultivation of well-being. Recuperado de: http://scan.oxfordjournals.org/ content/2/4/259.full.

75. Schön, D. (1992). La formación de profesionales reflexivos: hacia un nuevo diseño de la enseñanza y del aprendizaje de las profesiones. Barcelona: Paidós. 
76. Schonert, R. (2010). The Effects of a Mindfulness-Based Education Program on Pre- and Early Adolescents' Well-Being and Social and Emotional Competence. Recuperado de: http://link.springer.com/article/10.1007/ s12671-010-0011-8\#/page-1.

77. Sotomayor, C. y Gysling, J. (2011). Estándares y Regulación de la Calidad de la Formación de Profesores: discusión del caso chileno desde una perspectiva comparada. Revista Calidad en la Educación, (25), 91-129.

78. Tobón, S. (2013) Formación integral y competencias. Pensamiento complejo, currículo, didáctica y evaluación. Bogotá, Colombia: Ecoe, Ediciones.

79. UNESCO (1998). Declaración mundial sobre la educación superior en el siglo XXI, Visión y Acción. París: UNESCO.

80. UNESCO (2004). Informe de la Comisión Internacional sobre la Educación para el siglo XXI. París: UNESCO.

81. - (2014). Temas críticos para formular nuevas políticas docentes en América Latina y el Caribe: el debate actual. París: OREAL/UNESCO CHILE.

82. - (2015). Educación de calidad, equitativa e inclusiva, así como un aprendizaje durante toda la vida para todos en 2030, artículo «Transformar vidas mediante la educación». Corea: UNESCO-Foro Mundial de Educación.

83. Van de Ven, A., Polley, D., Garud, R. y Venkataraman, S. (2001). El viaje de la innovación. El desarrollo de una cultura organizacional para innovar. México: Oxford.

84. Vázquez, G. (1991). La pedagogía como ciencia cognitiva. Revista Española de Pedagogía, 49(181), 123-146. 


\section{[ 70 ] Innovación educativa: nuevas metodologías}

y experiencias en el aula

85. Vázquez, G. (1993). Inteligencia, tecnología y escuela en la sociedad postindustrial. Madrid. Paidós.

86. Vázquez, G. y Bárcena, F. (1999). Pedagogía cognitiva: la educación y el estudio de la mente en la sociedad de la información. Teoría de la Educación. Educación y Cultura en la Sociedad de la Información, (1), 10.

87. Wolfe, R. (1994). Organizational innovation: Review, critique and suggested research directions. Journal of Management Studies, 31(3), 405-43.

88. Welch, J. (2005). Winning. Estados Unidos: Harper Bussiness.

89. Zaballos, L. (2013). El conocimiento situado y los sistemas de actividad. Un modelo teórico para repensar el prácticum. Revista de educación, (359), 629-642. 


\section{MODELO DE ENSEÑANZA- APRENDIZAJE DE EDUCACIÓN SUPERIOR POR COMPETENCIAS}

\section{RESUMEN}

E1 modelo tiene la finalidad de desarrollar en los estudiantes las competencias genéricas requeridas en el mercado laboral y es una alternativa para las instituciones de educación superior, sustentado con teorías científicas sobre el aprendizaje. Asimismo, busca responder a las necesidades de la sociedad y del sector productivo, combinando diferentes elementos para generar en los egresados las competencias demandadas en los tiempos actuales y contar con profesionistas que puedan producir los resultados esperados (Alcántara, 2007).

Se basa en desarrollar las diecisiete competencias que se detectaron en la investigación explicada en párrafos anteriores, y cuyo listado se muestra a continuación:

1. Trabajo en equipo.

2. Productividad.

2 Doctora en investigación en psicología. Es docente de la Escuela de negocios y la Escuela de graduados en administración y dirección de empresas para la maestría en administración del Tecnológico de Monterrey en distintas sedes. Es parte de la Red de investigadores sobre competencias de América Latina.

3 Maestra en administración, especialidad en finanzas por el Tecnológico de Monterrey y Licenciada en contaduría pública por la Universidad Nacional Autónoma de México. Es docente de la Escuela de Negocios del Tecnológico de Monterrey. 


\section{[ 72 ] Innovación educativa: nuevas metodologías}

y experiencias en el aula

3. Integridad.

4. Compromiso.

5. Capacidad de aprender.

6. Calidad en el trabajo.

7. Adaptabilidad al cambio.

8. Comunicación.

9. Liderazgo.

10. Visión emprendedora.

11. Proactividad (iniciativa).

12. Negociación.

13. Flexibilidad.

14. Innovación.

15. Trabajo bajo presión.

16. Empuje.

17. Generación de conocimiento.

Es importante resaltar que las competencias del manejo del idioma inglés y del uso de tecnologías de información son requisitos en un profesional, conforme con lo indicado por las empresas y universidades que conforman la muestra. 
El modelo incluye los elementos fundamentales que deberán interactuar en las instituciones y que vinculan la generación de un currículo esencial para el desarrollo de cualquier ámbito de especialización académica.

Se propone que el modelo sea flexible, no solamente para el estudiante sino para las instituciones de educación superior, en la vinculación con las competencias requeridas en el entorno regional, nacional e internacional (Alles, 2002), (Alonso Castañón, "Los retos de la Educación Basada en Competencias para el diseño del perfil profesional: El Caso de la Universidad Politécnica de San Luis Potosí”. , 2007).

El objetivo es lograr el desarrollo de competencias, por parte del estudiante, en espacios de aprendizaje que tengan la capacidad de adaptarse a los cambios dinámicos del entorno, con la adquisición no únicamente de saberes complejos, sino la capacidad de actuar en el contexto laboral y social (Bericat, 1989).

\section{PROPÓSITOS Y SUPUESTOS}

Dado que los contextos organizacionales son competitivos y globales, se requiere un modelo educativo planteado desde una perspectiva sistémica, en un contexto abierto y dinámico que se mantenga en constante cambio y movimiento, donde se conjuguen teoría y práctica para lograr una educación integral, holística y humanista. Esta educación integral debe atender el dominio cognitivo, el dominio socioafectivo y el psicomotor, así como el desarrollo de inteligencias múltiples que permitan al estudiante ampliar sus capacidades y aprovechar al máximo su potencial. La educación holística se basa en la concepción de que cada realidad es un todo distinto a la suma de las partes que lo componen (Aebli, 1998), (Alonso Castañón, 2007).

La mayoría de los programas de enseñanza solo se basan en las inteligencias lingüística y matemática, dando una mínima importancia a las otras. Las inteligencias múltiples en las que se enfoca este modelo serán la intrapersonal y la interpersonal. Este tipo de inteligencias son fundamentales para lograr trabajar en equipo, que es la competencia principal buscada en el mercado laboral (UNESCO, 1998). 
El desarrollo de las inteligencias corporal-cinestésica y musical deberán reforzarse en las actividades extraacadémicas que pueda llevar a cabo la universidad, como la realización de deportes y de actividades artísticas como baile y teatro.

Sin embargo, para lograr la innovación y la creatividad, el alumno debe utilizar todas las inteligencias que posea para buscar las soluciones a los problemas que enfrenta.

Basándose en los ideales de su comunidad y contexto social, la enseñanza humanística deberá buscar los valores de la verdad, la belleza, la moral y la justicia, educando a seres humanos que comprendan el mundo y examinen formas de mejorar cada día usando su inteligencia, su libertad y su voluntad (Díaz-Barriga, 2002).

Se considera que una persona que no posea estos valores no podrá contribuir a la cultura ética en las empresas para las que labore. Como se deriva de nuestra investigación, el desarrollo de la competencia "integridad" es fundamental para lograr una sociedad enfocada al cuidado del medio ambiente y cuyo propósito no se limite a las ganancias monetarias, sino que incluya y persiga el beneficio social (Dugua, 2007).

La universidad tiene que preparar en la innovación y la creatividad a fin de que estudiantes y docentes respondan al nuevo paradigma de responsabilidad y complejidad. Es indispensable aprender a reconocer los daños ecológicos que afectan nuestro mundo y buscar predecir las consecuencias, enseñar a reducir, reutilizar y reciclar materiales, ahorrar en el uso de energía e instituir profesiones que busquen un desarrollo sostenible y que apoyen en la fundación o administración de organizaciones socialmente responsables.

La universidad debe ser ejemplo de este uso adecuado de los recursos naturales, pero sobre todo debe crear conocimiento por medio de la investigación, así como promover el intercambio universitario y la cooperación internacional que fomenten la generación de prácticas positivas en la protección del ambiente y de la salud. Con base en lo anterior se ha creado el "Modelo de Enseñanza-Aprendizaje de Educación Superior" (MaaC), propuesto para el desarrollo de las competencias requeridas en el mercado laboral. 
Los tres ejes centrales de este modelo se sustentan en desarrollar las tres competencias que, de acuerdo con la investigación realizada, son las mayormente requeridas en la actualidad: trabajo en equipo, innovación y creatividad y capacidad de aprender (Fernández López, 2005).

Se puede afirmar que la práctica efectiva de una competencia necesariamente requiere de otras para su desarrollo, es decir, que su perfeccionamiento y ejecución implican el uso y aprendizaje de otras competencias. Se hace difícil establecer separaciones entre una y otra competencia y darles prioridad a algunas sobre otras. Sin embargo, en este modelo se ha buscado establecer en cada competencia central las competencias directas e indirectas que están inmersas en su ejecución.

Así, por ejemplo, para la competencia de innovación y creatividad se requiere de proactividad, visión emprendedora y adaptabilidad al cambio (Barrera, 2002).

En este modelo -por medio de las competencias de capacidad de aprender, innovación y creatividad y trabajo en equipo- convergen los tres intereses de las instituciones educativas: el conocimiento, la creación y las formas de ejecución. 


\section{EJES CENTRALES PARA EL DESARROLLO POR COMPETENCIAS.}

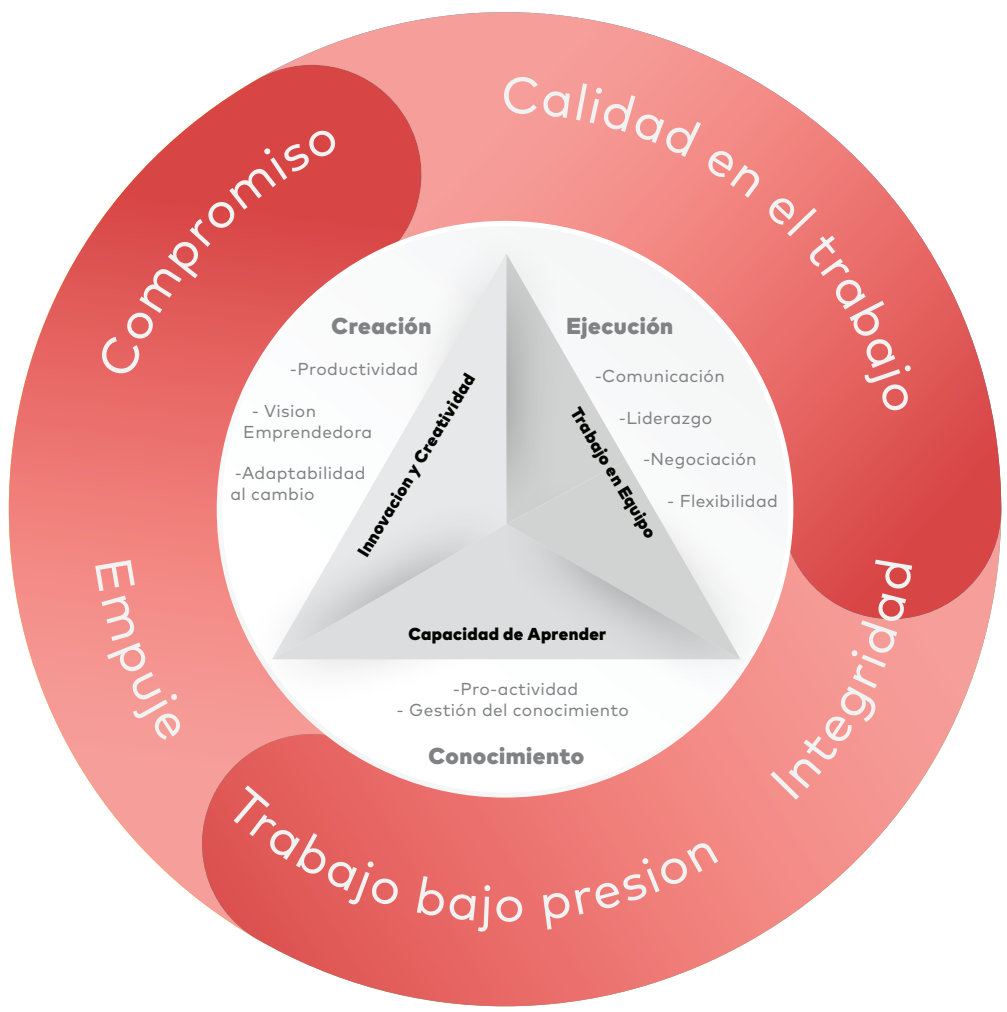

Ilustración 1. Ejes centrales de las competencias mayormente demandadas en el mercado laboral

\section{IINNOVACIÓN Y CREATIVIDAD}

La innovación se define como la capacidad de idear soluciones nuevas y diferentes para resolver problemas. Para lograr esta competencia se debe convertir cada actividad didáctica en una posibilidad de dar soluciones creativas e innovadoras, dejando en un segundo plano la memorización y la repetición, convirtiendo al estudiante en el actor protagónico.

El pensamiento creativo requiere estar abiertos a nuevas experiencias; por lo tanto, se hace prioritario enfrentar al estudiante, preferentemente, a 
problemas reales de su comunidad y que para él sean significativos (Álvarez Medina, 2005).

En realidad, no existe actividad humana que no sea factible de ser mejorada por medio de la innovación y la creatividad; sin embargo, el profesor puede hacer uso de diversos métodos didácticos que fortalezcan esta competencia. Entre ellos se encuentran el método de casos, el aprendizaje basado en problemas, aprendizaje orientado a proyectos, por mencionar algunos, y que serán explicados más adelante.

Otro método que puede ser útil es el sinéctico, que ha sido empleado tanto en empresas como instituciones educativas para el desarrollo de innovaciones, buscando trabajar en colaboración, con el propósito de desarrollar productos y resolver problemas (Joyce, 2002).

El empleo de analogías constituye el elemento fundamental de la sinéctica. Estas comparaciones metafóricas luego serán utilizadas por los estudiantes para resolver problemas y abordar nuevas ideas.

Lo que importa es resaltar que tanto estudiantes como profesores se encuentren dispuestos a tomar riesgos y a persistir en la solución de problemas complejos, apartándose de la comodidad que dan los problemas predeterminados con soluciones fijas. Por tanto, se deben desarrollar actividades físicas o intelectuales que lleven al alumno a estar más alerta y promuevan su creatividad e innovación. En cada actividad se deben desafiar las suposiciones y la forma tradicional de hacer las cosas, preguntándose constantemente por qué y cómo se puede mejorar.

El profesor debe ayudar a modificar los esquemas mentales y de aprendizaje que muchos de los estudiantes adquirieron en etapas anteriores de estudio, y buscar la flexibilidad y la apertura a los cambios. En la búsqueda de la innovación y la creatividad deben llevarse a cabo acciones deliberadas, por parte del profesor y el alumnado, con el fin de mejorar la práctica existente en la perspectiva de ciertos objetivos determinados. Por esto, la búsqueda de innovación y creatividad conlleva patrones determinados de acción y desarrollo que dan como producto una mejora, transformación, optimización o sustitución de un proceso, situación u objeto. 


\section{[ 78 ] Innovación educativa: nuevas metodologías y experiencias en el aula}

- A la luz de lo expuesto, no cabe duda que el profesor debe desarrollar un nuevo perfil dentro y fuera del aula como innovador-investigador (Barrera, 2002).

- Los esfuerzos del profesor y de los estudiantes redundarán en cambios en la actividad didáctica, por ejemplo:

- Generar actividades que propicien el pensamiento estratégico, creatividad e innovación.

- Los profesores deben crear un clima que dé poder y apertura a los estudiantes para innovar.

- Se debe valorar y admirar el proceso creativo.

- Respetar la diversidad de ideas y el cuestionamiento del estudiante.

- Confiar en que los alumnos puedan aprender cosas nuevas.

- Los estudiantes deberán asumir mayor responsabilidad y buscar diversas fuentes de información.

- Profesores y estudiantes deberán estar abiertos a nuevas experiencias.

- Utilizar diversas técnicas para desarrollar la creatividad.

- Romper reglas y límites impuestos por otros.

- Hacer uso de técnicas diversas para fomentar las ideas, como uso de analogías, lluvia de ideas, etc.

- Buscar generar múltiples soluciones a un problema.

- Todos los individuos deberán ser considerados fuentes de información.

- Perder el miedo a lo desconocido y a cometer errores. 
- Poseer una tolerancia a la incertidumbre, al riesgo y la inseguridad.

- Trabajar en equipos multidisciplinarios.

- Aprender a escuchar a otros y a comunicar las ideas propias.

No debemos olvidar que la creatividad requiere de espacios y tiempos para generarse y que la innovación solo se logra trabajando. Al desarrollar la innovación se utilizan y perfeccionan las siguientes competencias: proactividad, visión emprendedora, adaptabilidad al cambio, trabajo en equipo, comunicación, capacidad de aprender, compromiso, empuje, generación de conocimiento, productividad entre otras.

Una característica de las instituciones superiores es que tanto maestros como alumnos encuentran su razón de ser en la búsqueda común de conocimiento, por lo cual participan en un proceso interminable de investigación que fortalece la innovación y la creatividad (Andión, 2007).

\section{CAPACIDAD DE APRENDER O APRENDER A APRENDER}

La competencia básica que deben desarrollar los estudiantes es su $c a-$ pacidad de aprender o aprender a aprender. Las ideas, teorías, tecnologías y mundo en general cambian a velocidades a las que universidades y profesores no pueden seguir el paso.

El estudiante y futuro profesional debe ser capaz de buscar la información que necesite y adaptarse a nuevas formas de hacer las cosas, sin esperar que el conocimiento que adquirió en la universidad sea suficiente para enfrentar los retos del mundo laboral.

Bajo la premisa de que es posible enseñar a pensar, el profesor puede utilizar métodos didácticos que permitan al estudiante recopilar, organizar, manipular y utilizar la información para resolver problemas y capacitar a los alumnos en la construcción y verificación de hipótesis. El aprendizaje se 
debe considerar una constante en su vida y deberá extenderse al centro de trabajo y a cualquier actividad que se realice.

La capacidad de aprender pude adquirirse identificando las operaciones mentales que se requieren en la apropiación de conocimientos, y el profesor debe planear las situaciones didácticas más propicias para estimular el aprendizaje.

Lo que debe descubrir el alumno son las diversas formas en que desarrolla su propio aprendizaje, y el profesor debe ayudarlo - por medio de preguntas y reflexiones- a adquirir conciencia de la manera en que logra dicho aprendizaje. En este modelo los errores son vistos como oportunidades de aprender (Bericat, 1989).

E1 reto es formar eficientemente estudiantes que sean autónomos y disciplinados, es decir, personas que sean capaces de hacer por sí mismos el análisis de las situaciones que enfrenten, la búsqueda de información y establecer estrategias a fin de tomar decisiones.

Para el logro de esta competencia es necesario partir de la vida cotidiana, de situaciones reales. El profesor debe buscar que la situación, los temas, las interrogantes que presente tengan una relación directa con el alumnado, y que por medio de la investigación y acciones dirigidas se le dé respuesta.

Los principales pasos que se deben tomar en cuenta para desarrollar soluciones con los métodos didácticos elegidos por el profesor y que deben apoyar el entendimiento de los estudiantes en su forma de aprender son:

1. Conocer los hechos o situación que se vive.

2. Definir la situación o problema.

3. Investigar y explicar las diversas causas, consecuencias, teorías y sistemas que ayuden a entender el problema.

4. Buscar posibles soluciones, estrategias y modelos.

5. Aplicar las acciones de solución. 
6. Analizar los procesos y operaciones mentales básicas que llevaron a cabo los estudiantes para enfrentar el problema.

7. El alumno evalúa su aprendizaje y recibe retroalimentación de su accionar, por sus compañeros y profesores.

8. El alumno reconoce sus fortalezas y debilidades y establece cursos de acción para su mejora.

La reflexión sobre el aprendizaje y la práctica ejecutada es una necesidad imperativa en el proceso de aprender a aprender, que permite tener conciencia de los pasos realizados para alcanzar la meta.

Esta reflexión debe abarcar:

- Una actitud de autocrítica.

- Una voluntad de auto-perfeccionamiento.

- La necesidad constante en la búsqueda de nuevos conocimientos y su aplicación.

Se recomienda el uso extensivo de los equipos de trabajo para facilitar el aprendizaje. Los miembros del equipo se apoyan mutuamente en la adquisición de los contenidos académicos y el desarrollo de habilidades.

Además de las competencias de proactividad y gestión del conocimiento, al aprender a aprender se refuerzan las competencias de trabajo en equipo, productividad, comunicación y adaptabilidad al cambio, entre otras.

\section{TRABAJO EN EQUIPO}

La nueva cultura del aprendizaje establece que este es una actividad social y no una acción solitaria e individual. En general, en los sistemas educativos el trabajo en equipo se lleva a cabo dividiendo a los estudiantes en 
grupos de cuatro a seis personas, cuya finalidad es alcanzar en conjunto las metas establecidas.

Una de las dificultades principales en el trabajo en equipo ocurre cuando se pide a los estudiantes que trabajen con otros sin que hayan recibido con anterioridad un entrenamiento claro de lo que implica la colaboración y de las dificultades a las que se pueden enfrentar.

Se sugiere que en el diseño de las clases y antes de iniciar un proyecto, los estudiantes reciban un entrenamiento de al menos tres horas sobre el trabajo en equipo.

Para que estos equipos sean efectivos, requieren:

- Tener clara la razón u objetivo de ser un equipo de trabajo.

- Comunicarse abiertamente entre sí, para lo cual se les debe entrenar en lo referente a comunicación clara, precisa y no violenta.

- Manejar los conflictos de manera abierta.

- Apoyarse unos a los otros.

- Reconocer que juntos son más fuertes y eficaces que individualmente.

- Comprender que el aprendizaje se da al conocer los puntos de vista y contribuciones de los otros miembros.

- Respetar la diversidad de opiniones, personalidades y formas de hacer.

- Establecer los métodos que utilizarán para llevar a cabo la toma de decisiones.

- Reconocer el trabajo de todos.

- Manejar técnicas de retroalimentación para establecer acciones correctivas. 
- Llevar a cabo coevaluaciones entre miembros de los equipos y entre equipos.

El profesor además debe poseer:

- Visión clara de la función del equipo en el logro de las metas de aprendizaje.

- Conocimiento preciso de evaluar con exactitud el desempeño del grupo.

- Capacidad de dirigir los proyectos y habilidad de planeación de las labores.

- Destreza para manejar el cambio y fomentar competencias de equipo.

Se ha demostrado que la motivación para el trabajo en equipo se logra cuando el grupo debe llevar a cabo una tarea compleja, caracterizada por altos grados de interdependencia.

La experiencia ha expuesto que muchas instituciones de educación superior implantan formas de evaluación y entregas de reconocimiento o recompensas que obstaculizan el trabajo en equipo. Por ejemplo, es frecuente encontrar premios individuales a los mejores promedios, como becas para estudios de posgrado. Estos incentivos individuales desalientan la conducta cooperativa; por lo tanto, se debe, en los salones de clase y en las estructuras universitarias, efectuar acciones que alienten, reconozcan y apoyen a quienes trabajan en conjunto.

Además, el estudiante debe tener claro el objetivo del desarrollo de su inteligencia interpersonal como una de las claves para lograr su eficacia profesional y personal; esta inteligencia interpersonal es aquella que le permite entender a los demás, mostrar empatía y comunicarse efectivamente; estas habilidades son básicas para el trabajo en equipo.

La tarea de la universidad es la de promover una cultura de tolerancia, paz, no violencia, es decir, debemos enseñar formas de solución de conflictos basadas en la colaboración, y tenemos que reconocer la paz como la única forma de convivir, lo cual favorece el desarrollo de la competencia de negociación. 


\section{[ 84 ] Innovación educativa: nuevas metodologías y experiencias en el aula}

Es innegable que al trabajar en equipo y al establecer altos estándares de exigencia, los estudiantes fortalecerán las siguientes competencias: comunicación, liderazgo, negociación, flexibilidad, compromiso, trabajo bajo presión, calidad en el trabajo e integridad entre otras.

A continuación, se presenta una tabla que resume los rasgos del modelo, y posteriormente se explica a detalle cada los uno de componentes.

Tabla de rasgos del Modelo de Enseñanza-aprendizaje por competencias para la educación superior.

RASGOS DEL MODELO

DESCRIPCIÓN

Perspectiva sistémica Muestra las interrelaciones existentes entre las diversas variables que conforman el modelo educativo. Los acontecimientos pueden estar distanciados en el espacio y el tiempo, pero se encuentran conectados y cada uno influye sobre el resto.

CONTEXTO ABIERTO Y El contexto es la agrupación de circunstancias especíDINÁMICO ficas de lugar y tiempo. Es abierto en cuanto efectúa importantes interacciones con su medio; tanto recibe como entrega información. Esto implica un proceso de cambio infinito que lo hace dinámico.

EDUCACIÓN INTEGRAL, HOLÍSTICA Y HUMANÍSTICA.
Al estudiante se le considera un ser humano único, valioso e irrepetible, que debe alcanzar su plenitud logrando adquirir su máxima potencialidad en las diversas áreas que lo conforman como un ser integral; estas son: físicas, psicológicas, sociales, artísticas, e intelectuales, entre otras.

El alumno utiliza los tres ejes centrales del desarrollo de competencias: capacidad de aprender, trabajar en equipo e innovar y creatividad en su propia mejora y en la de su comunidad.
VALORES ÉTICOS
Búsqueda de la moral, la justicia, la verdad y la belleza, entendiéndose esta última como lograr la excelencia y perfección; la concientización de la responsabilidad en el cuidado de los recursos naturales y el desarrollo sostenible. La moral, como todo aquello que lleve al hombre a defender y crecer en su dignidad de persona. 
INTELIGENCIAS INTRAPERSONAL E INTERPERSONAL
El modelo fortalece el desarrollo de la inteligencia intrapersonal, que es la capacidad de ver quiénes somos y qué deseamos; y la inteligencia interpersonal, que es la capacidad de entender a otras personas, interactuar con ellas y entablar empatía.

El actor central de este modelo es el estudiante (1), e interactúan en su formación los profesores, el currículo y la sociedad en general (3). Es por ello que para lograr el objetivo de transformar a la universidad tradicional en una que desarrolle las inteligencias intrapersonales e interpersonales y se fortalezca el desarrollo de competencias genéricas, se tiene que partir desde una labor en conjunto.

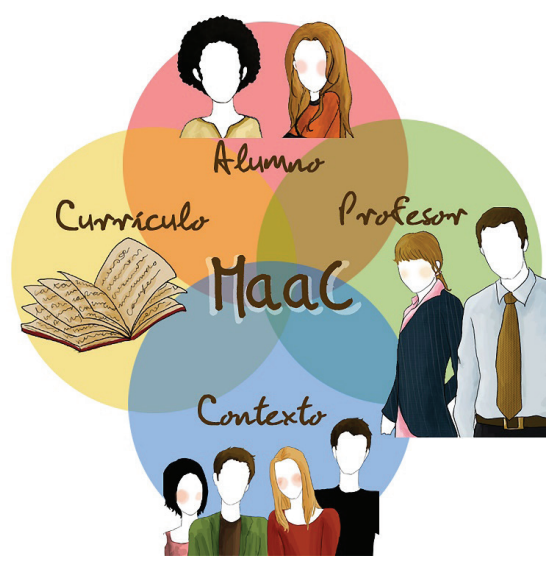

Ilustración 2. Explicación de la interrelación de currículo, estudiante, profesor y contexto.

Al estudiante se le considera un ser humano único, valioso e irrepetible que debe alcanzar su plenitud logrando adquirir su máxima potencialidad en las diversas áreas que lo conforman como un ser integral, y estas son: físicas, psicológicas, sociales, artísticas, e intelectuales entre otras. 


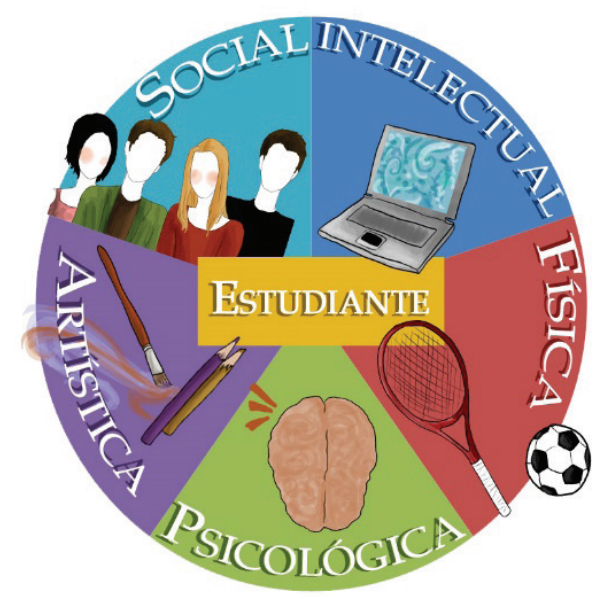

Ilustración 3. Ser integral que alcanza la plenitud.

Otro de los factores clave que interactúa en este modelo es el profesor (2) y la manera en que lleva a cabo las clases. El profesor debe crear estrategias de enseñanza-aprendizaje que sean retadoras para el estudiante y propiciar así que el alumno lleve a cabo actividades cognitivas y sociales que pueda aplicar en múltiples escenarios.

En este modelo, a medida que el estudiante domina ciertas competencias, el resultado de cada experiencia de aprendizaje no se limita a una sola materia. Lo que se busca es que el estudiante tenga claro cómo transferir ese conocimiento a problemas reales y a otros escenarios.

La base o fundamento del modelo radica en conseguir que el estudiante y futuro profesional logre aprender a aprender (4), es decir, que posea la capacidad de aprender por cuenta propia. Este es el resultado más importante a largo plazo, ya que será la competencia fundamental que le permitirá enfrentar el cambio y la actualización constante que le demandará el futuro (ANECA, 2008).

Los estudios universitarios tienen una duración aproximada de cuatro a cinco años, este periodo se dividirá en cuatro etapas (5) con los siguientes objetivos: 
Etapa I: (aproximadamente el primer año de estudios) aquí es donde el alumno adquirirá las bases teóricas de su profesión, además de llevar materias que fortalecerán sus competencias de comunicación oral y escrita. Por medio de todas las etapas se buscará fortalecer el manejo del idioma inglés y el uso de tecnologías de información.

Etapa II: (aproximadamente el segundo año de estudios) el estudiante participará directamente en proyectos reales, vinculados con las empresas o con proyectos de acción social basados en el desarrollo sostenible. Estos proyectos tendrán continuidad durante la duración de sus estudios profesionales. Se continúa fortaleciendo el manejo del idioma inglés y el uso de tecnologías de información.

Etapa III: (aproximadamente el tercer año de los estudios universitarios) el estudiante participa en la creación de un nuevo producto, servicio, proceso o en la mejora de alguno ya existente. Este periodo puede hacerlo nacional y/o internacionalmente, fortaleciendo así la competencia central de innovación y creatividad. Se continúa mejorando el manejo del idioma inglés y el uso de tecnologías de información.

Etapa IV: (entre el cuarto y quinto año de los estudios universitarios) el estudiante lleva a cabo una estancia en empresas con una duración mínima de seis meses. Esta estancia puede ser nacional y/o internacional, dependiendo de sus oportunidades.

Para lograr la capacidad en los estudiantes de educarse a sí mismos o volverse aprendices constantes, los docentes tendrán que hacer uso de las técnicas didácticas (6) que refuerzan estos comportamientos, y estas son:

a). El aprendizaje basado en problemas.

Esta estrategia de enseñanza-aprendizaje tiene como meta que un grupo de estudiantes analice y busque posibles soluciones a un problema relacionado con su entorno. El objetivo de la técnica no es resolver el problema, sino identificar temas de aprendizaje. 
b). Método de casos.

Al analizar un caso, que es la descripción de una situación real y compleja, el participante -junto con sus compañeros- propone soluciones, haciendo uso de su experiencia y conocimiento. Después de una discusión, los integrantes del equipo presentan una alternativa de solución para el caso presentado; debemos recordar que el método de casos no exige una solución única, sino que más bien acepta las alternativas, siempre y cuando estén bien fundamentadas.

c). Aprendizaje colaborativo.

Es una forma de aprender por medio de un trabajo conjunto con compañeros, para alcanzar una meta que puede ir desde actividades sencillas hasta las más complejas.

d). Aprendizaje orientado a proyectos.

Se presenta a los estudiantes una situación concreta y real a la que se busca dar solución mediante el diseño y desarrollo de un proyecto, el cual se desarrolla durante todo el periodo académico y, en ocasiones, se extiende un poco más.

e). Aprendizaje basado en investigación.

Por medio de esta técnica, el estudiante se incorpora de manera parcial o total en una investigación, aplicando una metodología disciplinaria o interdisciplinaria para investigar una hipótesis, problema o pregunta, con la supervisión de un profesor investigador.

El profesor deberá elegir aquella técnica didáctica que mejor se adapte a los objetivos de sus asignaturas y que cumpla con desarrollar el autoaprendizaje y la adquisición de las competencias requeridas para el profesional del siglo XXI. Dependiendo de la flexibilidad de la institución educativa y de la creatividad del profesor, este buscará la mejor forma de disponer de los recursos o generar nuevas alternativas. 
Conforme los estudiantes obtengan mayores estrategias podrán desarrollar aprendizajes más complejos. Realizar proyectos vinculados a las empresas y comunidades, así como crear nuevos productos, servicios o procesos, o mejorar los ya existentes, contribuyen a la integración de conocimientos flexibles, adaptables a diversas problemáticas y no a la memorización de conceptos.

Al trabajar en proyectos vinculados con empresas o de acción social, el estudiante contribuye para resolver problemas prácticos y desarrollar estrategias de cambio para la sociedad. Así podrá entender los conceptos por medio de las consecuencias observables, ya que este aprendizaje implica el contacto directo con la realidad. Trabajar con proyectos, casos e investigación, le brindará al estudiante un conjunto de atractivas experiencias de aprendizaje significativo, involucrándolo en problemas complejos y del mundo real, mediante los cuales desarrollará y aplicará diversas competencias (Buendía, 2007).

Durante todas las actividades académicas, los estudiantes requerirán trabajar en equipo (7), dentro y fuera del salón de clases, y con esto reforzarán sus competencias de liderazgo, flexibilidad, negociación y adaptabilidad al cambio. Una actividad fundamental para lograr esta competencia es que el grupo de profesores trabaje en equipo para estructurar los planes de estudio y para dar clases colaborativas. La idea es que el estudiante obtenga diversos puntos de vista de un problema (8) en las lecturas asignadas y en el salón de clase, y evitar así la ceguera del conocimiento que ocurre, de acuerdo con Morin (1999), cuando se enseña en las universidades solo un punto de vista de un conocimiento, especialmente cuando este es complejo y está constituido por diferentes elementos (Bunk, 1994).

Los profesores tendrán que diseñar o contar con actividades, casos o problemas de enseñanza en los que el estudiante tenga que buscar alternativas, tomando en cuenta todos los elementos para brindar una posible solución. Por ejemplo, en la educación tradicional un estudiante está acostumbrado a que existe una solución única y verdadera frente al problema planteado; en este modelo, el estudiante aprende que el conocimiento es complejo y cambiante, y que en una situación real existen múltiples respuestas que pueden ayudar en la solución de un problema, que a su vez es 
causado por multi-factores. De esta manera, el estudiante tendrá que hacer frente a la incertidumbre que existe ante las soluciones que se brindan en el mundo laboral y utilizar su innovación y creatividad (Castro, 2007).

A continuación, se presentan los elementos fundamentales que se interrelacionan para el desarrollo de las competencias entre los que se incluyen el profesor, el estudiante, el contexto, la evaluación, las empresas e instituciones.

\section{EL PROFESOR}

La actividad del profesor es de vital importancia en este modelo, por lo que se requiere centrar los esfuerzos en capacitar al maestro y llevar a cabo una campaña de comunicación, de tal forma que para el docente quede clara la finalidad del modelo y que él contribuya de manera sustancial en la definición del currículo. El punto clave consiste en el diseño de los ambientes de aprendizaje que realice el profesor, en donde los estudiantes puedan relacionarse entre sí y desarrollar sus propios aprendizajes.

Además, dentro de las actividades diseñadas en el currículo, se requiere que el estudiante cumpla altos estándares de exigencia que le permitan desarrollar las competencias de calidad en el trabajo, trabajo bajo presión, productividad y empuje (9).

Dificultades presentadas:

- En muchas ocasiones el profesor de universidad es un profesional que no tiene conocimientos de didáctica.

- Existen profesores de tiempo completo en las universidades y aquellos que llevan a cabo la actividad de la docencia, además de otras actividades laborales.

- Se requiere equilibrar la carga del profesor para que pueda dedicar tiempo a colaborar con otros docentes en el diseño del currículo, en actividades académicas y en su propio desarrollo. 
- Además de las actividades anteriormente mencionadas, el profesor tiene que realizar labores de tutoría, asesoría, extensión e investigación.

- El salario que recibe, en ocasiones, no lo estimula para seguir desarrollándose y realizar esfuerzos para modificar sus clases.

- Existe una resistencia al cambio, natural en todo ser humano.

Soluciones posibles:

- Brindar capacitación continua al profesor sobre métodos didácticos y los fines que se persiguen para superar la resistencia que presenten al cambio, así como aclarar las dudas que pudieran tener.

- Todo manejo eficaz del cambio requiere que exista una motivación por parte de los actores de este; además, debe crearse un propósito compartido de ese cambio, proporcionando una visión futura de los resultados esperados. Se requiere el apoyo claro de la dirección y una campaña eficaz de comunicación.

- Se debe manejar la transición realizando actividades planeadas y estructuradas, y sostener el impulso al cambio para que se realice en su totalidad.

- Establecer estímulos económicos a aquellos profesores que cumplan cursos de capacitación.

- Tener acceso a recursos bibliográficos, científicos y tecnológicos.

- Que exista vinculación entre investigación y docencia.

E1 profesor debe conocer la materia que va a enseñar, conocer a sus estudiantes, planificar actividades que favorezcan el aprendizaje del grupo por medio de las técnicas didácticas para provocar retos y desafíos en sus estudiantes. Diseñar apoyos didácticos y visuales que apoyen la comprensión del material.

La meta central de la actividad del profesor es incrementar el desarrollo de las competencias en sus estudiantes, para lograr su autonomía y su deseo 
de seguir aprendiendo. Para lograr esto, el profesor debe crear un clima en el salón de clases o en las actividades académicas de auténtico respeto hacia las ideas, creencias y opiniones de otros. Aceptar y fomentar la diversidad de pensamientos y comportamientos, establecer relaciones interpersonales de empatía y tolerancia. Enfocarse en sus estudiantes y en todos aquellos factores que puedan ayudarlos a aprender a aprender, tales como su entorno, historia, intereses, capacidades, cultura, etc.

Igualmente, debe fortalecer la autoestima de sus estudiantes, creando una atmósfera de participación en donde el éxito de las actividades de aprendizaje dependa de todo el grupo y no se centre en el profesor. Debe reconocer que cada estudiante es único e irrepetible, por lo que es apreciado. Debe actuar como mediador del aprendizaje, proponiendo situaciones pedagógicas como casos, proyectos y problemas, que permitan a los estudiantes el desarrollo de las competencias establecidas y la reorganización de su propio saber al interactuar con su entorno.

Los recursos que el profesor puede utilizar para el logro del autoconocimiento son:

retroalimentación por parte de los compañeros, autoevaluaciones, cuestionarios, dinámicas y actividades en las que el estudiante pueda reconocerse a sí mismo, además de sus áreas de oportunidad y fortalezas. Los estudiantes en este tipo de ambiente no se sienten amenazados al reconocer sus fortalezas y debilidades, y su autoestima se fortalece con el propio reconocimiento de que ellos pueden cambiar y modificarse si así lo desean.

El papel del profesor es ayudar al estudiante a tomar conciencia de los cambios que desea lograr y establecer estrategias para alcanzar dichos cambios (Andrade Cázares, 2008), (Arriola, 2007).

\section{LA EVALUACIÓN DEL APRENDIZAJE}

Los términos evaluación y aprendizaje se encuentran ampliamente relacionados. La evaluación, de acuerdo con el modelo educativo presentado, tiene como propósitos: 
1. Determinar las necesidades de aprendizaje de los estudiantes, diagnosticando áreas de oportunidad y fortalezas.

2. Establecer los avances alcanzados conforme con los objetivos planteados.

3. Ofrecer retroalimentación y orientación para encauzar los esfuerzos de aprendizaje a la obtención de las competencias requeridas en el mercado laboral.

4. Reforzar, alentar y motivar a los estudiantes al reconocer sus logros en su trayectoria de adquisición de competencias.

5. Ayudar a establecer experiencias nuevas de aprendizaje y seleccionar materiales de enseñanza.

En el proceso de evaluación, en este modelo participan los compañeros del estudiante, el propio estudiante, los profesores y, en el caso de los proyectos de vinculación y de acción social, participan las empresas o la comunidad en donde se lleven a cabo las acciones (Barrera, 2002).

La autoevaluación consiste en la apreciación que haga el estudiante de su aprendizaje. El hacerse consciente de su propia percepción con respecto a su aprendizaje le permite hacer correcciones y auto-regularse.

La coevaluación es la estimación que realizan los compañeros o pares sobre el esfuerzo, trabajo, resultados, calidad y cantidad de la labor llevada a cabo por un estudiante para alcanzar ciertos objetivos de aprendizaje.

La evaluación realizada por el profesor, la empresa o la comunidad brindará la visión del experto sobre el aprendizaje adquirido, ofreciendo una retroalimentación clara y positiva del proceso y los resultados obtenidos. La evaluación debe verse como una herramienta de apoyo que ayuda a reflexionar y a reforzar al aprendizaje (Bericat, 1989), (Buendía, 2005). El profesor debe enfatizar la importancia de la evaluación en la construcción del aprendizaje y evitar que se vea como un instrumento de castigo. 


\section{EL ESTUDIANTE}

En este modelo se busca que el estudiante sea proactivo. Para ello tiene que saber que posee autodeterminación para elegir de manera constante quién es, qué desea y cómo va a actuar para lograrlo. El modelo debe inhibir los comportamientos de víctima en donde el estudiante sienta que no tiene poder para tomar decisiones o cambiar situaciones. Así, él responde conscientemente a las situaciones que enfrenta en la vida.

Además, el estudiante tiene que estar constantemente trabajando en su autoconocimiento, de manera que pueda reconocer sus fortalezas y debilidades e incidir proactivamente sobre ellas. Debe aceptar que no importa en qué circunstancia se encuentre inmerso, él puede llevar a cabo acciones para modificar esa situación. Desarrollará su inteligencia intrapersonal al ser consciente de ver quién es realmente y definir sus metas y objetivos, así como los caminos que tomará para lograrlos.

El conocimiento del yo interno es considerado el punto central del comportamiento humano. La capacidad de manejarse a sí mismo y de llevar las relaciones con otros es identificada en este modelo como uno de los factores más importantes del éxito que se obtenga como futuros profesionales. A1 reconocerse responsable del nivel de aprendizaje que logre, y del éxito de los proyectos en los que se encuentre trabajando, estará motivado para alcanzar los logros establecidos a los que observa como un reto.

El estudiante que posee autodeterminación, autoconocimiento y motivación de logro verá reforzada su autoestima. La comprensión que posea de sí mismo y de su propia autoestima es fundamental para mejorar sus competencias. Se requiere un claro conocimiento del nivel de capacidad que posee actualmente para poder desarrollarse o mejorar.

Esta autoestima, definida como el reconocimiento de su propio valer y capacidades para enfrentar las situaciones de la vida, brinda confianza en los procesos mentales y le da la seguridad para actuar de formas diversas e incrementar su calidad de vida, la cual le provee la seguridad para establecer metas más altas, ser flexible e íntegro en su comportamiento y adaptarse al cambio. 
El estudiante debe construir su aprendizaje orientado por el problema o proyecto que se le presente como parte de las técnicas didácticas. Debe ser capaz de flexibilizar los conceptos y conocimientos que posea para adaptarse a los nuevos retos educativos que enfrente e incorporarlos a diferentes situaciones y objetos (Dirube Mañueco, 2004).

\section{LA EMPRESA Y LAS INSTITUCIONES}

En este modelo se requiere una vinculación constante entre la universidad y las organizaciones o las instituciones empleadoras. Esta vinculación es entendida como la unión y relación de las universidades y las organizaciones de manera continua, teniendo claro que el éxito y sobrevivencia de una depende de la otra.

Es importante resaltar que no es suficiente con enviar al alumno a trabajar en las organizaciones en tareas rutinarias; lo que se espera de esta vinculación es la inmersión del estudiante en actividades donde pueda adquirir competencias y contribuir con su conocimiento en la consecución de los objetivos organizacionales.

Esta relación bidireccional debe mantener una comunicación incesante sobre las necesidades, metas y estrategias recíprocas, además de contribuir al logro de las metas establecidas y brindar beneficios mutuos.

A medida que se requieren nuevos conjuntos de habilidades para adecuarse al mundo laboral y a los nuevos puestos de trabajo, es de suma importancia que el binomio empresa o institución y universidad establezca formas de retroalimentación para determinar las competencias requeridas en los profesionales del siglo XXI. Para lograr esto, y como parte de las funciones de docencia, investigación y extensión de la universidad, se deberá contar con instancias de profesores para llevar a cabo proyectos empresariales.

Para poder graduarse es recomendable que los estudiantes realicen un proyecto dentro de una empresa, con duración de al menos seis meses. Estos proyectos deberán estar claramente definidos con objetivos, tiempos y resultados esperados. Asimismo, la evaluación que se dé a los estudiantes deberá llevarse de manera conjunta entre profesor y jefe inmediato de la 
empresa. Con esta actividad los alumnos reforzarán sus competencias de productividad, calidad en el trabajo, trabajo bajo presión, empuje y compromiso entre otras.

Por su parte, la empresa debe aprovechar la relación con la universidad para capacitar y desarrollar a sus empleados, dar respuesta a problemas organizacionales con la ayuda de expertos, uso de la tecnología, investigación y el uso de los parques tecnológicos e incubadoras de empresas.

Una de las tareas básicas de la vinculación es desarrollar investigación y desarrollo que fortalezca la actividad industrial y académica y promueva la innovación y la creatividad. Para que esta relación empresa o institución y universidad sea fructífera, se requiere:

1. Desarrollo de políticas adecuadas que no solo permitan estas relaciones, sino que las fomenten y faciliten.

2. Un plan estratégico que incluya estas relaciones como actividades prioritarias, tanto para la empresa como para la universidad.

3. Una oferta de proyectos en que se pueda trabajar unidos para lograr los resultados esperados.

El reto es encontrar el espacio donde ambas puedan trabajar en conjunto y lograr el crecimiento esperado.

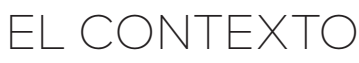

En este modelo se establece la propuesta de mantener una relación continua entre universidad y el contexto. De diversas maneras, la universidad está influenciada por las familias, la economía, la política, los mercados laborales, la industria y la sociedad en general. Se parte de la premisa que los seres humanos somos sociales y que buscamos identidad en el mundo por medio de las instancias que hemos creado para organizarnos.

Este contexto es multi-variable y complejo, por lo que se deben establecer mecanismos que faculten a la universidad para mantener la comunica- 
ción constante y formar una relación que permita convenir las necesidades sociales con las necesidades del individuo.

Es necesario que las instituciones de educación superior reconozcan los factores regionales, nacionales e internacionales que determinan la labor educativa. En el nivel de la educación superior los planes de estudio se deben revisar por lo menos cada dos años, de tal forma que satisfagan las necesidades cambiantes de la sociedad.

Para realizar su función central en el progreso y desarrollo del país, la universidad debe establecer un enlace con el mercado laboral, que le permita conocer la demanda de empleos basada en las actividades productivas.

Los ejes centrales del desarrollo de competencias que hemos propuesto como parte de este modelo emanan de los requerimientos señalados por empleadores, docentes y alumnos. Así, por ejemplo, entre las exigencias actuales de los empleadores están las competencias de trabajo en equipo y productividad, mientras que los docentes y alumnos señalan también innovación, creatividad y capacidad de aprender como las más deseables; de tal suerte que la universidad debe modificar su organización a fin de adaptarla a las competencias requeridas en el mercado laboral.

En una economía abierta se establece una relación entre el mercado nacional laboral y el mercado internacional. Con esto se busca que el mayor número de profesionales posean las competencias que les permitan adaptarse al mundo laboral y crearse oportunidades de empleo, ya sea dentro de una organización o en el autoempleo.

De esta forma, la universidad será capaz de integrar al mercado laboral a profesionales que puedan ejercer sus trabajos con calidad y con una formación compatible con los cambios previsibles del mercado del trabajo.

Hasta aquí se ha presentado el Modelo de enseñanza-aprendizaje de Competencias para la educación superior, y se ha descrito cada uno de sus elementos, componentes y la interrelación entre ellos.

El modelo educativo propuesto toma como base el desarrollo de la competencia de aprender a aprender o capacidad de aprender para el desarrollo de las competencias requeridas en el mercado laboral. Se espera que este 
[98 ] Innovación educativa: nuevas metodologías y experiencias en el aula

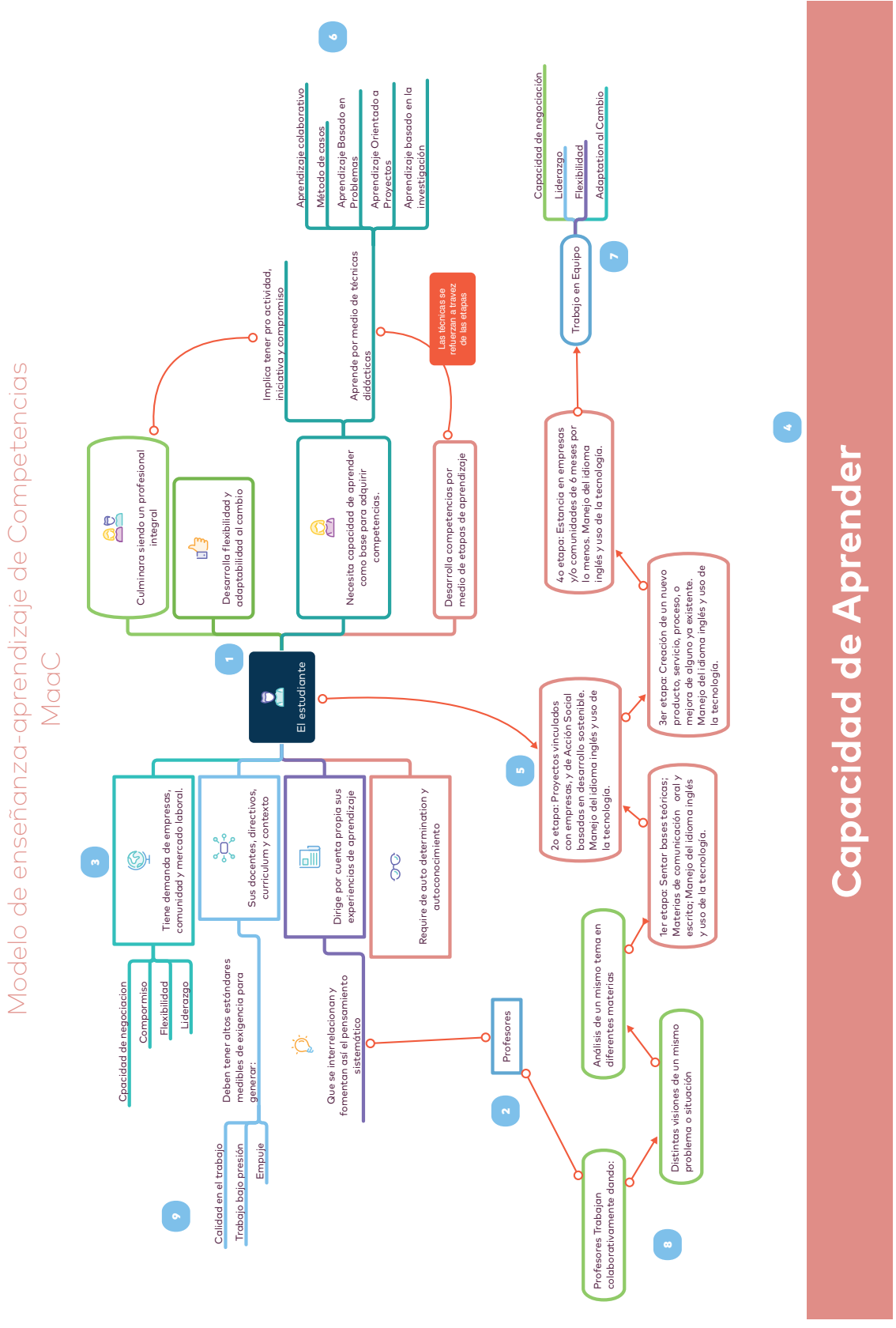

llustración 4: Modelo de enseñanza aprendizaje de competencias MaaC 
modelo pueda ser utilizado por las universidades, considerando el contexto diferente en el que se encuentran.

Este modelo se muestra a detalle en la Ilustración No. 4 de la siguiente página. Al modelo se le ha nombrado "Modelo de enseñanza-aprendizaje por competencias”, que de forma abreviada llamamos MaaC.

\section{CONSIDERACIONES FINALES}

Los modelos educativos que se han expuesto, tanto en el marco teórico como en las propuestas de enseñanza-aprendizaje de competencias, requieren de un esfuerzo de políticas educativas y de los directivos en general, para capacitar al docente y brindarle un alto nivel de habilidades personales y profesionales. Por otra parte, se exige una gran variedad de recursos didácticos que no siempre se encuentran en disposición del profesor.

Muy posiblemente uno de los principales obstáculos se encuentra en el hecho que muchos de los profesores no han tenido la experiencia de emprender sus propios negocios o de innovar en las empresas con productos y servicios. Es prioritario establecer nuevas investigaciones que den respuesta a las interrogantes existentes sobre la capacitación requerida por los docentes, así como las evaluaciones de los resultados obtenidos.

En líneas generales, esta investigación se realizó buscando conocer las competencias demandadas en el mercado laboral por empresas empleadoras; sin embargo, es importante realizar otros estudios que abarquen las competencias requeridas para ser emprendedores y crear fuentes de trabajo.

Es elemental resaltar la dificultad que se presenta al hacer comparaciones entre instituciones de educación públicas y privadas, estudiantes y profesores que provienen de contextos y circunstancias muy distintas. Igualmente, existen brechas significativas en el desarrollo de las competencias alcanzadas por los estudiantes provenientes de niveles educativos inferiores al llegar a la universidad; es por esta razón que se hace necesario una revisión constante de los objetivos propuestos por las instituciones, los recursos empleados y los procesos de aprendizaje a favor de la calidad educativa, lo cual debe incluir un cambio radical en todos los niveles educativos, en la 
forma tradicional de dar clase, si deseamos -como sociedad- hacer frente a la competitividad internacional. Por esta razón se deben crear normas y políticas educativas que apunten en esta dirección, creando centros de apoyo a las escuelas y docentes.

Es conveniente continuar investigando sobre instrumentos de evaluación que exploren la calidad de la educación y su vinculación con el desarrollo de las competencias idóneas, tanto en profesores como estudiantes.

\section{REFERENCIAS}

1. Aebli, H. (1998). Los factores de la enseñanza que favorecen el aprendizaje autónomo. ( $3^{\mathrm{a}}$ ed.). Madrid, España: Narcea.

2. Alcántara, A. (2007). Reencuentro. Análisis de Problemas Universitarios, (50), 21-27.

3. Alles, M. (2002). Dirección estratégica de recursos humanos: gestión por competencias: el diccionario. Buenos Aires, Argentina: Granica.

4. Alles, M. (2005). Gestión por competencias: el diccionario. Buenos Aires, Argentina: Granica.

5. Alonso Castañón, M. (2007). Los retos de la Educación Basada en Competencias para el diseño del perfil profesional: El Caso de la Universidad Politécnica de San Luis Potosí. Ponencia presentada en el Congreso Mundial sobre las Competencias Laborales. Cali, Colombia.

6. Álvarez Medina, L. y De la O Pérez, C. (2005). Evaluación y certificación de las competencias laborales en México. El caso de las dependencias del gobierno federal. Contaduría y Administración, (216), 13-34. 
7. Andión, M. (2007). Reencuentro. Análisis de Problemas Universitarios, (50), 83-92.

8. Andrade Cázares, M. (2008). Un acercamiento al enfoque por competencias profesionales. Trabajo presentado en la Universidad de Guanajuato/ Universidad Marista de Querétaro. Querétaro.

9. ANECA. (2008). Agencia Nacional de Evaluación de la Calidad y Acreditación. Madrid, España. Recuperado de: www.aneca.es/estudios/estu_informes.asp

10. ANUIES. (2009). Oferta Educativa. Recuperado de: http://www.observatoriolaboral.gob.mx/wb/ola/ola_tabla_institutos_anuies?area=6\&subarea

11. Argudín, Y. (2005). Educación basada en competencias: nociones y antecedentes. México: Trillas.

12. Argüelles, A. (Comp.) (1996). Competencia laboral y educación basada en normas de competencia. México: CONALEP/Limusa.

13. Arriola, M., Sánchez, G. y Romero, M. (2007). Desarrollo de Competencias en el proceso de instrucción. México: Trillas.

14. Artidiello, I. (2006). La administración de RRHH y la Gestión por Competencias. Recuperado de: http://www.wikilearning.com/monografias/instruccion_recursos_humanos/busqueda/1

15. Barrera, J. (2002). La persona correcta en el lugar correcto. Revista Mundo Ejecutivo. Recuperado de: www.sld.cu/galerias/doc/sitios/infodir/la_persona_correcta_en_el_lugar_correcto.doc 
16. Berg, B. (1998). Qualitative research methods for the social sciences. Boston: Allyn and Bacon.

17. Bericat, E. (1989). La integración de los métodos cuantitativo y cualitativo en la investigación social: significado y medida. Barcelona: Ariel.

18. Buendía, A. (2005) Competencias del Ciudadano en la Ciudad del Conocimiento. España: Deusto.

19. Buendía, A. (2007). Hacia una nueva sociedad del conocimiento: retos y desafíos para la educación virtual. México: Limusa

20. Bunk, G. (1994). La transmisión de las competencias en la formación y perfeccionamiento profesionales en la RFA. Berlín: CEDEFOP.

21. Castro, M., y Castillo, F. (2007). Enfoques alternativos en la educación superior. México: I.T.E.S.M. Campus Toluca.

22. Chapela, L. (2007). Saberes en movimiento. Reflexiones en torno a la educación. México: NOSTRA.

23. CINTERFOR, OIT. (1997). Boletín Técnico Interamericano de Formación Profesional. Educación Tecnológica, (141).

24. Compendio de la Declaración Mundial sobre la educación superior. (2009). UNESCO. Recuperado de: http://portal.unesco.org/education/es/ev.phpURL-ID=19189\&URL_DO=DO_TOPIC\&URL_SECTION=201ht$\mathrm{ml}$

25. Conferencia Mundial sobre la Educación Superior en el siglo XXI. (1998). Tendencias de la Educación Superior. Recuperado de: http://www.mecesup.cl/mecesup1/difusion/revista1A.pdf 
26. Cortina, A. (1997). Ciudadanos del mundo. Hacia una teoría de la ciudadanía. Madrid: Alianza.

27. Cortina, A. (1998). El mundo de los valores. "Ética mínima" y educación. Bogotá: El Búho.

28. Delors, J. (1996). La educación encierra un tesoro. París: UNESCO.

29. Díaz-Barriga, F. y Hernández, G. (2002). Estrategias docentes para un aprendizaje significativo. Una interpretación constructivista. (2a ed.). México, D.F.: McGraw Hill.

30. Dirube Mañueco, J. (2004). Un modelo de gestión por competencias: lecciones aprendidas. Barcelona: Gestión.

31. Ducci, M. (1997). El enfoque de competencia laboral en la perspectiva internacional, en: Formación basada en competencia laboral. Montevideo: CINTERFOR/OIT.

32. Duckworth, E. (2000). Cuando surgen ideas maravillosas. Y otros ensayos sobre la enseñanza y el aprendizaje. Barcelona, España: Gedisa.

33. Dugua, C. (2007). La Cultura en el aprendizaje escolar. Elementos para una pedagogía dentro y fuera del aula. México, D.F.: Trillas.

34. Dyer, W. (2008). Equipos de trabajo de alto desempeño. México, D.F.: Grupo Editorial Patria.

35. Fernández López, J. (2005). Gestión por competencias. Un modelo estratégico para la dirección de Recursos Humanos. México: Prentice Hall. 
36. Fernández Olivares, A. (2005). Definición y análisis de las competencias organizacionales requeridas por personal actual y futuro de una empresa global. México: Tecnológico de Monterrey, Campus Monterrey.

37. Fletcher, S. (1997). Competencia Laboral. Antología de Lecturas. México: SEP/CONOCER.

38. Fletcher, S. (2001). Herramientas y Técnicas para analizar trabajos, Funciones y Puestos. México: Editorial Panorama.

39. Flores Campos, M., y Nadira Rodríguez, D. (s.f.). La educación a distancia como herramienta para el desarrollo de competencias. Recuperado de: http://www.simet.gob.mx/boletin/educativo/no1/Educacion_a_Distancia_Y_competencias.pdf

40. Fresán Orozco, M. (2007). Repensar la calidad en la educación superior en el nuevo milenio. Reencuentro. Análisis de Problemas Universitarios, (50), 52-59.

41. Gallart, M, y Jacinto, C. (1995). Competencias laborales: tema clave en la articulación educación-trabajo. Boletín Educación y Trabajo, 6(2). Buenos Aires.

42. Gardner, H. (2000). La educación de la mente y el conocimiento de las disciplinas. Lo que todos los estudiantes deberían comprender. Barcelona, España: Paidós.

43. Gardner, H. (2005). Las cinco mentes del futuro. Un ensayo educativo. Barcelona: Paidós.

44. Gardner, H. (2005). Mentes flexibles. El arte y la ciencia de saber cambiar. Barcelona: Paidós. 
45. Giles Sánchez, E. (2007). Las Competencias Laborales de Empresa. Vinculación Estratégica. CONALEP, Morelos - Capufe. México: Colegio de Educación Profesional Técnica del Estado de Morelos. CONALEP Morelos. Ponencia presentada en el Congreso Mundial sobre las Competencias Laborales. Cali, Colombia.

46. Giry, M. (2003). Aprender a razonar. Aprender a pensar. (2a ed.). México: Siglo Veintiuno.

47. Glaser, B. y Strauss, A. (1999). The discovery of grounded theory: strategies for qualitative research. New York: Aldine de Gruyter.

48. González, A. (1991). El enfoque centrado en la persona. Aplicaciones a la educación. ( $2^{\mathrm{a}}$ ed.) México: Trillas.

49. González, J., Wagenaar, R. y Beneitone, P. (2006). Tunning-América Latina: Un proyecto de las universidades. Bilbao, España: Manpower Inc.

50. Hager, P. y Andrew, G. (1991). Competency-based Standards: A boom for continuing professional education? Studies in Continuing Education, 13(1), 24-40.

51. HayGroup (2001). The manager Competency Model. Hay Acquisition Company I, Inc.

52. Hellriegel, D., Jackson, S. y Slocum, J. (2005). Administración: un enfoque basado en competencias. México: Thompson.

53. Hernández, R., Fernández, C. y Baptista, P. (2007). Metodología de la investigación (4å. Ed.). México, D.F.: Mc Graw Hill. 
54. Huerta Amezola, J., Pérez García, I. y Castellanos Castellanos, A. (s.f.). Desarrollo curricular por competencias profesionales integrales. Recuperado de: http://educar.jalisco.gob.mx/13/13Huerta.html

55. I.T.E.S.M (2007). Programa de desarrollo de habilidades docentes. Recuperado de: http://www.ccm.itesm.mx/rh/capacitación/pdhdnuevo.htlm

56. Ibarra Almada, A. (1996). El sistema normalizado de Competencia Laboral. En: Competencia laboral y educación basada en normas de competencia. México: SEP, CONOCER, CONALEP.

57. Ibarra Almada, A., (2000) Formación de los Recursos Humanos y Competencia Laboral. Consejo de Normalización y Certificación de Competencia Laboral de México. México, D.F.: CONOCER.

58. Iglesias González, J. (2007). Evaluación de las competencias del personal de Tecnologías de Información, su importancia en México y las competencias que son necesarias desarrollar en nuestro país. Trabajo de Tesis. Instituto Tecnológico y de Estudios Superiores de Monterrey, Campus Monterrey, Monterrey, Nuevo León.

59. INEGI (2005). Estadísticas censos y conteos. México. Recuperado de: http://www.inegi.org.mx/est/contenidos/espanol/sistemas/conteo2005/localidad/iter/default.asp?s=est\&c=10395

60. Jessup, G. (1991). Outcomes: NVQs and the emerging model of education and training. Londres: Falmer Press.

61. Joyce, B., Weil, M. y Calhoun, E. (2002). Modelos de enseñanza. Barcelona, España: Gedisa.

62. Juárez, J. y Comboni, S. (2007). Reencuentro. Análisis de Problemas Universitarios, (50), 60-72. 
63. Larraín, A. y González, L. (s.f.). Formación universitaria por competencias. Recuperado de:

64. Latapí Sarre, P. (2007). Conferencia Magistral al recibir el Doctorado Honoris Causa de la UAM. Reencuentro. Análisis de Problemas Universitarios, (50), 15-20.

65. Lema Labadie, J. (2007). La calidad educativa, un tema controvertido. Reencuentro. Análisis de Problemas Universitarios, (50), 10-14.

66. Levy-Leboyer, C. (2003). Gestión de las competencias: cómo analizarlas, cómo evaluarlas, cómo desarrollarlas. Barcelona: Gestión.

67. Madrigal, B. (2009). Habilidades directivas. México, D.F.: McGraw Hill.

68. Maldonado, M. (2006). Las competencias, método y genealogía. Pedagogía y didáctica del trabajo. Bogotá: Ecoe Ediciones.

69. MANPOWER (2006). El futuro del trabajo en el mundo. Recuperado de: http://www.manpower.com.mx/sala/documents/ei/Futuro\%20del\%20 Trabajo\%20en\%20el\%20Mundo.pdf

70. Marelli, A. (2000). Introducción al análisis y desarrollo de modelos de Competencias, s/d.

71. Martínez Moctezuma, L. y Padilla Arroyo, A. (Coord). (2006). Miradas a la historia regional de la educación. México: UAEM/Porrúa/Siglo XXI.

72. Martínez, P., y Echeverría, B. (2009). Formación basada en competencias. Manuscrito no publicado de próxima edición en Revista de Investigación Educativa, (1). 
73. Masseilot, H. (s.f.). Competencias laborales y procesos de certificación ocupacional. OIT/CINTERFOR. Recuperado de: http://www.cinterfor. org.uy/public/spanish/region/ampro/cinterfor/publ/boletin/149/pdf/massei.pdf

74. McCombs, B. y Whisler, J. (2000). La clase y la escuela centradas en el aprendiz. Estrategias para aumentar la motivación y el rendimiento. Barcelona, España: Paidós.

75. Meraz Salazar, E. (2003). Prácticas de valor para adoptar un enfoque por competencias laborales. México: Tecnológico de Monterrey. Recuperado de: http://biblioteca.itesm.mx/cgi-bin/doctec/listdocs?co_recurso=doctec:104036

76. Mertens, L. (1996). Competencia Laboral: sistemas, surgimiento y modelos. Montevideo: CINTERFOR/OIT.

77. Messner, D. (1996). Dimensiones espaciales de la competitividad internacional. Revista Latinoamericana de Estudios del Trabajo, 2(3).

78. Monereo, D. (coord.); Badia, A. (2005). Internet y competencias básicas: aprender a colaborar, a comunicarse, a participar, a aprender. Barcelona: Graó.

79. Morín, E. (1999). Los siete saberes necesarios para la educación del futuro. México: UNESCO.

80. Nielsen, C., Carranza, D., Oblak, M. y Fowler, D. (2007). Functional Strategic Issues Track: Strategic Human Resources Management. Preparing Future Managers for Successful Careers: A Comparison of University Students in Mexico and the U.S. Paper presented at the Strategic Management in Latin American Conference, Santiago, Chile. 
81. Novick, M. (1997). Una mirada integradora de las relaciones entre empresas y competencias laborales en América Latina. Recuperado de: www.cinterfor.org.uy/public/spanish/region/ampro/cinterfor/ publ/novick/pdf/novnovic.pdf

82. Novik, M., Bartolomé. M., Buceta, M., Miravalles, M. y Senén González, C. (1998). Nuevos puestos de trabajo y competencias laborales, un análisis cualitativo en el sector metalmecánico argentino. Montevideo, Uruguay: CINTERFOR.

83. Observatorio Laboral (2005). ¿Cómo se espera que sea el trabajo en el futuro? Recuperado de: http://www.observatoriolaboral.gob.mx/ index.asp?index $=2$

84. OCDE (2007). Pisa 2006: Aptitudes para las ciencias para el mundo del mañana. Nota informativa para México. Organización para la Cooperación y el Desarrollo Económico. Recuperado de: http:// www.oecd.org/dataoecd/58/54/39730555.pdf

85. OECD Organisation for Economic Co-operation and Development (2004). Territorial Reviews: Mexico City. París, Francia. Recuperado de: http://www.oecd.org/dataoecd/41/62/33819913.pdf

86. OECD Organisation for Economic Co-operation and Development (2009). Regions at a Glance Organisation for Economic Co-operation and Development. París, Francia. Recuperado de: http://www.oecd.org/documentprint/0,3455, en_2649_34413_42396233_1_1_1_37429,00.html

87. Organización Internacional del Trabajo. (2009) Competencia Laboral: 40 preguntas sobre competencias laborales. Recuperado de: http://www.ilo.org/public/spanish/region/ampro/cinterfor/temas/ complab/xxxx/esp/ii_a.htm 
88. Organización Internacional del Trabajo. (2009) Competencia Laboral: 40 preguntas sobre competencias laborales. ¿Cómo inició la aplicación del enfoque de formación basada en competencia laboral? Recuperado de: http://www.ilo.org/public/spanish/region/ampro/ cinterfor/temas/complab/xxxx/esp/ii.htm

89. Organización Internacional del Trabajo. (2009). Competencia Laboral: 40 preguntas sobre competencias laborales. Definiciones de competencia en las instituciones dedicadas a la formación y desarrollo de los recursos humanos. Recuperado de: www.ilo.org/public/ spanish/region/ampro/cinterfor/temas/complab/xxxx/esp/i_a.htm

90. Organización Internacional del Trabajo. (2009). Competencia Laboral: 40 preguntas sobre competencias laborales. Definiciones de competencias en instituciones de formación profesional. Recuperado de: www.ilo.org/public/spanish/region/ampro/cinterfor/temas/ complab/xxxx/esp/i_b.htm

91. Organización Internacional del Trabajo. (2009). Conceptos básicos sobre competencia laboral. Recuperado de: http://www.ilo.org/ public/spanish/region/ampro/cinterfor/temas/complab/xxxx/esp/i. htm

92. Parra Acosta, H. (2006). El modelo educativo por competencias centrado en el aprendizaje y sus implicaciones en la formación integral del estudiante universitario. Ponencia presentada en el $6^{\circ}$. Congreso Internacional Retos y Expectativas de la Universidad. México: Universidad Autónoma de Chihuahua.

93. Pedroza Flores, R. y García Briceño, B. (comp). (2005). Flexibilidad Académica y Curricular en las Instituciones de Educación Superior. México: UEA Morelos-UAE México-Porrúa.

94. Perrenoud, P. (2002). Construir competencias desde la escuela. Santiago de Chile: Dolmen Ediciones. 
95. Perrenoud, P. (2004). Diez nuevas competencias para enseñar: invitación al viaje. Barcelona: Graó.

96. Ponce, M. (2005). Cómo enseñar mejor. Técnicas de asesoramiento para docentes. México, D.F.: Paidós.

97. Posada Alvarez, R. (s.f.). Formación superior basada en competencias, interdisciplinariedad y trabajo autónomo del estudiante. Facultad de Educación, Universidad del Atlántico. Colombia. Recuperado de: http://www. rieoei.org/deloslectores/648Posada.PDF

98. Pozo, I. (1999). Aprendices y maestros. La nueva cultura del aprendizaje. Madrid, España: Alianza Editorial.

99. Proyecto Tuning (2005). Proyecto Tuning América Latina. Consulta sobre Competencias Genéricas. Resultados Área Matemáticas. Recuperado de http://www.scm.org.co/subidos/tuning/informecompetenciasgenericasmatematicas.pdf

100. Quinn, R. (1995). Maestría en la gestión de organizaciones: un modelo operativo de competencias. Madrid: Ediciones Díaz de Santos.

101. Quiroz, E. (2007). Reencuentro. Análisis de Problemas Universitarios, (50), 93-99.

102. Real Academia Española (2009). 'Competencia'. Recuperado de: http:// buscon.rae.es/draeI/SrvltConsulta?TIPO_BUS=3\&LEMA=competencia

103. Reflex. (2007) El profesional flexible en la Sociedad del Conocimiento. Informe Ejecutivo. Madrid, España: ANECA. 
104. Resnik, S. (2000) Habilidades Básicas en Australia, Nueva Zelandia, Estados Unidos, Canadá y Gran Bretaña, y el Estudio de Análisis Ocupacional. México, D.F.: CONOCER.

105. Rodríguez, S. y Sánchez, N. (2006). Identificación y normalización de competencias informacionales: un estudio de caso. Recuperado de: http:// bvs.sld.cu/revistas/aci/vol14_6_06/aci02606.htm

106. Rogers, C. (1990). El proceso de convertirse en persona. México, D.F.: Paidós.

107. Roldán, N. (2008). México, el peor país de la OCDE en ciencias. Recuperado de: http://www.milenio.com/mexico/,milenio/nota.asp?id=574131

108. Romero Díaz, D. (2004). Modelo evolutivo de administración de recursos humanos basado en competencias. México: ITESM, Campus Monterrey. Recuperado de: http://biblioteca.itesm.mx/cgi bin/doctec/listdocs?co_recurso $=$ doctec: 132347

109. Romero Díaz, D. (2004). Modelo Evolutivo de Recursos Humanos Basado en Competencias. Trabajo de Tesis. Instituto Tecnológico y de Estudios Superiores de Monterrey Campus Monterrey, Monterrey, Nuevo León.

110. Romero, T., y Rangel, B. (2008). Profesionales del siglo 21; las nuevas habilidades; reclutadores de empresas trasnacionales dicen qué características buscan en los recién egresados universitarios. México: Reforma.

111. Rosell, W., y Más, M. (2003). El Enfoque sistémico en el contenido de la enseñanza. Recuperado de: http://www.bvs.sld.cu/revistas/ems/ vol17_2_03/ems02203.htm 
112. Rubio Oca, J. (2007). La evaluación y acreditación de la educación superior en México: un largo camino aún por recorrer. Reencuentro. Análisis de Problemas Universitarios, (50), 35-44.

113. Sánchez, S. y Domínguez, A. (2006). Significado psicológico del talento en la docencia: maestros talentosos vs. Buenos maestros. La psicología social en México, 11, 483 - 489.

114. Sánchez, S. y Domínguez, A. (2007). Buenos Maestros vs. Malos Maestros. Psicología Iberoamericana, 5(2), 11-16.

115. Sánchez, S. y Domínguez, A. (2008). Elaboración de un instrumento de viñetas para evaluar el desempeño docente. Revista Mexicana de Investigación Educativa, 13(37), 625-648.

116. SENAC, Referencias para la educación profesional del Senac, 2002.

117. SENAI, Metodología de Elaboración de Perfiles Profesionales. Brasilia, 2002.

118. Senge, P. (1990). La quinta disciplina: Cómo impulsar el aprendizaje en la organización inteligente. Buenos Aires, Argentina: Ediciones Granica.

119. Senlle, A. (1988). Pedagogía humanista. Lo que educadores y padres deben saber. España: Ediciones Mensajero.

120. SEP (2007). Apoyo a proyectos de investigación básica. Convocatoria SEP/CONACYT 2007. Recuperado de: http://www.sep.gob.mx.

121. Singh, K., Gómez, A. y Escamilla, J. (2006). Teoría, consideraciones éticas y prácticas, metodología y cambio educativo. 1er Simposio Nacional de Investigación sobre la Innovación Educativa. Monterrey, México: I.T.E.S.M. 
122. Tejada Fernández, J. (1999). Acerca de las competencias profesionales. Revista Herramientas, 1(56), 20-30.

123. Tobón, S. (2006). Formación basada en competencias: pensamiento complejo, diseño curricular y didáctica. Bogotá, Colombia: Ecoe Ediciones.

124. Tobón, S. (2007). Competencias en la Educación Superior. Bogotá, Colombia: Ecoe Ediciones.

125. UNESCO (1998). La educación superior en el siglo XXI. Visión y acción. Conferencia Mundial sobre la Educación Superior, Informe final. París, Francia. Recuperado de: http://unesdoc.unesco.org/images/0011/001163/116345s.pdf

126. UNESCO (2005). Hacia las sociedades del conocimiento. París, Francia: Ediciones UNESCO.

127. Unidad de Bolonia. Consejo de Estudiante (1998). Declaración de la Sorbona (Traducido al español). Recuperado de: https://www.uniroja.es/ceur/ archivos/ubo/declaracion_sorbona.pdf

128. Universidad de Deusto (2003). Tuning Educational Structures in Europe. Recuperado de: www.relint.deusto.es/TUNINGProject/spanish/doc_ fase1/Tuning_Educational_1.pdf

129. Universidad de Deusto, Universidad de Groningen (2007). Reflexiones y perspectivas de la educación superior en América Latina. Recuperado de: http://tuningunideusto.org/tuningal

130. Vargas Zúñiga, F. (2004). Competencias Clave y Empleabilidad. Montevideo, Uruguay: CINTERFOR. 


\section{AULA INVERTIDA EN EL \\ PROGRAMA DE NEGOCIOS}

\section{INTERNACIONALES \\ DEL POLITÉCNICO \\ GRANCOLOMBIANO

Uno de los retos más importantes dentro de las aulas de clase es llegar a los estudiantes de manera más dinámica, con clases orientadas a la formación integral y con un sentido de práctica más estructurado, de tal forma que no sean esas clases donde se imparte conocimiento sino, por el contrario, espacios de formación que claramente aportan de manera significativa al aprendizaje colectivo.

La educación tradicional ha estado en cuestionamiento por la forma en la cual se otorgan conocimientos memorísticos que impiden el desarrollo de emprendimientos, la iniciativa en ideas y en líderes capaces de resolver problemas. De la manera tradicional se está viendo estudiantes que repiten lo que el docente les dice, y el interés se pierde; los alumnos solamente están resguardados por la nota y el pasar la asignatura, que en definitiva es lo que mueve al estudiante.

4 Magister en negocios internacionales. Es Decana de la facultad de Ciencias Administrativas, Económicas y Contables de la Institución Universitaria Politécnico Grancolombiano

5 Magister en educación. Es Profesora de Tiempo completo asistente en la Institución Universitaria Politécnico Grancolombiano. 


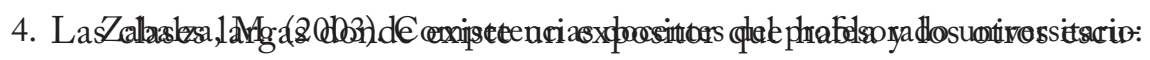

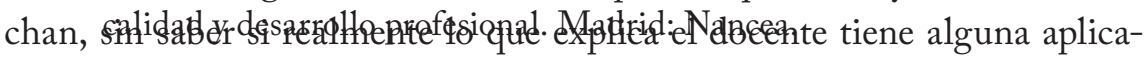
ción o lógica.

Las clases se convierten en recintos donde existen expositores y receptores, no hay intercambio de conocimiento y solo existe una vía que la evaluación reafirma con mediciones que no consolidan el proceso de enseñanzaaprendizaje.

El objetivo de esta investigación es realizar un piloto de aplicación del modelo de aula invertida, usando como metodología cualitativa la recolección documental y un estado del arte, que luego de la inspección de más de 321 documentos y mediante selección, permita establecer coincidencias y puntos de vista sobre la metodología barrido que se hace en Scopus y Emerald utilizando Medeley y Google académico. Posteriormente se va a revisar datos de evaluación, como dos focus group con el fin de evidenciar lo bueno y lo malo de este pilotaje.

En definitiva, se trata de probar alternativas didácticas y uso de las tecnologías de la información y comunicación, un acercamiento a formas de enseñanza que permitan explorar y dinamizar habilidades y competencias enfocadas a un logro definitivo de la asignatura de Negocios y relaciones internacionales.

Se va a realizar en dos cursos presenciales de Negocios Internacionales: el grupo A, de 46 estudiantes, y el grupo B, de 39 estudiantes, aplicando esta metodología y evaluando la metodología de aula inversa.

\section{EL AULA INVERTIDA, DEFINICIONES Y EJEMPLOS}

El aula al revés o invertida es una idea que se da precisamente con miras a maximizar el tiempo que se utiliza en el aula de clase, extendiendo los tiempos en los encuentros mediante el apoyo de las tecnologías de información. 
Según Aaron (2014, pág. 19): "Dar la vuelta a la clase establece una estructura con la cual se asegura que los alumnos reciben una educación personalizada, diseñada a la medida de sus necesidades individuales”.

La nueva generación de los estudiantes es cada vez más afín a la tecnología, con estructuras mentales totalmente diferentes a la educación tradicional. Los chicos constantemente se preguntan: ¿esto para qué sirve, esto qué me está enseñando como aporte en mi formación y cómo lo voy a usar en el futuro trabajo?

Existen, entonces, los docentes que se cuestionan sobre sus propias enseñanzas, o simplemente docentes que responden 'pues esto es lo que hay y ya', generando inconformismo en el estudiante y aún más preguntas sobre la aplicación práctica de los contenidos ofrecidos en las aulas (Leupin, 2016). Por otra parte, está el resultado del aprendizaje diferencial en las universidades, orientado al futuro laboral, con una didáctica realmente estructurada para el aprendizaje y su aplicación (Jancsó, 2016).

\section{Es importante señalar que aunque con este método pedagógico el alumno trabaja de forma autónoma, nunca lo hace solo porque el profesor actúa de guía en su proceso de aprendizaje, seleccionando los contenidos que debe estudiar, asimilar y retener, poniéndolos a su disposición a través de diver- sos medios (Albaladejo, 2013, pág. 3).}

La idea es no dejar al estudiante nunca solo, y lo contrario, aprovechar las aplicaciones y la tecnología como eje central del proceso de formación. No se trata solo de dejar unos vídeos y organizar actividades conexas desde la didáctica. El aula invertida implica acercarse al estudiante y empezar a generar procesos de innovación en la forma de hacer la clase y también de recibirla; los resultados académicos deben dar un vuelco total (Lacleta, 2015) (Bourdieu, 2016).

Estudios como el de Del Pino, Prieto y Prieto (2016), aplicado a la ingeniería, cuestiona la educación tradicional y da un aporte fundamental a una práctica que maximiza el tiempo y brinda acceso directo a las competencias de los estudiantes. Estos autores lo realizaron para una asignatura específi- 
ca, tal como es la idea e intención de esta investigación, y complementado con herramientas tecnológicas propias de los jóvenes actualmente.

Talbert (2015), por ejemplo, es un autor que ofrece una enorme referencia en la forma de enseñar matemáticas y cómo se debe abordar el conocimiento y el aprendizaje en estos aspectos. La herramienta de YouTube fue fundamental en el desarrollo del aula inversa.

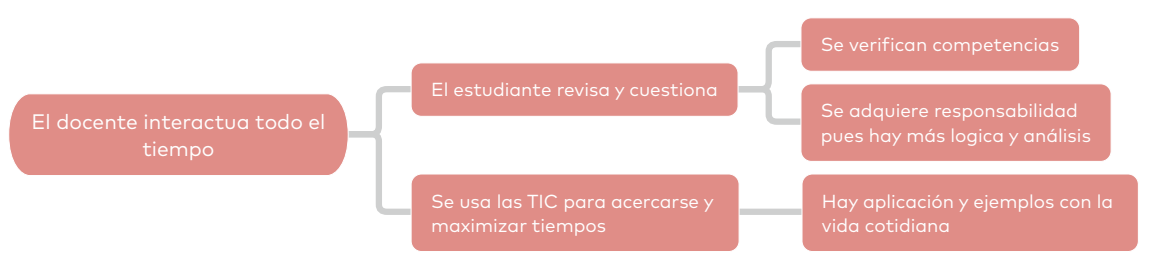

llustración 1: El sistema de aula invertida

Fuente: elaboración propia, 2017.

Para Albaladejo (2013, pág. 15), "la idea básica inherente a este modelo educativo sería la de promover que el alumno trabaje por sí mismo y fuera del aula los conceptos teóricos a través de diversas herramientas que el docente pone a su alcance, principalmente vídeos o podcasts grabados por su profesor".

Pero no cualquier vídeo por salir del paso. Se trata de mezclar la pedagogía con la explicación, vídeos y podcast cortos que motiven al estudiante a conocer y a seguir investigando; esta es la clave de la interacción: tener un lenguaje que los estudiantes quieran escuchar, tal como lo enfatiza en varios estudios el Tecnológico de Monterrey (TEC, 2014), institución precursora en la dinámica de nuevos métodos en el aula: formación completa, no que sature al estudiante con conocimiento que se acabe o se aprenda en un tiempo determinado y que no tenga aplicación alguna.

La aplicación del aula inversa depende también de retos pedagógicos y de llevar a los jóvenes a espacios interactivos de búsqueda, interés y de análisis colaborativo, de manera práctica y organizada. 


\section{EL AULA INVERSA COMO ESENCIAL PARA APROVECHAR LAS TIC}

El aula inversa o invertida parte del desarrollo pedagógico constructivista basado en experiencias significativas. Esta es una herramienta didáctica que aporta a los estudiantes un método diferente de entender y verificar la realidad de la educación, dejando de lado aprendizajes memorísticos y rompiendo esquemas, captando su atención y en busca de un perfil profesional más competitivo.

Acercamientos teóricos como los de Vidal y Morales (2016), ejemplifican claramente la metodología y la manera de organizar el tiempo en el que los estudiantes pueden ver vídeos y utilizar herramientas tecnológicas que los capaciten, al mismo tiempo que van generando estos hábitos.

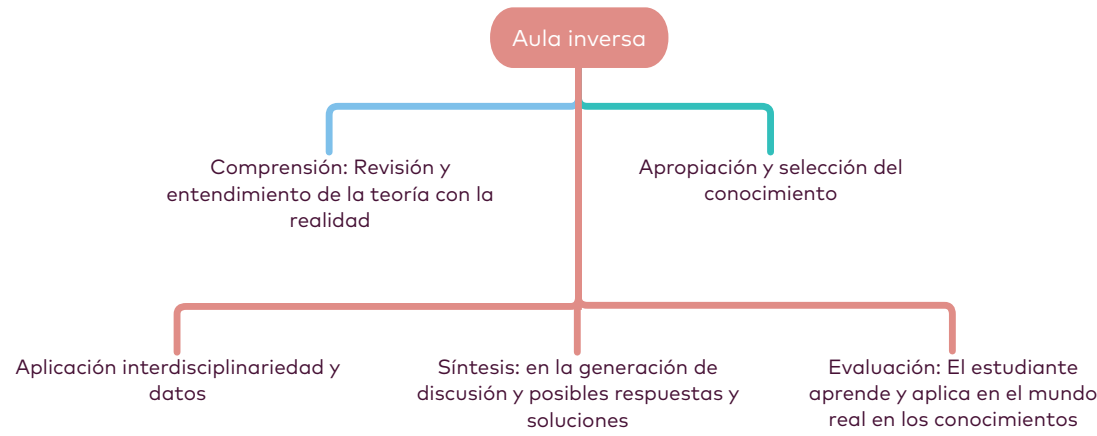

Ilustración 2: Aula inversa desde un enfoque didáctico

Fuente: : elaboración propia, basada en Vidal y Morales (2016).

El uso de las nuevas metodologías en las clases presenciales se convierte en llevar procesos de innovación y creatividad a las aulas, donde no exista encierro, sino que, al contrario, sea un gusto para el estudiante apasionarse por nuevos enfoques y nuevas formas de ver la educación.

Existen estudios que apoyan las metodologías sobre aula inversa o invertida. Entre los ejemplos de este cambio desde la raíz están Ruíz, Sánchez y Sánchez (2014), que hablan sobre la flexibilización en las aulas como una fuerte necesidad, para no seguir encerrando a los estudiantes en un ejercicio 
unidireccional. Igualmente, Mosquera Cucalón (2012) resalta aún más el papel constructivo y la relación entre los docentes y estudiantes, de manera similar al estudio realizado por Griffiths (2016), quien enfoca todo al aprovechamiento de las habilidades y las competencias de los alumnos, teniendo en cuenta a cada uno de ellos y en definitiva a sus habilidades, así como su forma de aprender y aprehender. Por su parte, Ramírez (2017) complementa la información y va más allá, pues propone una reforma desde el currículo y el micro currículo, pero el inicio desde una asignatura es esencial como piloto.

Blasco (2016) es reiterativo en asumir una relación docente y estudiante, y aporta nuevas metodologías enfocadas a una buena clase. No se trata de la clase más excéntrica, sino aquella que otorgue valor al estudiante, le dé un sentido mayor al proceso de enseñanza aprendizaje, siendo muy cuidadosos con las herramientas didácticas, pues el aprendizaje debe ser completo, complementario y darle un eje al sentido de la enseñanza.

\section{LA ASIGNATURA DE NEGOCIOS Y RELACIONES INTERNACIONALES, PILOTAJE CLASE INVERSA.}

Da Silva López, Pedrosa-de-Jesús y Watts (2016) señalan la importancia de la web 2.0 tanto para los docentes como para los estudiantes. Este tema es esencial, pues la tecnología es inevitable y cada vez más dinámica, por tanto, no se debe esconder, sino que todos debemos adaptarnos de manera directa.

Desde el campo de los negocios todo ha evolucionado: la forma y los métodos de consumo, la segmentación de los mercados y la misma cultura de hacer transacciones comerciales se ha modificado gracias a la tecnología. Ahora bien, las aulas de clase de negocios siguen siendo las mismas: un orador y unos receptores. Móviles apagados, portátiles cerrados, tabletas guardadas; nada de tecnología, teniendo tanta afuera, hace que los estu- 
diantes se sientan relegados de los procesos nuevos y simplemente se sientan apartados de la actualidad y de la comunicación.

Luján-Mora (2013), por ejemplo, enfatiza en didácticas de empoderamiento del conocimiento enfocado en el estudiante, dándole mayor apropiación y responsabilidad frente a la temática, que se puede dividir en subtemas. Este espacio debe generar una amplia investigación conjunta, con liderazgo del (o los) estudiante(s) experto(s), lo cual facilitará el proceso de enseñanza.

Esta participación activa se enfoca en la competencia argumentativa y comunicativa que todo estudiante debe desarrollar, por tanto, el aula invertida es solamente una herramienta con muchas aristas y didácticas para su desarrollo.

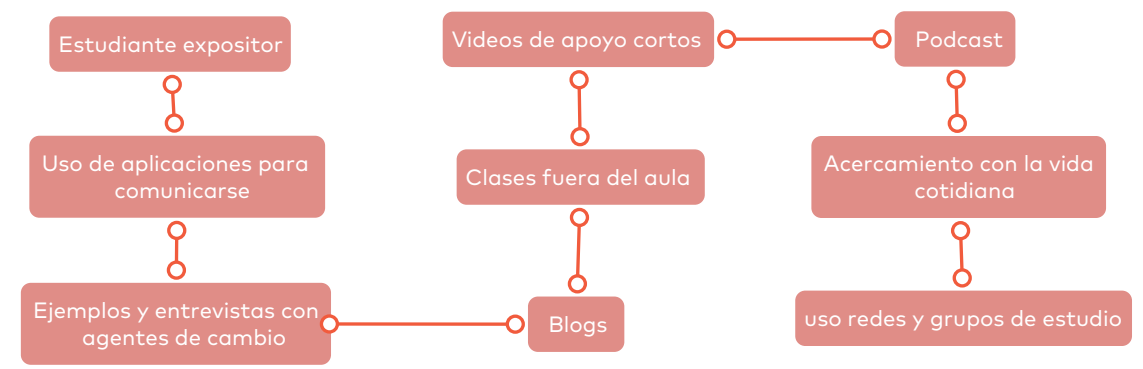

Ilustración 3: Herramientas en aula invertida

Fuente: elaboración propia, 2017.

(Sánchez Rodríguez, 2014) (Blasco A. C., 2016) (Prieto Lobato, 2017) El cambio de paradigma entonces no solo es desde lo experimental hay que hacerlo estructuralmente, por ejemplo no es dejar estas actividades y ya el reto es enganchar al estudiante para que realice trabajos y tareas propias de la temática de la clase, los videos por tanto deben ser cortos explicativos y muy dinámicos para evitar la pérdida de interés por parte de los estudiantes.

Las posibilidades también son retadoras no todos pueden pensar que esta nueva metodología es buena y consideran que el método tradicional es mejor que lo nuevo es evidente en (Gálvez, 2015) de igual manera enfatiza 
en el grado de responsabilidad e incremento de carga en el docente pues requiere mayor personalización para relazar el método como se quiere.

Pero en la educación hay que arriesgarse evidentemente se requieren perfiles que realmente apoyen los procesos productivos de los países, para el programa de Negocios Internacionales del Politécnico Grancolombiano es muy importante realizar un pilotaje que empiece también a cuestionar los procesos tradicionales y en definitiva aporte de manera real al proceso de formación de los estudiantes.

Una de las ventajas que se tienen en la universidad es la apertura a las nuevas tecnologías de la información, la institución se preocupa por contar con equipos e instalaciones cómodas, igualmente es pionera en educación virtual por tanto se cuenta con videos y con recursos tecnológicos que permiten el desarrollo de clases interesantes que puedan incluir el modelo de clase inversa. (Angelini, 2012) (Fernández-Mesa, 2016)

Por ejemplo, enfatiza sobre la formación docente con mucha pedagogía, esto apoya la mencionada crítica de que no cualquiera puede hacer clase, la sola disciplina no basta, se requiere de experiencia y de estudios en pedagogía.

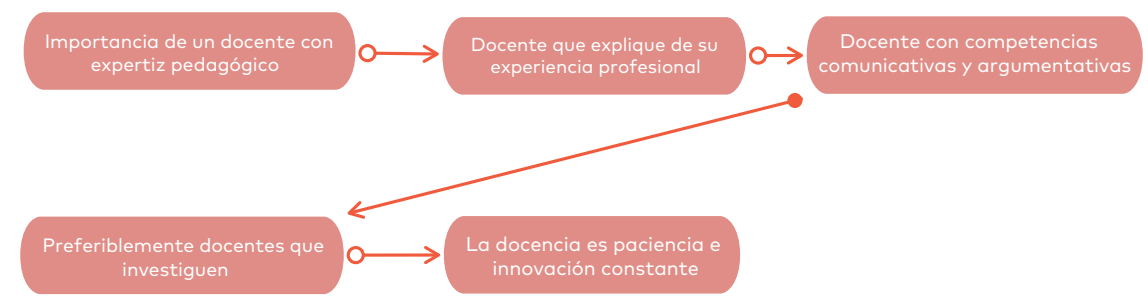

llustración 4: El docente idea para aula invertida

Fuente: elaboración propia 2017.

Para Sobrino Morrás (2014), el tema va más allá: se parte del constructivismo al conectivismo, desde lo bueno de la tecnología; el aula invertida requiere de los espacios, de los docentes y de los estudiantes, que ya traen el chip tecnológico y que algunas veces se coarta por parte de los profesores. 
La educación y el conocimiento son humildad, una frase frecuente que se queda solo en palabras, centrados en la ineficiencia. Esto mismo se ve mucho en las empresas, donde los empleados llegan con mucho impulso por hacer, por crear, y simplemente se les cortan las alas y se adoctrina para que todos sean iguales; al que piensa y actúa diferente se le cataloga como extraño, como pedante o como loco, y en ocasiones de esas cosas 'locas' son las que requerimos. Cuántas conferencias de innovación y emprendimiento se enfocan en los retos individuales, en gente famosa, inventores, artistas; grandes pensadores fueron relegados por pensar y actuar diferente, y a pesar de ser relegados dejaron un legado importante en la historia (Rodríguez, 2016), (Abío, 2017).

Igualmente, se debe tener en cuenta la transversalidad de los procesos tecnológicos en función de la educación y de encontrar significación en los procesos de aprendizaje, incluidos retos y nuevas formas de usar las aplicaciones tecnológicas en la educación (López-Savirón, 2016), (Fernández Mesa, 2016).

E1 Politécnico Grancolombiano es una institución universitaria ubicada en Bogotá, y el programa de Negocios Internacionales se encuentra adscrito a la facultad de ciencias Administrativas, Económicas y Contables. El programa de negocios internacionales cuenta con la siguiente malla: 


\section{NEGOCIOS INTERNACIONALES \\ Modalidad Presencial - SNIES: 7470}
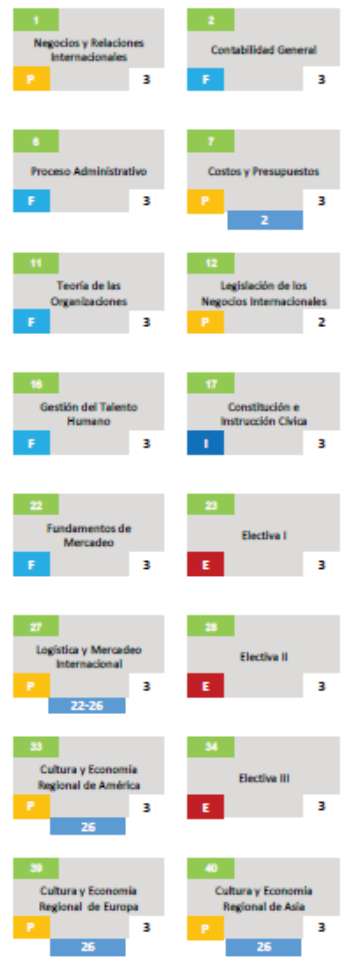
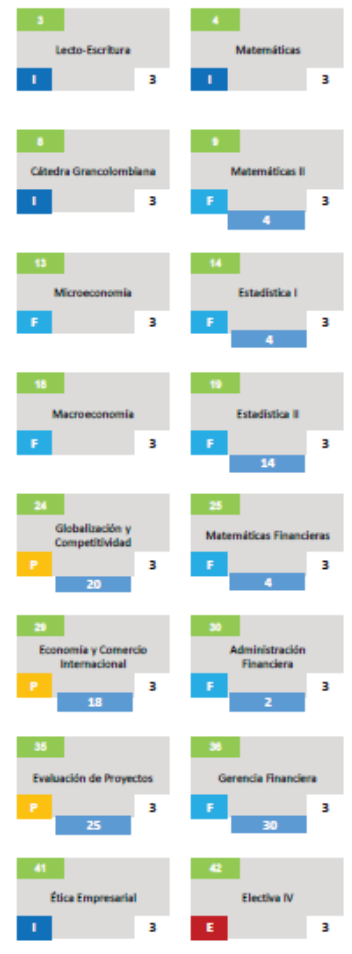

Facultad de Ciencias

Administrativas Económicas y

Contables
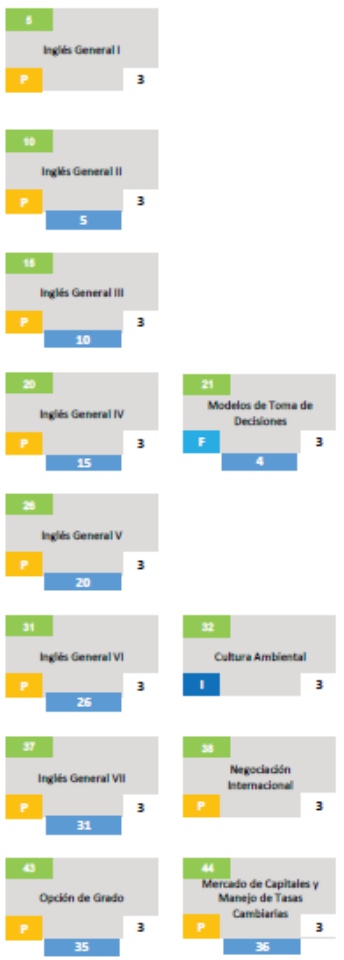

Ilustración 5: Plan de estudios Negocios Internacionales 2017.

La ventaja que tiene este programa es que cuenta con acreditación de alta calidad expedido por el Ministerio de Educación, por tanto, el programa permanece en constante cambio, evolución e innovación con el fin de crecer y reorganizarse de acuerdo con los perfiles y el mercado.

La aplicación del aula invertida en el área de Negocios internacionales se da en la asignatura de Negocios y Relaciones Internacionales, dirigida por la profesora Ángela Julieta Mora Ramírez. Dentro de la estrategia se empezó con una prueba piloto, con un curso de 46 estudiantes y otro de 39 estudiantes. Esta asignatura es electiva, por tanto existe un componente 
adicional: existen estudiantes no solamente de Negocios internacionales, sino de Mercadeo y publicidad, Medios audiovisuales, Comunicación social, Psicología, Derecho, Ciencia política e Ingeniería industrial, haciendo del piloto algo muy interesante, y más diversa la población.

Los estudiantes de Negocios internacionales son de primer semestre y llegan con toda la voluntad, a la vez con las falencias de la educación media. El reto es apropiarse de la tecnología y construir sobre lo planeado algo que realmente les genere interés a los estudiantes actuales.

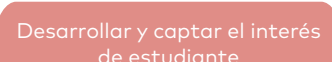
de estudiante
Generar procesos de auto estudio y disciplina
Complementar y realizar actividades didácticas diferentes
Desarrollar competencias y habilidades en cada estudiante
Aprovechar el aula virtual y las TIC para el desarrollo de las clases

Ilustración 6: Un gran reto pedagógico

Fuente: elaboración propia, 2017.

Ahora bien, la temática de la asignatura de Negocios y relaciones internacionales debe estructurar el proceso y enfocarlo en estudiantes que integren los negocios internacionales desde todas sus aristas. La idea inicial en el aula fue estructurar una metodología nueva relacionada con películas y enfocada a crear también equipos y competencias entre ellos de manera sana y dinámica.

En este orden de ideas, se empezó a desarrollar una estrategia para motivar a los estudiantes a conocer y hacer parte del pilotaje de aula inversa, una gran propuesta que integra escenarios propios de interés y, obviamente, una dinámica para el aula. 


\section{LA ESTRATEGIA Y LA MOTIVACIÓN EN LA APLICACIÓN DE AULA INVERSA}

Para el desarrollo de la experiencia se empezó no solo a aplicarla. Se hizo una documentación estricta con un gran estado del arte, que indicara la metodología más adecuada o la mezcla de procedimientos en el desarrollo y aplicación de la estrategia.

Teórico-Práctica
Escenarios internacionales a estudiar
Presencial y uso de componentes TIC

Ilustración 7: Descripción de la asignatura

Fuente: elaboración propi, 2017.

La interacción de una asignatura teórico- práctica incluye una metodología que realmente identifique en el estudiante una relación de lo teórico con lo práctico. La intención es desarrollar actividades donde se incluyan las TIC y el tiempo sea más aprovechado en las horas y encuentros en las aulas (Falco, 2017).

Por lo tanto, la idea es empezar con un gran viaje que asocie películas y unos títulos atractivos para el buen desarrollo de las clases.

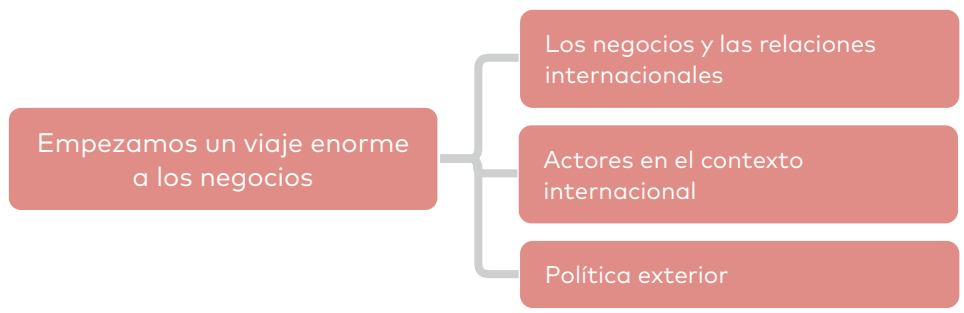

Ilustración 8: Núcleo Temático 1 Voyager Rouge one?

Fuente: elaboración propia, 2017.

En esta parte del sílabo o programa, desde su estructura, se encuentra el acercamiento inicial con los negocios internacionales y las relaciones internacionales: se enfoca en describir los negocios desde lo económico, lo político y lo social. 
Se maneja como un viaje, en la medida que empieza un reconocimiento de la evolución de los negocios a lo largo de la historia, su importancia y aplicación; con este viaje vienen también las herramientas metodológicas para el desarrollo y didáctica de la clase.

\section{CÓMO LO VAMOS A DESARROLLAR}

Fase inicial se plantea como propuesta de cambio cada mes representa una historia frente a una película adaptada a los negocios, conformación de los equipos de trabajo

En esta etapa se desarrolla dentro de la asignatura un ejercicio específico en estudio de caso desde el libro de Hill y con la herramienta Edmodo, YouTube para la organización con los equipos de trabajo mediante el uso de un concurso donde exista co- evaluación sobre el resultado diferencia entre negocios y relaciones, comercio, inversión extranjera directa

Desarrollo de los bloques y enfoca la didáctica a trabajo colaborativo y la realización de un plan exportador incluyendo análisis de mercado y verificación de oportunidades de negocios se apoya en videos de refuerzo lecturas pre establecidas, taller y seminario Alemán

Fase final desarrollo del plan establecer un blog y la presentación con videos debidamente soportada para la sustentabilidad del negocio de la empresa real, se efectúa con la empresa evidencia empírica y fuente primaria

llustración 9: Propuesta metodológica y estructural

Fuente: Propia

Dentro de las tecnologías a usar en el aula se encuentra activación de clases usando vídeos y material virtual, con el fin de que los estudiantes lleguen habiendo leído previamente los contenidos.

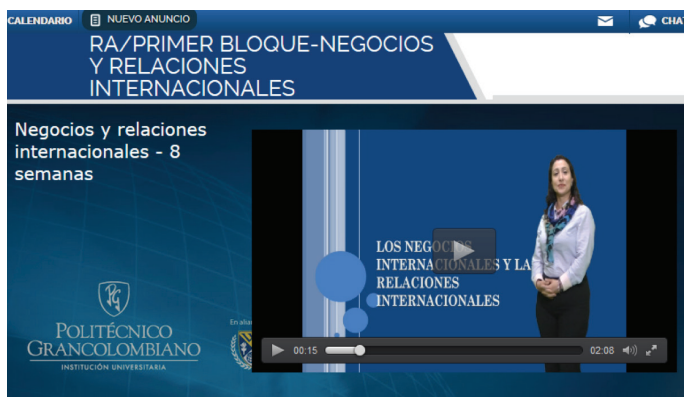


Con estos espacios de vídeos de no más de 20 minutos se puede interactuar en espacios de la misma clase y generar debate. De igual forma, mediante el uso de diferentes apps de teléfonos móviles se puede interactuar y mejorar el proceso de enseñanza- aprendizaje.

Como ejemplo está la aplicación Remind, que permite una comunicación directa con los estudiantes:

\section{Done}

\section{Keep communication in one place.}

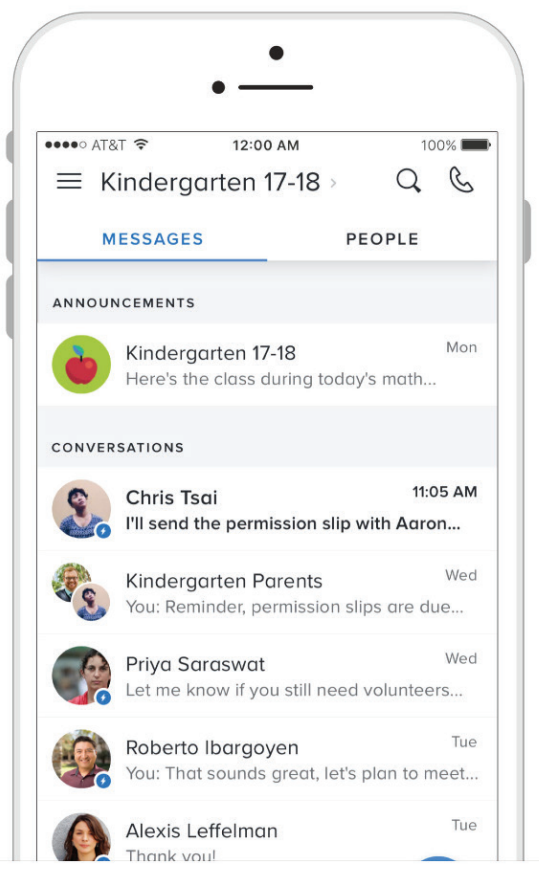

Con esta aplicación, al igual que la interacción en Moodle, la intención es que el estudiante no se aparte de la tecnología, por el contrario, se trata 
de activar la interacción, teniendo en cuenta las habilidades y competencias de nativos digitales de los estudiantes de esta generación.

Otro aplicativo con el que se puede jugar con fines didácticos es Capitales del mundo, que se puede ubicar en Google play o en el App store.

\section{Done}

\section{Capitals of the World}

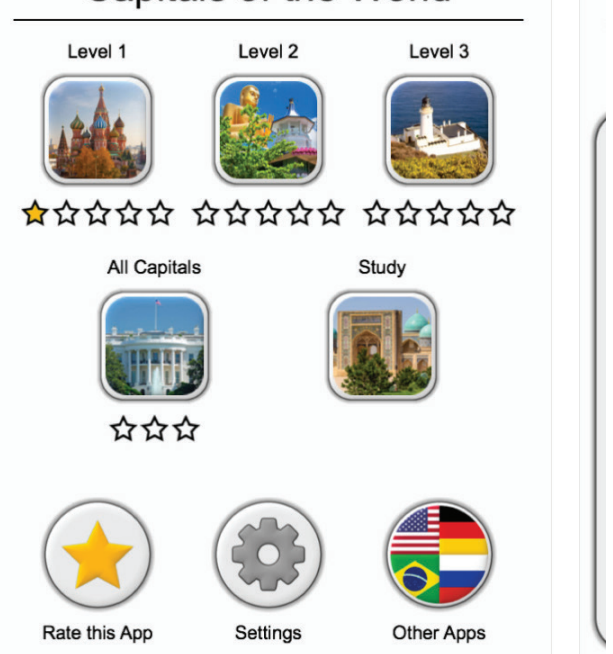

Estas aplicaciones hacen entretenida la hora de la clase pues se genera interacción y una dinámica mayor a la hora de realizar la clase.

Dentro de las actividades didácticas este primer corte que equivale al $30 \%$ realizamos énfasis en nuevas formas de tomar y ver la clase así: 


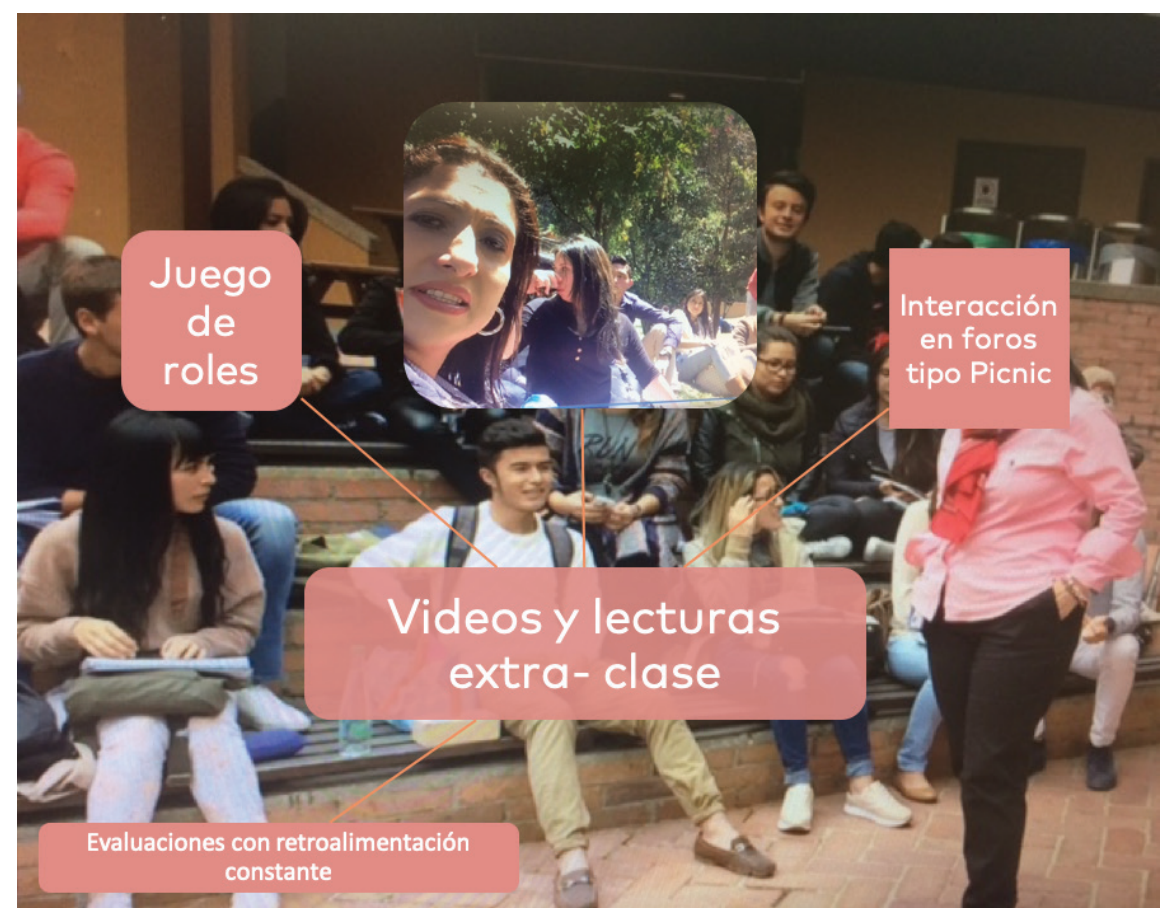

llustración 13: didácticas nuevas para enfoques que desarrollen las competencias.

La medición de los procesos va a desarrollarse en este corte de la siguiente manera: tabulación de notas, con el fin de verificar promedio ponderado en la aplicación de la metodología. Resultados del primer corte, tipo de medición: sobre la ponderación de evaluaciones del corte, se establece bajo criterio de pérdida y logro, determinando número por cada una de las notas, y verificando si la metodología impacta positivamente en las evaluaciones del grupo. 


\section{RESULTADOS PRIMERA MEDICIÓN}

\begin{tabular}{|c|c|c|c|c|}
\hline NOTAS & $\begin{array}{l}\text { NUMERO DE } \\
\text { ESTUDIANTES }\end{array}$ & PORCENTAJE & & \\
\hline 0.0 & 4 & $8,70 \%$ & & \\
\hline 1.2 & 1 & $2,17 \%$ & & \\
\hline 1.5 & 2 & $4,35 \%$ & & \\
\hline 1.7 & 2 & $4,35 \%$ & & \\
\hline 1.8 & 1 & $2,17 \%$ & & \\
\hline 1.9 & 2 & $4,35 \%$ & & \\
\hline 2.0 & 2 & $4,35 \%$ & & \\
\hline 2.1 & 1 & $2,17 \%$ & & \\
\hline 2.2 & 2 & $4,35 \%$ & & \\
\hline 2.3 & 3 & $6,52 \%$ & & \\
\hline 2.5 & 4 & $8,70 \%$ & & \\
\hline 2.8 & 1 & $2,17 \%$ & $54,35 \%$ & 25 \\
\hline 3.0 & 4 & $8,70 \%$ & & \\
\hline 3.1 & 1 & $2,17 \%$ & & \\
\hline 3.2 & 1 & $2,17 \%$ & & \\
\hline 3.3 & 2 & $4,35 \%$ & & \\
\hline 3.5 & 2 & $4,35 \%$ & & \\
\hline 3.9 & 1 & $2,17 \%$ & & \\
\hline 4.0 & 1 & $2,17 \%$ & & \\
\hline 4.2 & 4 & $8,70 \%$ & & \\
\hline 4.4 & 4 & $8,70 \%$ & & \\
\hline 4.5 & 1 & $2,17 \%$ & $45,65 \%$ & 21 \\
\hline $\begin{array}{l}\text { Total } \\
\text { general }\end{array}$ & 46 & $100,00 \%$ & $100,00 \%$ & 46 \\
\hline
\end{tabular}

Tabla 1: Medición del curso de Relaciones Internacionales

Fuente: elaboración propia (2017), apoyada con semilleros de investigación a cargo de las autoras. 
Es evidente que, de los 46 estudiantes con la aplicación de la metodología, el 54\% del grupo tuvo bajo rendimiento. Esto se debió a los siguientes factores:

En primer lugar, los estudiantes no comprenden suficientemente lo que leen, a pesar de que se notó habilidades potenciales en la competencia comunicativa oral, pues la primera evaluación fue un taller sustentado, pero en la competencia escrita de racionamiento y análisis se bloquearon y no construyeron un producto adecuado para el nivel exigido.

Es importante aclarar que entre las competencias que se estructuraron para evaluar se encuentran la comunicativa y la intelectual (por medio de la escritura), y la argumentativa como parte esencial de los procesos y dinámicas de crecimiento.

La metodología de aula inversa resulta nueva para ellos. Lo positivo es que cuando se dio la retroalimentación con el nuevo modelo, se vieron resultados y manifestaciones de reto hacia la asignatura en forma positiva: "profe, vamos a hacerlo, lo vamos a lograr"; esto es muy bueno desde la estructura pedagógica misma. En clase se les mostraron los resultados de las evaluaciones en gráfico:

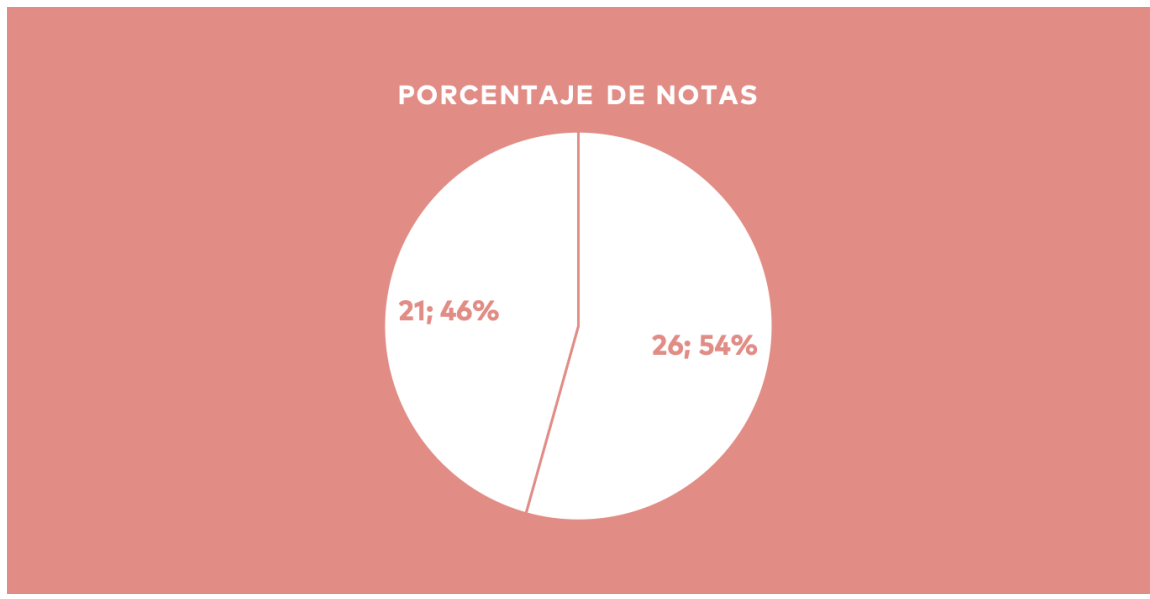

Grafica 2: resultados de pérdida

Fuente: elaboración propia (2017), con datos apoyados por semillero a cargo de las autoras. 
Esta eventualidad, desde la dinámica de la clase en la entrega de resultados, fue positiva en la medida que se mostró respuesta y, sobre todo, cuestionamiento. Como docente, la reacción de la profesora Mora fue: "estamos generando un cambio, se les mueve el piso".

Por su parte, del grupo de 39 estudiantes los resultados son los siguientes, para poder comparar posteriormente los dos grupos:

\begin{tabular}{|c|c|c|c|c|}
\hline Etiquetas De Fila & Cuenta De Estudiante & PORCENTAJE & & \\
\hline 0 & 2 & $5,13 \%$ & & \\
\hline 1.6 & 1 & $2,56 \%$ & & \\
\hline 2.4 & 1 & $2,56 \%$ & & \\
\hline 2.6 & 1 & $2,56 \%$ & & \\
\hline 2.7 & 1 & $2,56 \%$ & & \\
\hline 2.8 & 1 & $2,56 \%$ & 7 & $17,95 \%$ \\
\hline 3.0 & 4 & $10,26 \%$ & & \\
\hline 3.1 & 4 & $10,26 \%$ & & \\
\hline 3.2 & 1 & $2,56 \%$ & & \\
\hline 3.3 & 3 & $7,69 \%$ & & \\
\hline 3.4 & 1 & $2,56 \%$ & & \\
\hline 3.5 & 1 & $2,56 \%$ & & \\
\hline 3.6 & 2 & $5,13 \%$ & & \\
\hline 3.7 & 1 & $2,56 \%$ & & \\
\hline 3.8 & 1 & $2,56 \%$ & & \\
\hline 4.0 & 2 & $5,13 \%$ & & \\
\hline 4.1 & 2 & $5,13 \%$ & & \\
\hline 4.3 & 2 & $5,13 \%$ & & \\
\hline 4.4 & 2 & $5,13 \%$ & & \\
\hline 4.5 & 2 & $5,13 \%$ & & \\
\hline 4.6 & 1 & $2,56 \%$ & & \\
\hline 4.7 & 1 & $2,56 \%$ & & \\
\hline 5.0 & 2 & $5,13 \%$ & 32 & $82,05 \%$ \\
\hline Total general & 39 & $100,00 \%$ & 39 & $100,00 \%$ \\
\hline
\end{tabular}




\section{PORCENTAJE DE NOTAS}

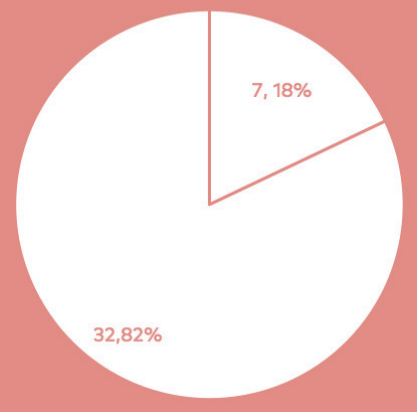

Gráfica 3: Porcentaje de pérdida y ganancia.

Fuente: semillero de investigación a cargo de las autoras, 2017.

Los estudiantes vienen de una formación memorista que solamente se expone con discusiones que se convierten en coloquiales. Lo bueno del ejercicio es que los estudiantes ya están cuestionando e interiorizando la necesidad de leer y ver los vídeos, de lo contrario, van a tener malos resultados; esto incluye una verificación del uso de la tecnología y las redes sociales de manera adecuada y centradas en la formación tal como los sustentan Fernández-Alonso (2015) y Castellanos Sánchez (2017).

De los dos grupos, en el más pequeño se dio una mejor actividad y desarrollo académico, pero aún hay falencias en temas de memoria y capacidad de análisis. Estas fallas se van a cubrir con más vídeos de apoyo y lecturas resumidas, con el fin de que el tiempo de trabajo en casa sea óptimo.

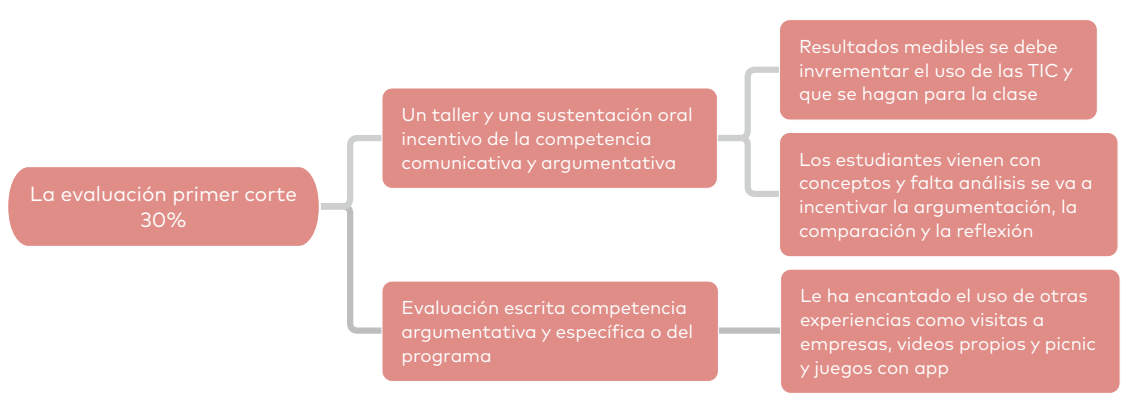

Ilustración 14: La experiencia desde la evaluación.

Fuente: elaboración propia, 2017. 
En el segundo corte académico se va a establecer desde las siguientes aristas, previo compromiso de los estudiantes acerca de qué ha sido lo más positivo y enriquecedor.

\section{LA GUERRA DE LOS CLONES, SEGUNDA FASE DEL PROCESO E IMPLEMENTACIÓN DE AULA INVERSA.}

Las empresas se han organizado de manera rápida y los países que vieron la oportunidad de crecimiento lograron desarrollo en su sistema nacional, el comercio y las regulaciones del estado; por otra parte, se dio la intervención, los malos manejos en los gobiernos y, al mismo tiempo, la búsqueda de organizar un sistema internacional.

Los países empiezan a competir de manera agresiva, como en la película La guerra de los clones, buscando el mercado.

Ante este escenario se presenta el jedi, que se asemeja a la hegemonía de los mercados que derriban las fronteras. Aquel desestabiliza escenarios ya creados y vulnera la convivencia entre los seres humanos. Las máquinas y las formas de negocio se muestran como estratégicas, y los seres humanos buscan maximizar ganancias a bajos costes.

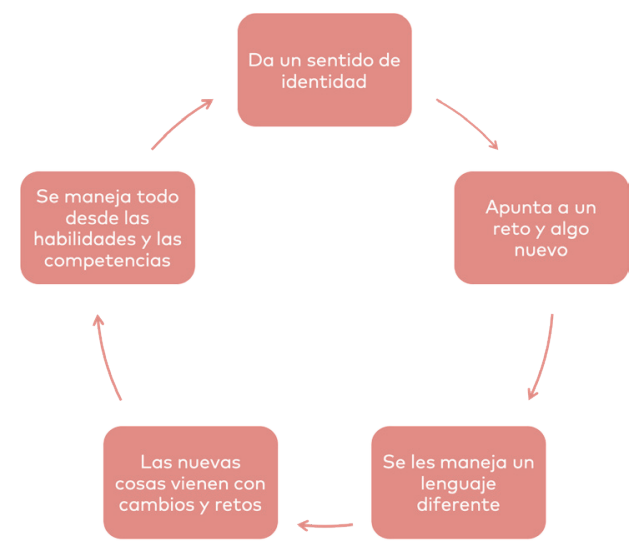

Ilustración 17: La asociación con una película 
De las alternativas que se empleen en el aula y la didáctica que se establezca allí, también mejora la conciencia y el uso de alternativas didácticas para el desarrollo y la mejora de los espacios de formación (Bakken et al., 2016), (Mateu, 2017).

La medición en la segunda fase se desarrolla mediante encuestas a los 85 estudiantes de los dos grupos, y revisar la adaptación y el desarrollo de la estrategia de aula inversa o invertida.

Apoyar la sesiones presenciales con TIC
Incrementar los temas y el uso de google académico
Usar retos y mayor énfasis en los temas

\section{ANÁLISIS DE RESULTADOS DE LA ENCUESTA FASE 2}

Fase final del proceso del pilotaje de aula inversa discusión y conclusiones

Esta fase se denominó El imperio contraataca. Cada situación del mercado se convierte en este momento en una oportunidad o amenaza, más aún si la empresa no es competitiva. Por tal razón, se va a enfatizar en la competencia descriptiva y de observación investigativa, trabajando en la empresa como tal en el sector, otorgando al estudiante una visión real de los procesos empresariales con fines de internacionalización.

La evaluación se hizo con rendimiento y seguimiento en las notas y en la aprobación final de los estudiantes de los dos cursos, de tal forma que pudiera generar acciones encaminadas a mejorar y construir una metodología válida para incrementar la calidad educativa en el programa de Negocios internacionales del Politécnico Grancolombiano. 
La finalidad de estas experiencias es, en definitiva, incrementar el rendimiento académico (Jancsó, 2017), (Hernández, 2017). La motivación en el aula es muy importante, en especial para promover el pensamiento crítico, como lo exponen en sus estudios Zacarías Munguía (2016), Villaplana (2016), Dreizzen (2016), (Cano Rodríguez (2017).

En esta fase se aplicaron dos instrumentos. Uno de ellos fue una encuesta en focus group tipo Likert validada con experto; la plantilla que se usó fue la siguiente:

Esta encuesta se realiza con fines educativos, responda cada una de las preguntas marcando con una $\mathrm{X}$ aquel criterio que considere correcto en el rango. (1 Total desacuerdo, 2 En desacuerdo, 3 De acuerdo y 4 Totalmente de acuerdo).

PREGUNTA

1. Los videos propuestos por la docente para ser vistos fuera del aula de clase han sido un apoyo en su proceso de formación.

2. La nueva metodología propuesta en el aula invertida lo ha beneficiado en su proceso de aprendizaje.

3. Con los temas vistos en los temas de Negocios y Relaciones Internacionales, considera que ha adquirido nuevas habilidades que le permitan ser aplicadas dentro y fuera de la clase.

4. Con la implementación del aula invertida se facilita la realización de los talleres y el parcial.

5. Los temas vistos en el aula invertida se pueden relacionar con la carrera que está cursando. 


\section{[138] Innovación educativa: nuevas metodologías y experiencias en el aula}

Análisis Esta prueba es una escala tipo Likert consta de 5 reactivos donde se pretende medir si el aula invertida ha beneficiado a los estudiantes en su proceso de formación, esta prueba está dirigida a estudiantes de diferentes carreras que estén cursando la asignatura de Negocios y Relaciones Internacionales de la jornada Diurna la cual consta de 2 grupos.

Ítem 1: $\quad$ El $72 \%$ de la población encuestada está totalmente de acuerdo que los videos propuestos por la docente han sido de gran apoyo para su formación concluyendo así que para la mayoría de estudiantes de los dos grupos han utilizado este recurso para una mejor comprensión de los temas vistos en clase.

Ítem 2: $\quad$ El 53\% de la población encuestada está totalmente de acuerdo que esta nueva metodología del aula invertida los ha beneficiado en su proceso de aprendizaje concluyendo así, que más de la mitad de los estudiantes pertenecientes a los dos grupos consideran que la nueva metodología es una manera innovadora de impartir clases y facilitar su aprendizaje.

Ítem 3: $\quad$ El $68 \%$ de la población encuestada está totalmente de acuerdo que ha adquirido nuevas habilidades que podrán aplicar dentro y fuera del aula de clases basándose en los temas vistos hasta ahora en la clase de negocios, llegando a la conclusión de que los estudiantes tienen presentes los nuevos conocimientos que han adquirido en esta clase y los llegan a aplicar en su diario vivir.

Ítem 4: $\quad$ El 53\% de la población encuestada considera que con esta metodología se les facilita más la realización de parciales y talleres concluyendo que esta metodología ha sido beneficiosa a la hora de evaluar su conocimiento.

Ítem 5: $\quad$ El $62 \%$ de la población encuestada considera que los temas vistos en la asignatura de Negocios puede estar relacionada con las distintas carreras que están cursando los respectivos estudiantes, concluyendo y corroborando que los temas vistos están siendo aplicados en otras áreas. 


\section{A MANERA DE CONCLUSIÓN}

Con el análisis de estos reactivos se logró concluir que la nueva metodología propuesta en el aula invertida es una excelente manera de impartir y recibir información, siendo un método más dinámico con el cual se facilita la comprensión de los temas vistos, a la vez que promueve su aplicación en las diferentes áreas de conocimiento, demostrando así lo polifacética que puede llegar a ser la asignatura de Negocios y relaciones internacionales.

En definitiva, la estrategia ha funcionado satisfactoriamente, el estudiante ha sido bien evaluado y ha dado enormes resultados de sus habilidades y competencias; los estudiantes han llevado sus conocimientos más allá de la teoría: por medio del análisis a la empresa han observado cómo funciona una compañía y de qué manera hay aplicación y practicidad.

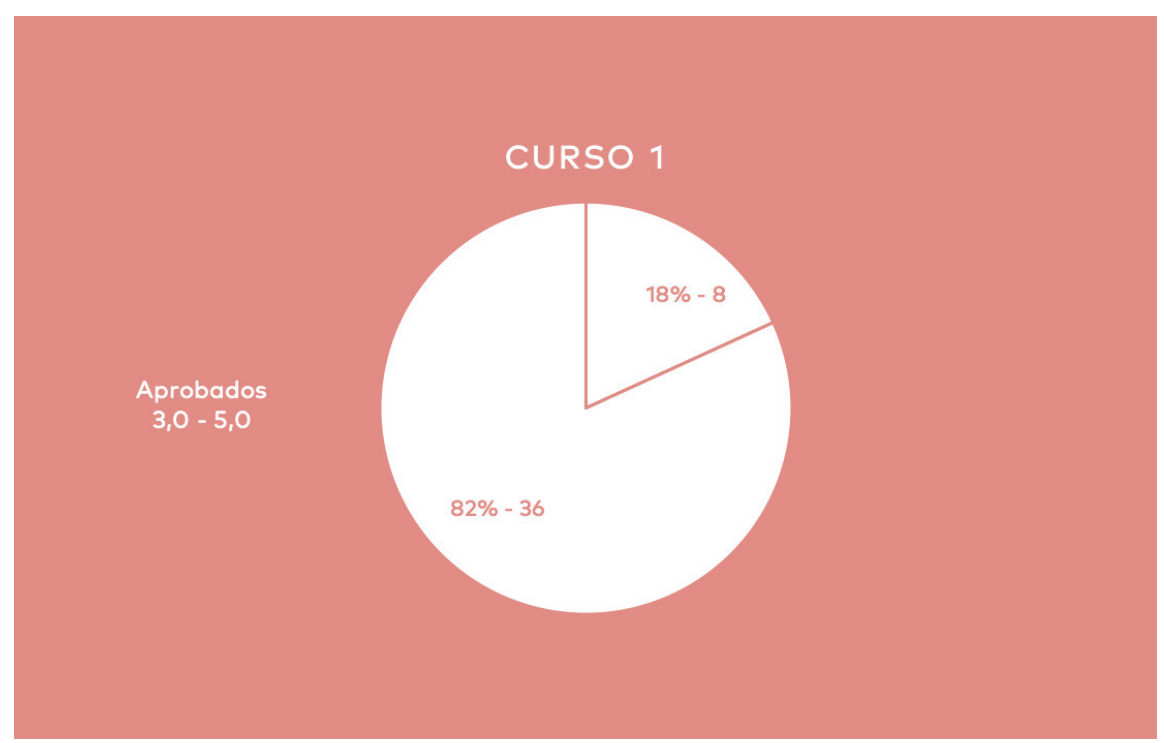

Ilustración 15: Resultados finales con notas, curso 1

Fuente: elaboración propia con apoyo del semillero de investigación a cargo de las autoras, 2017. Este dato es del curso de 44 estudiantes. 


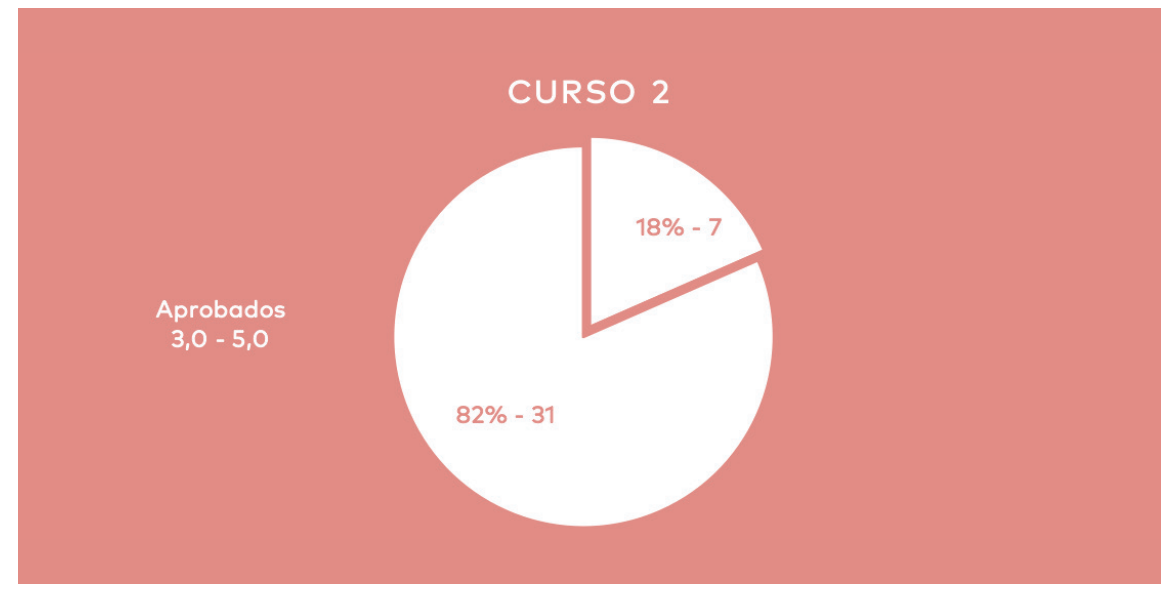

Ilustración 16: Resultados finales en notas curso 2

Fuente: elaboración propia con apoyo del semillero de investigación a cargo de las autoras, 2017. Este dato es del curso de 38 estudiantes.

Los dos cursos lograron superar con éxito la estrategia, llegando a una aprobación por encima del $80 \%$. Si bien esto representa una satisfacción enorme, queda un $20 \%$ en cada grupo que genera inquietud.

Este 20\% representa estudiantes que no culminaron su asignatura o que solo asistieron a los exámenes y no a las actividades adicionales: esto es un indicador que ahora les obliga a asistir a clase y a realizar todas las actividades en ella. Este 20\% demuestra que en ocasiones la motivación no es suficiente y que existen diversas dificultades personales, familiares, sociales, de aprendizaje, que no permiten captar su atención. De este porcentaje del 20\%, la mitad no superó el primer corte académico por problemas económicos, lo cual influye directamente sobre la deserción de los estudiantes de las aulas presenciales.

El exceso de laxitud con la que se trabaja en ocasiones no es positivo; el ejercicio evidencia que debe existir una creación de hábitos con retos, como se hizo con el 80\% en el que la motivación alcanzó un punto clave: estudiantes que lograron empezar a cuestionarse y a conectar las ideas con argumentos y capacidad crítica. El ejercicio se dio en competencias desde la argumentativa, la comunicativa y la específica, mostrando resultados no memorísticos. 
Ahora bien, cuando se verifica el $80 \%$ se sacan conclusiones positivas en cuanto a la forma de ver las diferentes habilidades de los estudiantes. En la última parte desarrollaron planes de negocio en empresas reales del sector del calzado, cuero y manufacturas, haciendo visitas a las empresas y, en general, revisando datos y comparando el sector con la teoría sobre internacionalizar una empresa.

Al ser una materia de tipo electivo, se empezaron a visibilizar grupos con áreas diferentes de conocimiento y, por tanto, con grupos mixtos en sus aportes y discusiones, lo cual fue un éxito, pues la transversalidad dio para que los estudiantes aprendieran desde sus áreas específicas acerca de cómo funciona una empresa del sector para su proceso de internacionalización.

Se hicieron aportes enriquecedores en relación con los negocios internacionales vistos desde el mercadeo, los medios audiovisuales, la administración de empresas, la psicología, el derecho, la ciencia política y la comunicación social.

Estudios como el de Reina Martínez (2017) proponen una visión diferente acerca de la transversalidad en el aula, y en este caso se piensa desde el aula inversa como una forma de llegar al estudiante, revisando sus competencias y habilidades, haciendo de la práctica una forma de conocimiento y haciendo de la teoría un aporte a la formación. Así, la innovación en las aulas de clase se ha desarrollado notablemente: se han descubierto estudiantes creativos para diseñar la imagen de las empresas, otros con dominio de vídeo y redes sociales, en fin, cada competencia se acrecentó de manera real.

Un ejercicio de transversalidad en el aula inversa -junto con ajustes particulares a la población objetivo como análisis del tiempo, de los hábitos, de la negociación misma, la ética y los recursos que nos hacen más humanos- debe llegar al punto clave del acercamiento con el estudiante. El valor del respeto, la aceptación del otro, decir las cosas de frente a tiempo y con diplomacia, son ejemplos clave de esto, tal como lo aborda Scavone (2017).

La transformación con esta estrategia de abordar al estudiante realmente funciona, la memoria se dejó de lado y los vídeos se convirtieron en algo esencial. El uso de la herramienta Remind también fue un éxito. Estas trasformaciones deben seguir dándose en las aulas de clase para empezar a 


\section{[142 ] Innovación educativa: nuevas metodologías y experiencias en el aula}

crear estrategias adaptadas a nuestra población, apoyándonos en las herramientas virtuales.
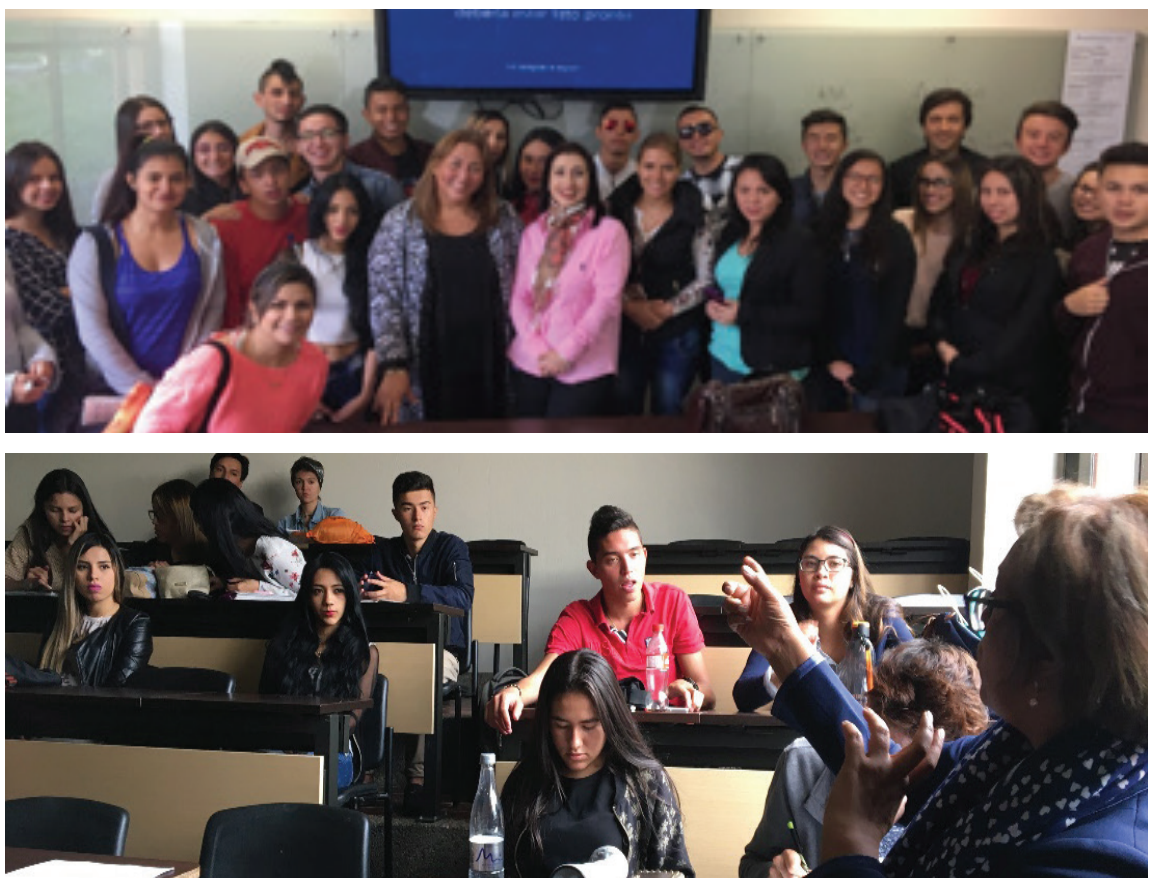

Ilustración 18: Registro fotográfico actividad final

Fuente: Propia

El acercamiento a cada estudiante se dio en mayor medida y realmente se aprecia un mejor nivel en términos de competencias y habilidades. El viaje no culmina aún: existen elementos para ajustar, desde el planteamiento inicial de Star wars como un apoyo en la intención de descubrir, de conocer, de apropiar imaginarios en función de la atención del estudiante, entusiasmarlo cada día para conocer acerca de los negocios internacionales. Por otro lado, como docente ha sido una experiencia enriquecedora, llevando al estudiante -desde la academia- a reconocerse, a cambiar, a adaptarse, a trabajar en equipo, a equivocarse, a hacer parte de la realidad que existe en el mundo laboral. 
E1 reto es importante: empezar a organizar situaciones de cambio donde el estudiante sea el actor principal, no solo llenar de datos, sino hacer que esta información sea útil, que tenga validez y aplicación en el mundo real.

\section{REFERENCIAS}

1. Aaron, B. (2014). Flip Your Classroom. Reach Every Student in Every Class Every Day. (págs. 1-107). Madrid, España.

2. Abío, G.. (2017). Laula invertida i l'aprenentatge en equip: dues metodologies per estimular l'alumnat repetidor. Revista d'Innovació Docent Universitària, $1-15$.

3. Aebli, H. (1998). Los factores de la enseñanza que favorecen el aprendizaje autónomo. Madrid, España: Narcea.

4. Albaladejo, C. (2013). Acerca de la utilidad del aula invertida . Recuperado de: https://web.ua.es/es/ice/jornadas-redes-2016/documentos/.../805139. pdf

5. Alcántara, A. (2007). Reencuentro. Análisis de Problemas Universitarios, (50), 21-27.

6. Alles, M. (2002). Dirección estratégica de recursos humanos: gestión por competencias. Buenos Aires, Argentina: Granica.

7. Alonso Castañón, M. (2007). "Los retos de la Educación Basada en Competencias para el diseño del perfil profesional: el caso de la Universidad Politécnica de San Luis Potosí". Ponencia presentada en el Congreso Mundial sobre las Competencias. Cali, Colombia. 
8. Álvarez Medina, L. (2005). "Evaluación y certificación de las competencias laborales en México. El caso de las dependencias del gobierno federal". Contaduría y Administración. Universidad Autónoma de México, (34).

9. Andión, M. (2007). Reencuentro. Análisis de Problemas Universitarios, (59).

10. Andrade Cázares, M. (2008). Un acercamiento al enfoque por competencias profesionales. Trabajo presentado en la Universidad de Guanajuato.

11. ANECA. (2009). Agencia Nacional de Evaluación de la Calidad y Acreditación. Recuperado de: www.aneca.es/estudios/estu_informes.asp

12. Angelini, L. (2012). Revista de Investigación en Educación DOI:10.13140/2.1.1533.5046. Integración de modelos pedagógicos en la formación de profesorado: La clase invertida y la simulación y juego, (10).

13. Arriola, M. (2007). Desarrollo de Competencias en el proceso de instrucción. Competencias, (23).

14. Barrera, J. (2008). La persona correcta en el lugar correcto. Revista Mundo Ejecutivo. Recuperado de: www.sld.cu/galerias/doc/sitios/infodir/la_persona_correcta_en_el_lugar_correcto.doc

15. Bericat, E. (1989). La integración de los métodos cuantitativo y cualitativo en la investigación social: significado y medida. Barcelona: Ariel.

16. Blasco, A. (2016). La clase invertida y el uso de vídeos de software educativo en la formación inicial del profesorado. Estudio cualitativo. @ tic. revista d'innovació educativa. (17). 
17. Bourdieu, P. (2016). La distinción: criterio y bases sociales del gusto. París: Taurus.

18. Buendía, A. (2007). Hacia una nueva sociedad del conocimiento: retos y desafíos para la educación virtual. México: Limusa.

19. Bunk, G. (1994). La transmisión de las competencias en la formación y perfeccionamiento profesionales de la RFA. Revista Europea, Formación Profesional, (10).

20. Cano Rodríguez, G. (2017). ConTIC aprendí: Aula invertida como modelo para promover el pensamiento crítico en estudiantes de grado noveno del Colegio Antonio García. Master's thesis. Universidad de La Sabana, 23-35.

21. Castellanos Sánchez, A. (2017). Nuevos modelos tecnopedagógicos. Competencia digital de los alumnos universitarios. Revista Electrónica de Investigación Educativa, (19).

22. Castro, M. (2007). Enfoques alternativos en la educación superior. México: I.T.E.S.M.

23. Del Pino, B., Prieto, B. y Prieto, A. (2016). Utilización de la metodología de aula invertida. Enseñanza y Aprendizaje de ingenieria de computadores, 1-9.

24. Díaz-Barriga, F. (2002). Estrategias docentes para un aprendizaje significativo. Una interpretación constructivista. México: McGraw Hill.

25. Dirube Mañueco, J. (2004). Un modelo de gestión por competencias: lecciones aprendidas. Barcelona. Gestión, (45). 


\section{[146] Innovación educativa: nuevas metodologías y experiencias en el aula}

26. Dreizzen, E. (2016). Proceso de implementación del nuevo entorno virtual de enseñanza y aprendizaje Moodle de la Facultad de Ciencias Médicas. UNLP. TE \& ET., (22).

27. Dugua, C. (2007). La cultura en el aprendizaje escolar. Elementos para una pedagogía dentro y fuera del aula. México: Trillas.

28. Falco, M. (2017). Reconsiderando las prácticas educativas: TIC en el proceso de enseñanza-aprendizaje. Tendencias Pedagógicas, (29).

29. Fernández López, J. (2005). Gestión por competencias. Un modelo estratégico para la dirección de Recursos Humanos. México: Prentice Hall.

30. Fernández Mesa, A. (2016). Valor pedagógico del repositorio común de conocimeinto para curso de dirección de empresa. Revista de Innovación Educativa, (9).

31. Fernández-Alonso, R. (2015). Homework and Performance in Mathematics: The Role of the Teacher, the Family and the Student's Background. Journal of Psychodidactics, (22).

32. Fernández-Mesa, A. (2016). Pedagogical value of a common knowledge repository for Business Management courses. @ tic. revista d'innovació educativa, (16), 39-47.

33. Gálvez, A. (2015). Uso del vídeo docente para la clase invertida: evaluación, ventajas e inconvenientes. Recuperado de: https://www.researchgate. net/profile/Alfonso_Rosa-Garcia/publication/266673438_Uso_del_video_docente_para_la_clase_invertida_evaluacion_ventajas_e_inconvenientes/links/570c9bb608aea660813b2c87.pdf

34. Gardner, H. (2005). Las cinco mentes del futuro. Un ensayo educativo. Barcelona: Paidós. 
35. Gardner, H. (2005). Mentes flexibles. El arte y la ciencia de saber cambiar. Barcelona: Paidós.

36. Griffiths, L. (2016). Implementación del modelo de aula invertida para el aprendizaje activo de la programación en ingeniería. Recuperado de: http:// sochedi2016.ufro.cl/wp-content/uploads/2016/10/SOCHEDI_2016_paper_54.pdf

37. Hernández, B. (2017). Impacto de la metodología "Aula Invertida" en el desempeño académico de alumnos universitarios en la materia Estadística Inferencial. Aplicaciones de la tecnología educativa en diversos ambientes de aprendizaje, (283).

38. Iglesias González, J. (2007). Evaluación de las competencias del personal de Tecnologías de Información, su importancia en México y las competencias que son necesarias desarrollar en nuestro país. México DF: Universidad de Querétaro.

39. Jancsó, K. (2017). ¿Cómo darle la vuelta al aula? El aula invertida y el uso de Edpuzzle y Powtoon en la enseñanza del español. Serie Didáctica, (1), 106-136.

40. Lacleta, S. (2015). Metodología de enseñanza inversa apoyada en b-learning y gestión del conocimiento. Revista de educación a distancia, (32).

41. Leupin, R. (2016). ¿Pedagogía activa o métodos activos? El caso del aprendizaje activo en la universidad. Revista Digital de Investigación en Docencia Universitaria, 16-27.

42. López-Savirón, P. (2016). El Flipped Classroom (Aula invertida) y su eficacia en la acción educativa. UNIR, 32. 
43. Luján-Mora, S. (2013). De la clase magistral tradicional al MOOC: doce años de evolución de una asignatura sobre programación de aplicaciones web. Revista de Docencia Universitaria REDU. Recuperado de: http://dx. doi.org/10.4995/redu.2013.5557, 279-300.

44. Mateu, M. (2017). Aula invertida: Experiència en el Grau d'Infermeria. Revista d'Innovació Docent Universitària, 115-123.

45. Miguélez, M. (2016). Validez y confiabilidad en la metodología cualitativa. Paradigma, (27), 7-33.

46. Mosquera Cucalón, W. (2012). Diseño de una propuesta didáctica para la enseñanza de sistema de dos ecuaciones lineales con dos incógnitas utilizando el método "Flipped Classroom" o aula invertida. Recuperado de: http://scielo.sld.cu/scielo.php?script=sci_arttext\&pid=S0864-21412016000300020

47. Politécnico Grancolombiano. (2017). Plan de estudios Negocios Internacionales. Recuperado de: http://poli.edu.co/content/negocios-internacionales-0

48. Prieto Lobato, J. (2017). “ Tecnologías de información y la comunicación en la docencia universitaria: una experiencia interdisciplinar e interuniversitaria”. Memoria Proyecto de Innovación Docente, 20-34.

49. Quecedo, R. y Castaño, C. (2002). Introducción a la metodologia de investigación cualitativa. Revista de Psicodidáctica Universidad del país Vasco, $1-36$.

50. Ramírez, L. (2017). El rol de la modelación para el fortalecimiento y adaptación del método aula invertida. Recuperado de: http://www.pedagogia. edu.ec/public/docs/Comision_2/el_rol_de_la_modelacion_para_el_fortalecimiento.pdf

51. Reina Martínez, S. (2017). Aportes de las TIC a proyectos transversales institucionales. Tesis de Maestría, Universidad de La Sabana, 21. 
52. Rodríguez, M. (2016). Tecnologías de la información y la comunicación. Un eje transversal para el logro de aprendizajes significativos. REICE, Revista Iberoamericana sobre Calidad, Eficacia y Cambio en Educación, (2).

53. Ruíz, J., Sánchez, J., y Sánchez, E. (2014). Flipped Classroom, una experiencia de enseñanza abierta y flexible. Recuperado de: https://riuma.uma.es/xmlui/bitstream/handle/10630/8431/RuizPalmero_SanchezRodr\%C3\%ADguez_SanchezRivas.pdf?sequence $=1$

54. Sánchez Rodríguez, J. (2014). Las clases invertidas: beneficios y estrategias para su puesta en práctica en la educación superior. Recuperado de: http://dspace.uma.es/ xmlui/handle/10630/7821

55. Scavone, G. M. (2017). La transversalidad de la ética en la enseñanza de las Ciencias Económicas. Anuario de Investigación USAL, (3).

56. Sobrino Morrás, Á. (2014). Aportaciones del conectivismo como modelo pedagógico post-constructivista. Propuesta educativa, 39-48.

57. Talbert, R. (2015). Inverting the Transition-to-Proof Classroom. PRIMUS, (13).

58. TEC. (2014). Aprendizaje invertido. Observatorio de educación TEC de Monterrey, 1-29.

59. Vidal, M. y Morales, V. (2016). Aula invertida, nueva estrategia didáctica. Búsqueda temática digital Scielo, 1-11.

60. Villaplana, E. (2016). Aplicando la metodología Flipped-Teaching en el Grado de Ingeniería Informática. Una experiencia práctica, (12).

61. Zacarías Munguía, V. (2016). Relación entre la metodología flipped classroom y el aprendizaje de alumnos en la universidad continental mediante el uso de TIC. PENZA, 23-50. 